\title{
SUSTAINING COMMUNITY ARCHIVES
}

\author{
By \\ Joanna M.A. Newman
}

A thesis submitted to the Victoria University of Wellington in fulfillment of the requirements for the degree of Master of Arts

School of Information Management

Victoria University of Wellington 


\section{Acknowledgements}

I would like to thank all the case study participants who gave their time so generously to this project and made it such an interesting and rewarding experience. The views expressed in interviews are the personal opinions and experiences of the individuals involved and do not necessarily represent the views of the organisations they belong to.

I wish to express my particular gratitude to two organisations for their assistance in carrying out this research: to The Dominion Post for the scholarship which allowed me to study fulltime, and to Local Government New Zealand for a grant which allowed me to travel to carry out case studies. I hope that both organisations will realise benefits from the research in future, albeit in very different (and possibly, at this point, unforeseen) ways.

I also wish to thank my supervisor, Dr Gillian Oliver, for her direction, advice and encouragement throughout.

Thanks go to Annie Newman and Vicki Thorpe, too, who blazed a trail for me in undertaking a research thesis. The experience and advice they shared, the time they committed to proof-reading, and their moral support, were invaluable. 


\section{Abstract}

All over New Zealand there are collections of archives, representing the recorded memory of their communities. They play an important role in our heritage and cultural well-being but the quality of care they receive and their accessibility vary greatly, giving rise to concerns about the longevity of some. This research investigates the factors required for maintenance of community archives over the long-term and assesses how well a selection of New Zealand Archives display these factors. A methodological framework for assessing likely sustainability of Community Archives was developed, based on requirements for managing community (or local history) archives documented by United States archivists. Four different Community Archives in New Zealand were then studied and the findings compared. Results show that many of the factors required for maintenance are inter-related and inter-dependent but that, above all, organisational factors have a significant impact on the maintenance of the archival records and the evidential value they contain. Different organisational structures and governance characteristics, and their consequent impact on other factors, indicate that, by addressing these aspects of Community Archives, their sustainability could be greatly enhanced. The study could, therefore, provide guidance for archivists and policy makers in future decision-making relating to Community Archives. 


\section{Table of Contents}

Acknowledgements ........................................................................................................ ii

Abstract .............................................................................................................. ii

Chapter 1 Introduction ...............................................................................................1

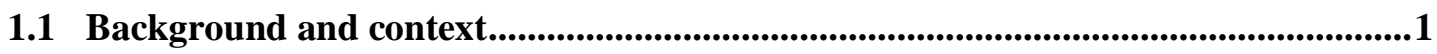

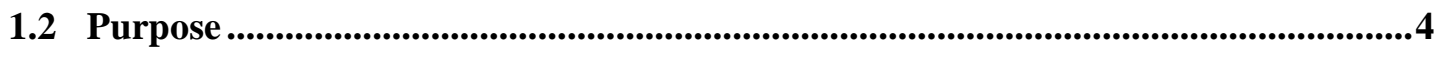

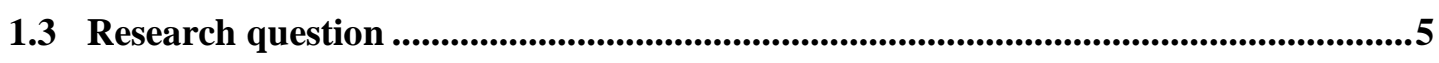

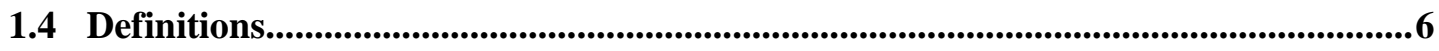

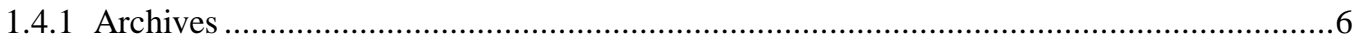

1.4.2 Community archives............................................................................................

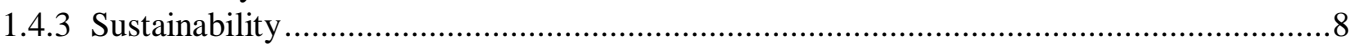

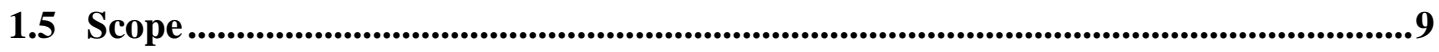

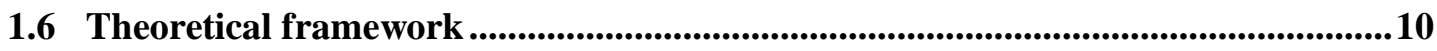

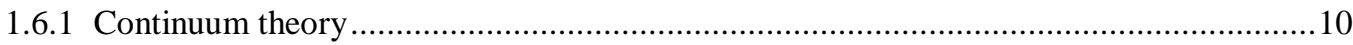

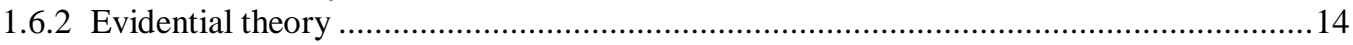

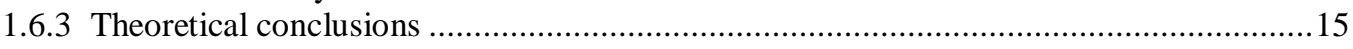

1.7 Methodological framework .........................................................................................16

1.8 Thesis overview ...............................................................................................................................16

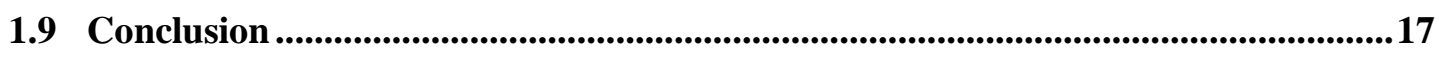

Chapter 2 Literature Review .....................................................................................18

2.1 Introduction..............................................................................................................................18

2.2 Social and cultural context ...........................................................................................18

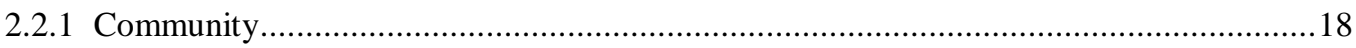

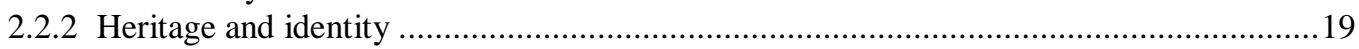

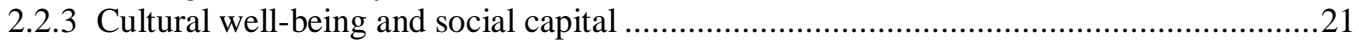

2.3 Community Archives in New Zealand.....................................................................22

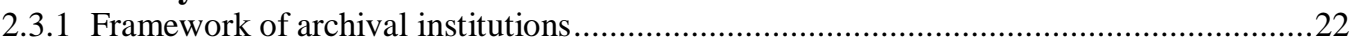

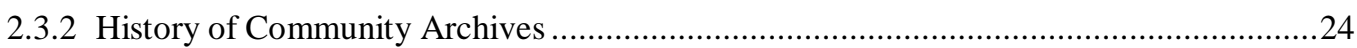

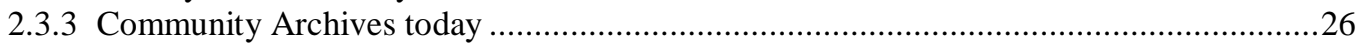

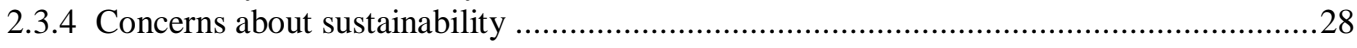

2.4 What constitutes sustainability for Community Archives? ......................................30

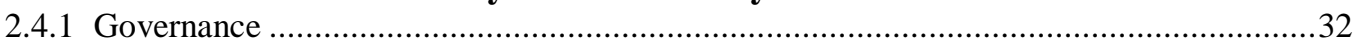

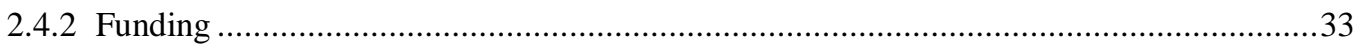

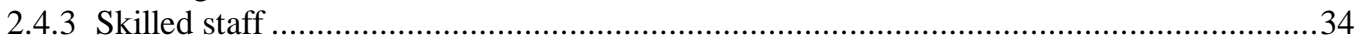

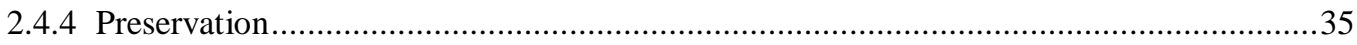

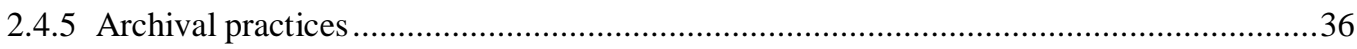

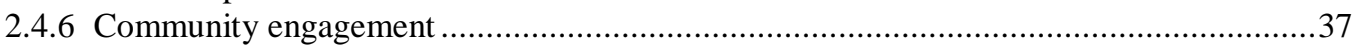

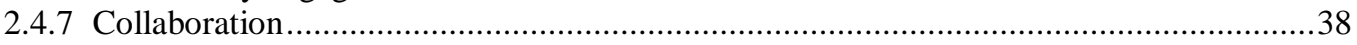

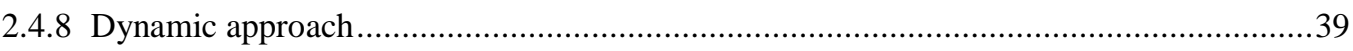

2.5 Community archives and archival theory ............................................................40

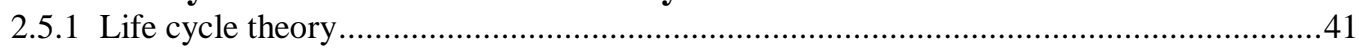

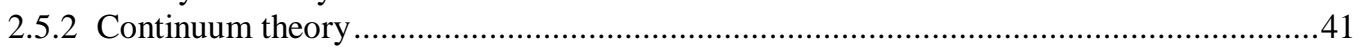

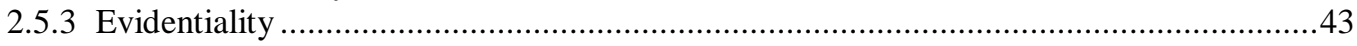

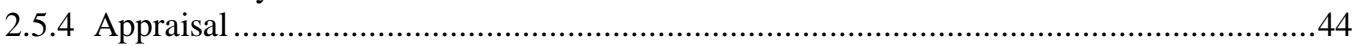

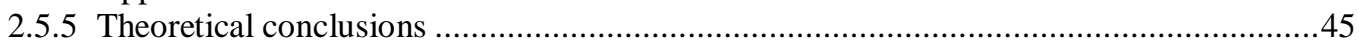




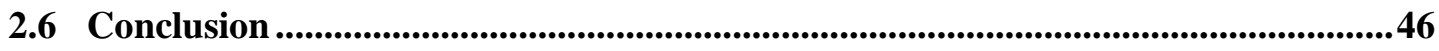

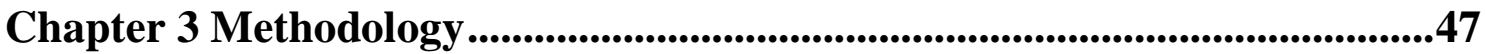

3.1 Introduction.............................................................................................................................47

3.2 Research design ......................................................................................................................48

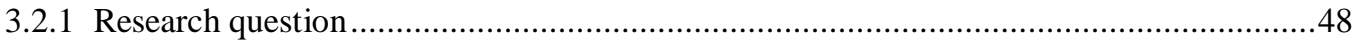

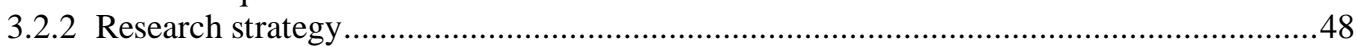

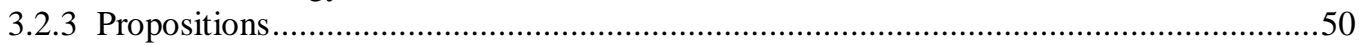

3.2.4 Criteria for interpreting the findings ......................................................................50

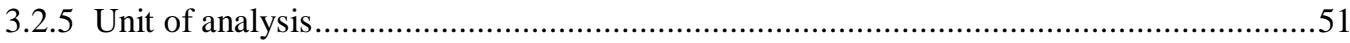

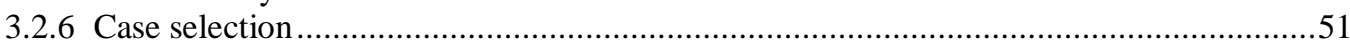

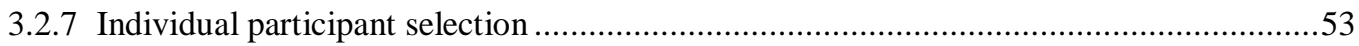

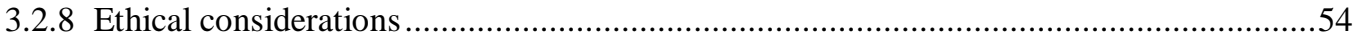

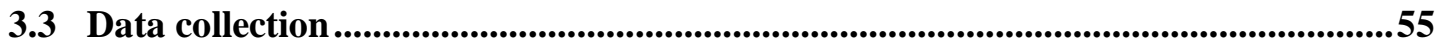

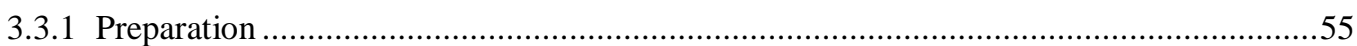

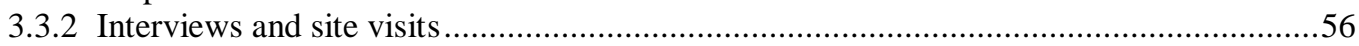

3.4 Methodological framework ...................................................................................................5

3.4.1 Factors required for maintenance of community archives........................................57

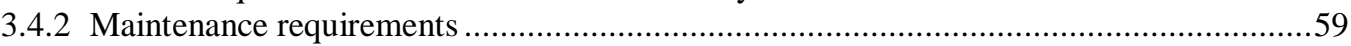

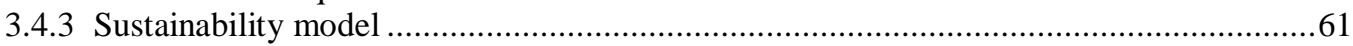

3.5 Data analysis and interpretation..................................................................................63

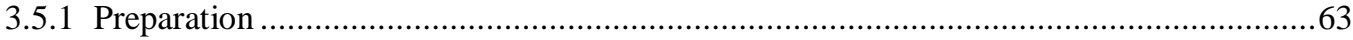

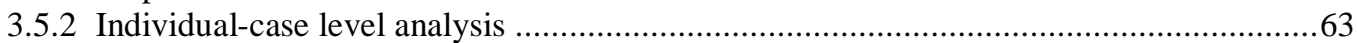

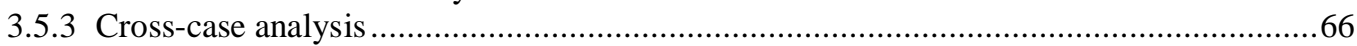

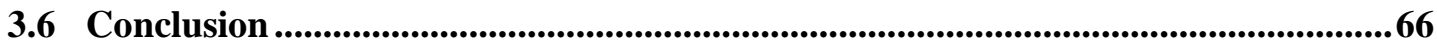

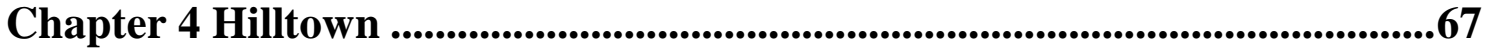

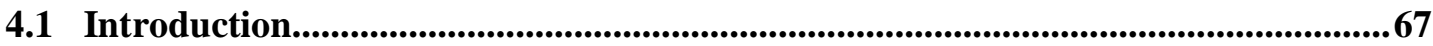

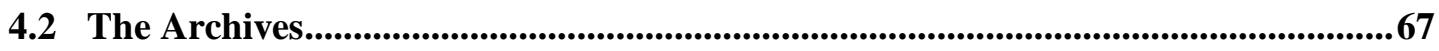

4.3 Summary findings...........................................................................................................................77

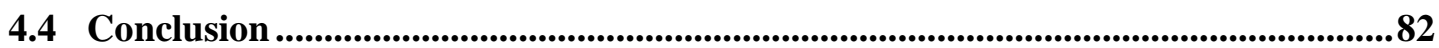

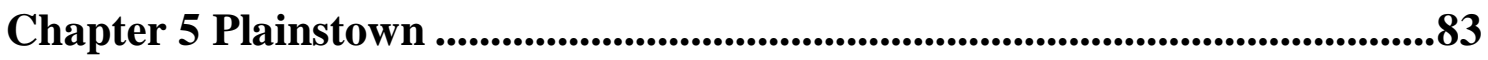

5.1 Introduction..................................................................................................................................83

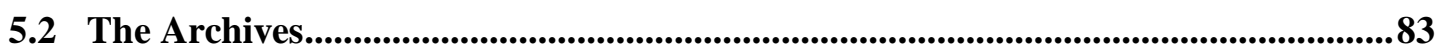

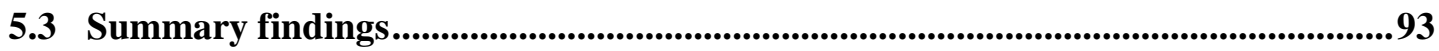

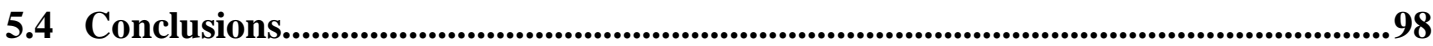

Chapter 6 Seatown .................................................................................99

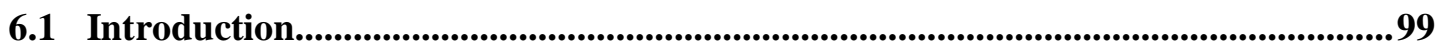

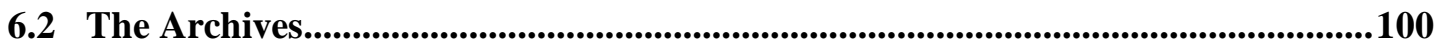

6.3 Summary findings...................................................................................................................111

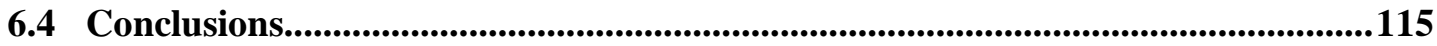

Chapter 7 Clifftown .....................................................................................116

7.1 Introduction..............................................................................................................................116

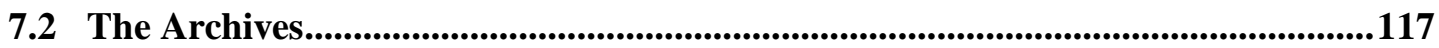

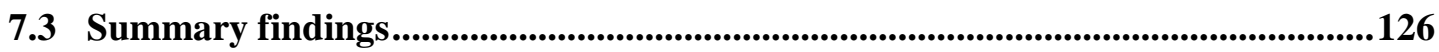




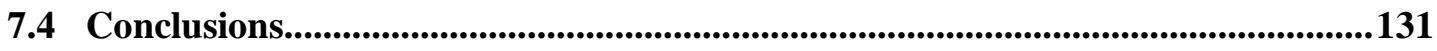

Chapter 8 Cross-case analysis and findings..............................................132

8.1 Introduction..........................................................................................................................132

8.2 Similarities and differences .........................................................................................132

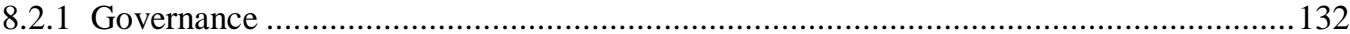

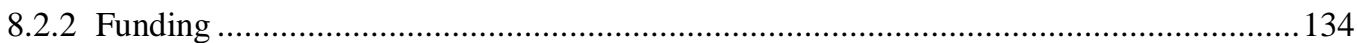

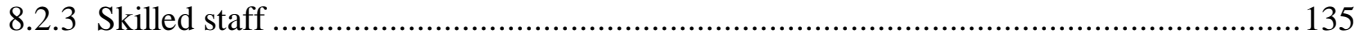

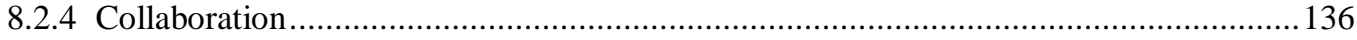

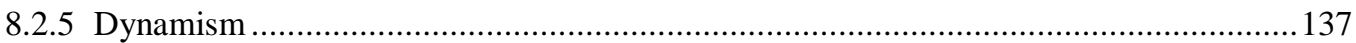

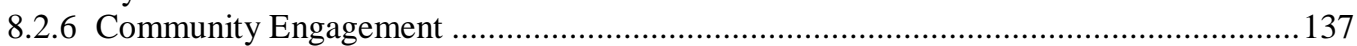

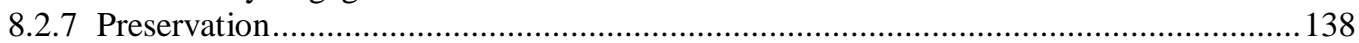

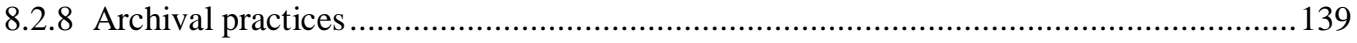

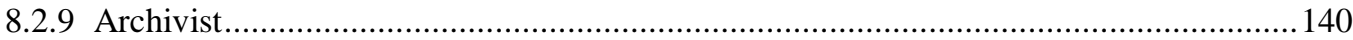

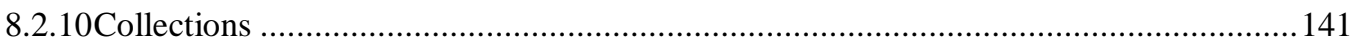

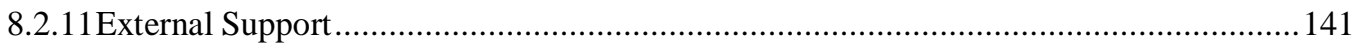

8.3 Overview ..............................................................................................................................142

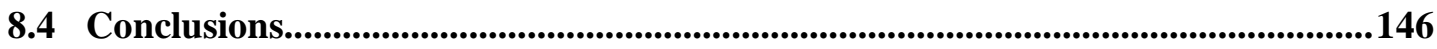

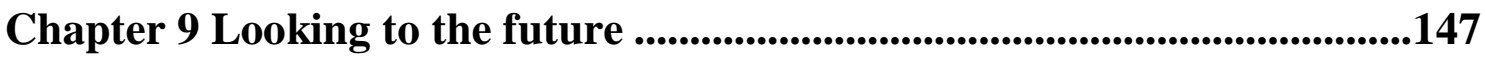

9.1 Introduction....................................................................................................................147

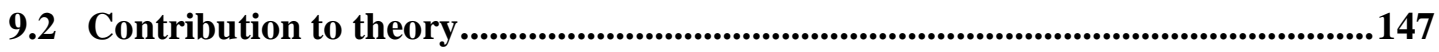

9.3 Factors required for sustainable Community Archives ….......................................148

9.4 Factors exhibited in case studies - recommended changes......................................149

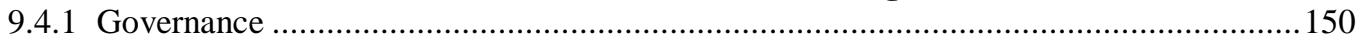

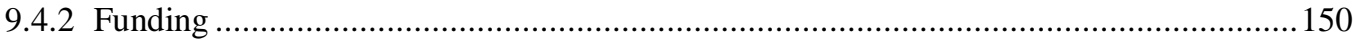

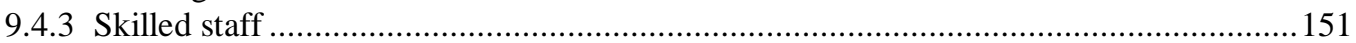

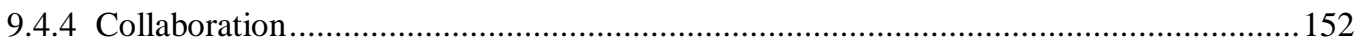

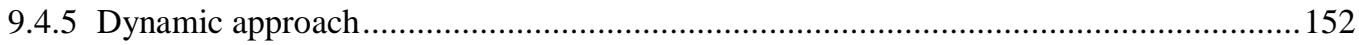

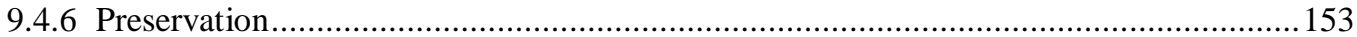

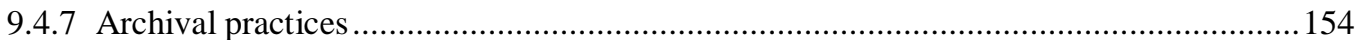

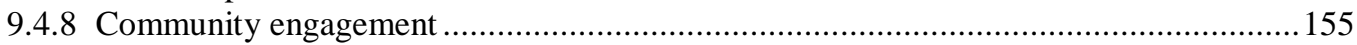

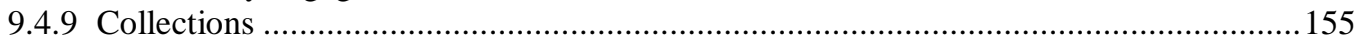

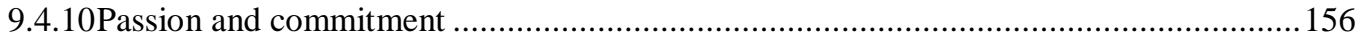

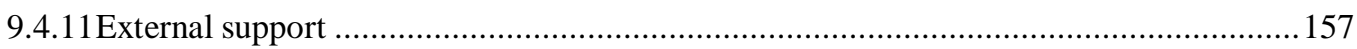

9.5 How sustainable are Community Archives in NZ? ...........................................158

9.6 Further research .........................................................................................................................159

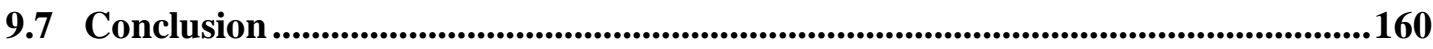

Appendix A Interview guide: Community stakeholder representative.......161

Appendix B Interview guide: Archives operational manager .....................162

Appendix C Interview guide: Governance funding/policy decision-maker 163 


\section{List of Figures}

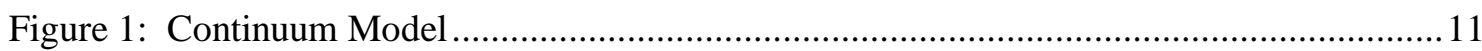

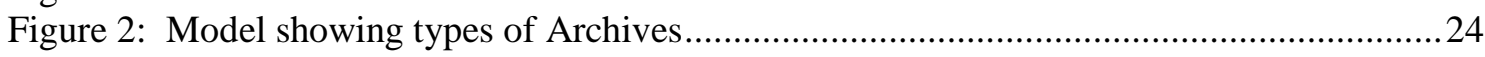

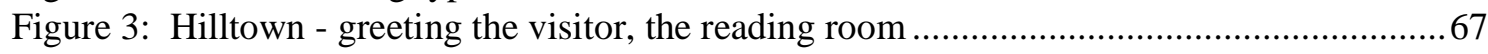

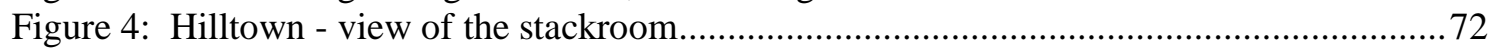

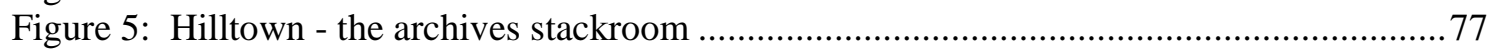

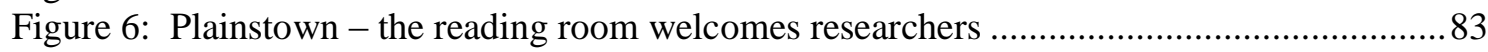

Figure 7: Plainstown - the archives processing room (and general storage) ............................. 84

Figure 8: Plainstown - the main repository, with standardised archival storage boxes ..............89

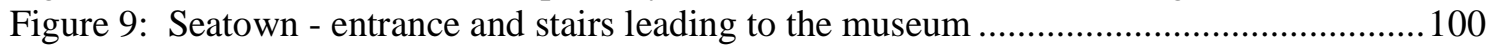

Figure 10: Seatown - costume display on the landing ........................................................ 101

Figure 11: Seatown - museum looking toward the archives/research end of the room .............103

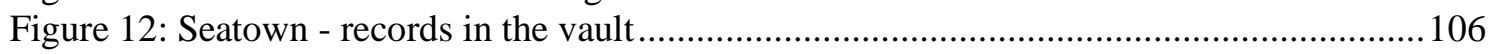

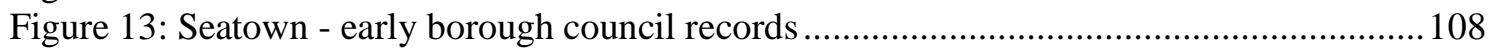

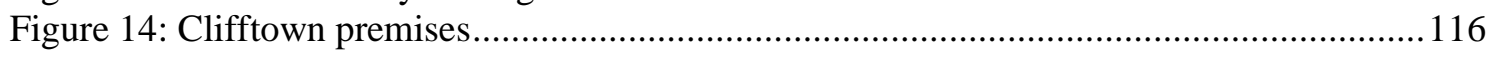

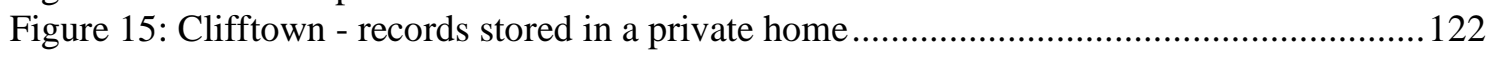

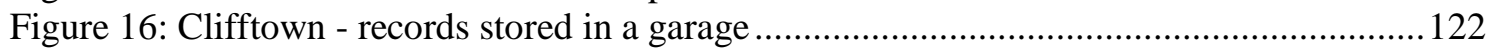

Figure 17: Comparison of Community Archives' sustainability ranking for factors.................144

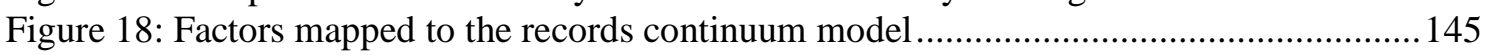

\section{List of Tables}

Table 1: Factors or elements required for maintenance of community archives........................58

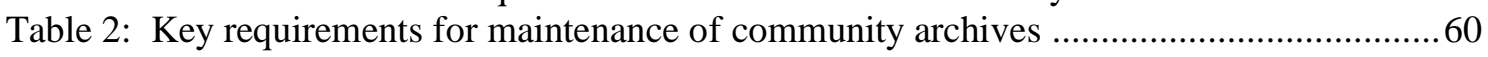

Table 3: Characteristics indicating likely sustainability of community archives ........................62

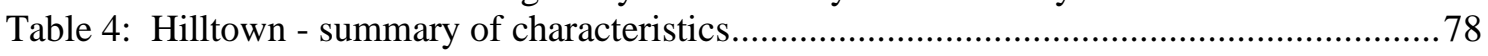

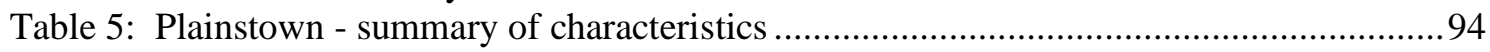

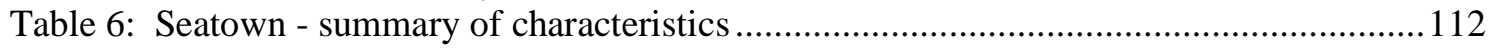

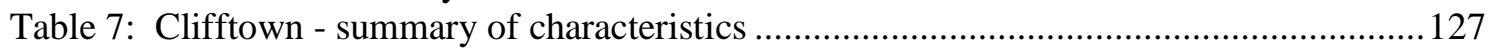




\section{Chapter 1}

\section{Introduction}

listening to these whispers in the records while understanding the record-making and -keeping process itself, we are able to hear all the voices involved in their creation.

(Bastian, 2003, p. 2)

\subsection{Background and context}

All over New Zealand there are collections of community or local archives. They are held by organisations as varied as the volunteer Carterton Historical Society, the Maori Ratana Archives and the local-government supported Wairarapa Archive.

These archives reflect our culture and identity and are therefore part of the heritage of all New Zealanders. Without them, or without appropriate management and handling of them, New Zealanders' ability to understand where they have come from is diminished. Richard Cox, writing on documenting localities, quotes an American guide to local history for schools to explain the importance of community history: "local neighborhood, town, or city, much like the family or the ethnic group to which one belongs, are social realities that help provide individuals with a sense of identity" (Metcalf \& Downey, as cited in Cox, 1996a, p. 7).

Regimes for the management and preservation of community archives must therefore be enduring and sustainable. Archives held within structures or environments which are not sustainable are potentially as much at risk as those 
which are never identified and preserved. If collecting and preserving certain records constitutes construction of memory, not doing so equates to forgetting (Jimerson, 2009).

The organisations responsible for community archives often struggle to survive and fulfill the commitment they have made to preserving and making accessible the documentary heritage of their local communities. Some are not even fully aware of what is required to preserve the archives which constitute that documentary heritage. This is not only a New Zealand problem: in the United States, the challenges and needs of local history archives programmes have been commented on frequently over the years (Dearstyne, 2000).

Given the importance of these archives to our sense of identity, it is essential to understand the reasons behind this situation and to explore what might make Community Archives ${ }^{1}$ more sustainable. This research looks at the factors required to ensure that Community Archives are sustainable and the extent to which these factors are present in four New Zealand Community Archives.

Central government archiving is relatively well-supported by a national archives institution (Archives New Zealand), legislation (the Public Records Act 2005) and central government funding. Local authority archives are also subject to legislation (the Public Records Act 2005 and the Local Government Act 2002), even if the Archives sometimes face competition for resources from other council activities. The smaller Community Archives, often run by volunteers with little knowledge, few resources and inadequate facilities, have no such framework and are considerably more at risk. This landscape of archives in New Zealand is described in more detail in section 2.3.1.

A review of the directory of Community Archives in May 2010 suggests that there are approximately 65 Community Archives in New Zealand (Archives

\footnotetext{
${ }^{1}$ Throughout this thesis, a capital ' $\mathrm{A}$ ' or ' $\mathrm{C} . . \mathrm{A}$ ' is used when the term "Archives" or "Community Archives" refers to the institution holding the archives (except where these terms appear in quotations), and a lower-case ' $a$ ' or 'c...a' when referring to the archival records. This is to help distinguish these two for readers.
} 
New Zealand, 2009a), but as the listing does not include some known to the researcher, this figure is probably an underestimate. A significant proportion of community archives are held within museums and largely voluntary historical societies, with a 2007 survey indicating that $30 \%$ of Community Archives are aligned with museums/art galleries and $30 \%$ with historical societies or voluntary organisations (Archives New Zealand, 2008, p. 10). A category within the community archives sector which has been growing in the last 15 years is Maori marae and iwi-based archives, often inspired by increased appreciation for documentary heritage resulting from Treaty of Waitangi claims research (Wareham, 2001). Other significant findings from the survey are that $40 \%$ of Archives responding had no paid staff, $35 \%$ had no qualified staff, and funding was seen as a major challenge and a priority for $32 \%$. At the same time, most hold archives dating back to the nineteenth century (Archives New Zealand, 2008). In summary, many small Archives caring for important collections are run with minimal resources by voluntary workers who lack archival knowledge or experience. (For further discussion on the nature of the community archives sector in New Zealand today, see section 2.3.3.)

There is no academic research in New Zealand on the sustainability of Community Archives. Research and reports from the archival sector have noted the problem and focused on raising awareness of the need to address it. As early as 1978, a report on the state of Archives in New Zealand suggested establishing regional archives because many small Archives did not have the expertise and the facilities required to care for their holdings (Smith, 1978). More recently, Archives New Zealand has commissioned research into Community Archives (cited above) but the participant selection and questions lacked rigour and the findings, although useful, are high-level.

Research has been conducted overseas into various aspects of Community Archives, however, and archivists and archival authorities have written of the challenges and issues facing them. Archival texts have also long documented the theory and principles required for successful archival programmes, whether community or institutional, and a number of publications provide frameworks 
for establishing or evaluating programmes. These could be considered the accepted, professional requirements for running an Archives.

Meeting and sustaining these requirements is different in practice, however. While there is ongoing evidence of the vulnerability of Community Archives in New Zealand, at the same time their numbers are growing and their importance to New Zealanders is likely to increase. Globalisation and changes in central government policy-making only serve to emphasise the value of region or locality (McKinlay, 2005).

\subsection{Purpose}

A sustainable Community Archives is one which is able to maintain, over the long-term, its commitment to preserving and making accessible archival material held on behalf of the community it represents. The purpose of this research is to determine what factors are most likely to ensure that such Archives will be sustainable.

Key aspects which should be sustainable for any Community Archives are:

- The archival records themselves and the evidence they contain. Will they endure; can they be maintained at a proper level or standard over the long term?

- The custodial structure around the archives. Will some supporting organisation (including the people) remain in existence to care for the archives long term?

- The community connection. Can the archives and the organisation retain their relevance to the community over time?

As archival institutions, Community Archives in New Zealand are not well documented and requirements for their maintenance and sustainability not well understood or considered. By presenting "thick descriptions" (Patton, 2002, p. 438) of different Community Archives, this study aims to provide a clear picture of the nature of these Archives. Commonalities and differences, and possible reasons for them, are explored through analysis and comparison of their 
circumstances and experiences. When results are compared with archival theory, standards and accepted practice, requirements for sustaining community archives may be able to be defined.

It is hoped that the findings from this research will be of value to policy makers (whether national, regional or local), heritage organisations and the archives sector in planning and decision-making around management, support or service provision to Community Archives, with the ultimate aim of ensuring better preservation and use of community archives and realising their value. For the Community Archives themselves, particularly those outside local government structures, the study could provide guidance around factors which they should consider in order to better meet their commitments as custodians of the community's documentary heritage and enhance their chances of sustainability.

\subsection{Research question}

The primary question posed by this research is: how sustainable are Community Archives in New Zealand?

In exploring this question, three subsidiary questions are asked:

- What factors need to be present in order to maintain community archives over the long term?

- How well do four Community Archives in New Zealand exhibit these factors?

- What changes might be required to enhance the sustainability of Community Archives in New Zealand?

A qualitative approach was employed for this study and interpretive case studies involving four Community Archives used to explore the effect that different factors have on sustainability. 


\subsection{Definitions}

A number of key terms require definition as early as possible as they may be employed in different ways in other fields, are often used loosely by lay people, or there is even variation in their use within the information management/cultural heritage sector. The terms 'archives', 'community archives' and 'sustainability' are discussed and defined below.

\subsubsection{Archives}

'Archives' is the most important term to understand, as this study is based on the meaning of the word as defined in archival theory and used by professional archivists. While the term may be used loosely by Community Archives themselves, and the true archives held in a Community Archives might be only part of their collections, this study is concerned only with those parts of collections held by Community Archives which meet the archival theory definition of archives.

Archives are "records of organisations and individuals that have been selected for indefinite retention on the basis of their continuing value for legal, administrative, financial or historical research purposes" (Bettington, Eberhard, Loo, \& Smith, 2008, p. 633). They can be simply defined as "those records of an organization or individual that have continuing value" (Hofman, 2005, p. 137).

Records are defined as "information created, received and maintained as evidence and information by an organisation or person in pursuance of legal obligations or in the transaction of business" (International Standards Organisation, 2001). For individuals, "transaction of business" refers as much to the conduct of their personal affairs as any formal business transactions; personal papers are evidence of activities and provide a basis for memory for the individual who created them (Cox, 1996b, p. 52).

'Archives' is therefore used in this study in the sense of records of continuing value created by individuals or organisations. It excludes copies 
(paper or digital) or transcriptions of original records retained as an historical information resource.

\subsubsection{Community archives}

The term 'community archives' tends to be loosely applied in New Zealand. It is a relatively new term, the definition of which is, in fact, the cause of some debate. The author of a report on ethnic community archives in London describes them in this way:

1. The subject-matter of the collection is a community of people. The classic example is a group of people who live in the same location, but there are 'communities of interest' as well, such as people who worked in a certain profession.

2. The process of creating the collection has involved the community. Typically, this means that volunteers have played a key role, sometimes alongside professional archivists. (Ander, 2007, p. 63)

In research currently being undertaken into community archives in the United Kingdom, Flinn describes community as "a group who define themselves on the basis of locality, culture, faith, background, or other shared identity or interest" and community archives as "the grassroots activities of documenting, recording and exploring community heritage in which community participation, control and ownership of the project is essential" (Flinn, 2007, p. 153). The National Council on Archives provides a similar definition: "collections of material that encapsulate a particular community's understanding of its history and identity...The community itself may be geographically based, or relate to a cultural or thematic community of interest. (National Council on Archives, 2007a, p. 3)" Ander defines community archives as "collections of primary source material about and generated by 'communities' widely defined" (Ander, 2007, p. 3).

The term is also frequently applied to collections which include materials compiled or created by the Community Archives itself (such as family histories, indexes of newspapers, transcriptions), as well as items received. Many Community Archives compile local or family history resources and collect artefacts, books, ephemera and other materials as well as archival records. 
While family and local history can be very closely connected and overlapping in terms of motivation, subject and materials, as Flinn et al. explain, "self-selection of the term 'archives' to describe many of these collections conveys a sense of the historical significance and treasured nature in which these materials are held by those responsible for the collection which perhaps the terms library or even museum might not", rather than reflecting professional use of the term (Flinn, Stevens, \& Shepherd, 2009, p. 74).

Based on the above, the following definition has been arrived at and scopes this research:

Community archives are collections of archival records that originate in a community - that is, a group of people who live in the same location or share other forms of community of interest - and whose collection, maintenance and use involves active participation of that community.

It should also be noted that the term 'community archives' may be used to refer to both the collections of material and to the groups or organisations which engage in community archives activities (Ander, 2007, p. 3).

\subsubsection{Sustainability}

'Sustainability' is the 'ability to sustain'. According to the Oxford English dictionary online, to 'sustain' means "to keep in being; to cause to continue in a certain state; to keep or maintain at the proper level or standard; to preserve the status of" (Oxford University Press, 2009).

Today, the term 'sustainability' is used in a variety of contexts. The meaning behind most uses, however, goes back to the definition from the Brundtland Report of the World Commission on Environment and Development of 1987, which states that sustainable development is development that "meets the needs of the present without compromising the ability of future generations to meet their own needs" (Museums Association, 2008, p. 4). While the maintenance of community archives is different from issues relating to economic development 
and the environment, this basic definition is entirely appropriate because the archives themselves are retained for the benefit of future generations.

Another important aspect of the term 'sustainability' in its contemporary sense is that it is generally applied to systems, where a number of components are interdependent and related (Adams, 2010, p. 7). Lozano's discussion of the challenges of representing sustainability in a way which captures the "complex dynamic inter-relations" emphasises this characteristic (Lozano, 2008, p. 1838). This is also relevant, in terms of community archives, where a number of entities (archives, organisation and community), processes and other factors are involved, as well as a temporal dimension.

In defining sustainability in relation to community archives, therefore, the concept of maintaining at a proper level over time, and the concept of responsibility to do so for future generations, are combined.

\subsection{Scope}

At the highest level, the boundaries of this study are determined by the definition of community archives set out in 1.4.2. The study excludes consideration of wholly in-house Archives, which hold only records created or maintained by the organisation of which the Archives are part (Eberhard, 2008). These remain part of business of the organisation and in the custody of the records creator or owner. In-house Archives include local government Archives, where only the records of that local authority or its predecessors are collected, and central government Archives, whether they are held within the department which created them or in Archives New Zealand.

Also outside the scope of this research are national archive-collecting institutions, such as the Alexander Turnbull Library, whose focus is on collecting archives of national significance. Research archive collections within universities (or university libraries) are also excluded.

Examples of alternative uses of the term community archives, particularly collections of digital objects contributed to by online communities and 
collections of copied or published sources held as a resource for the community, have also been considered out of scope. While community organisations may provide networked repositories for individuals or organisations to share digital material, and Community Archives may hold important historical materials other than community-generated archives, the research focuses on requirements to maintain the original records (whether analogue or digital) of the decisions and activities of individuals and organisations.

\subsection{Theoretical framework}

This research is motivated by an interest in the collection, maintenance, preservation and accessibility of original archival records created by members of communities and cared for within those communities. Systems and structures must be in place to ensure this happens over the long-term, but at the centre are the records or archives. The lens through which the research is viewed is therefore one of archival theory and standards, although other theories relating to heritage, community and sustainability are touched on. The two key archival theories underpinning the study are the records continuum theory and archival theory of evidence.

\subsubsection{Continuum theory}

The records continuum theory was developed by Frank Upward in the 1990's. It is best represented in the recordkeeping continuum model developed by him and reproduced below. 


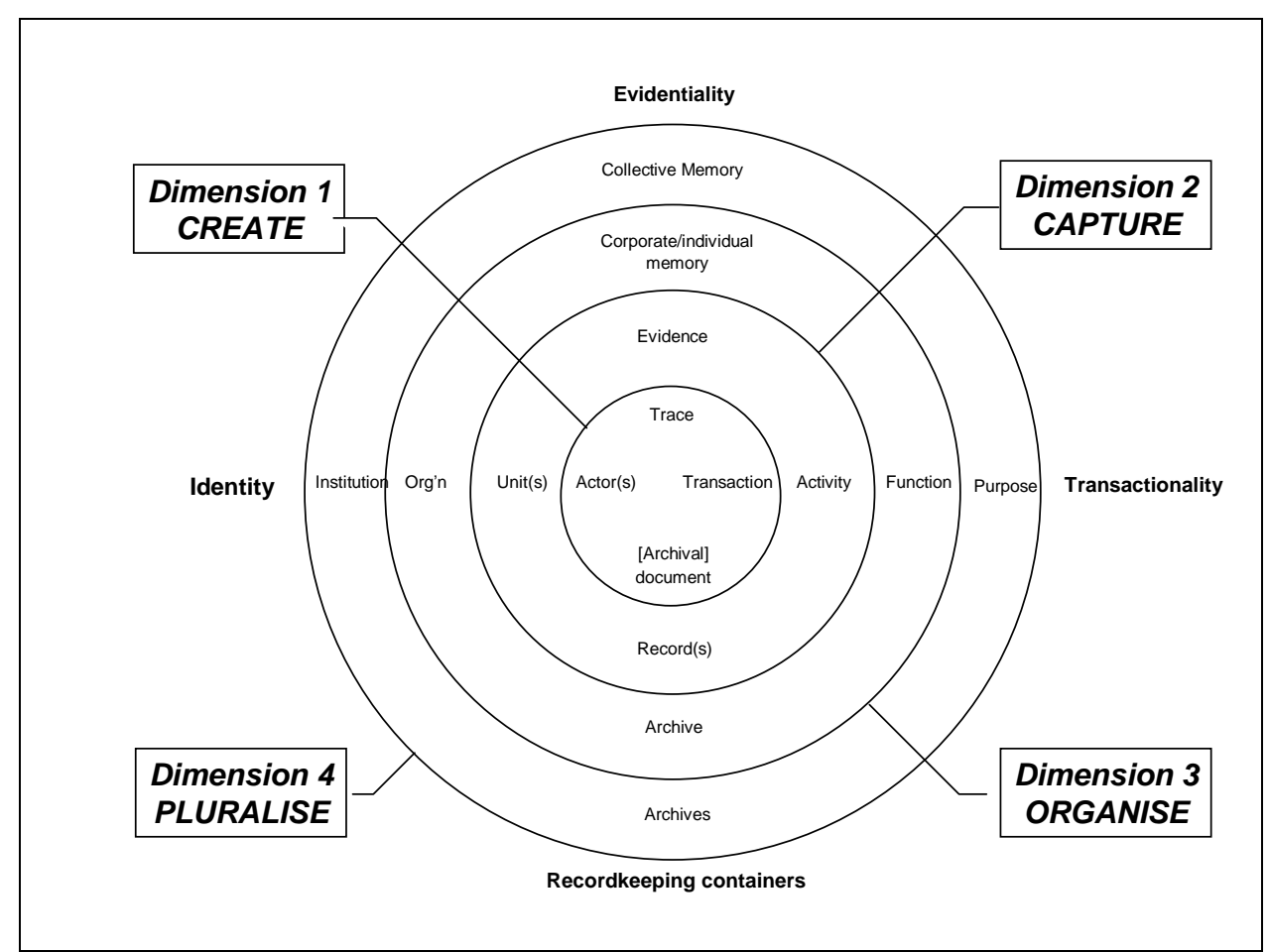

Figure 1: Continuum Model

(reproduced with permission from Frank Upward)

The records continuum is a way of thinking about recordkeeping in society. It identifies key evidential, recordkeeping and contextual features of the recordkeeping environment and shows their relationship to each other (McKemmish, 1997).

The continuum theory owes much to the structural principles in social systems described by Anthony Giddens. Giddens' structuration theory explains the reproduction of systems across time and space (Upward, 1997). It not only deals with action (or process across time) and structure (the features of a social system which stretch across time), but also assumes that these elements interact to shape each other (Upward, 1997, pp. 2, 4, 10). The records continuum theory developed from this by Upward provides the perfect framework within which to consider the system which comprises Community Archives.

To briefly describe the continuum model, the four 'process' or time dimensions are: Dimension 1, which encompasses the creation of documents, including the actions, communications and decisions behind them, and the actors involved; Dimension 2, where these documents are captured into recordkeeping systems, 
whether personal or corporate, enabling them to act as evidence of activities; Dimension 3, where recordkeeping systems organise the corporate memory of the entity; and Dimension 4, where the records of many individuals and organisations form part of a wider, collective memory accessible to society in general. The structural elements which intersect with the dimensions encapsulate the major concepts in archival science (Upward, 1996). The recordkeeping-containers axis represents the containers of the recorded information, from document through to all archives in society. The evidentiality axis is about the evidence contained in the records and its role in individual, organisational and collective memory. The transactional axis reflects the acts, functions and purposes related to recordkeeping, from the action or decision which leads to creation of a document through to the broader societal purpose. Finally, the identity axis represents the actor, whether at individual, organisational or wider societal-institution level.

Upward emphasises that the records continuum is "continuous and is a time/space construct" (Upward, 1996, p. 8). Boundaries are fluid and the structural principles for archival practice are flexible in their implementation. In addition, the model introduces the concept that pressure can work both inwards and outwards across the dimensions (Upward, 2005). The notion of pressure being exerted both ways across the dimensions, for instance, helps make clear the reality of an amorphous community which can be both the creator and the user of the records as well as the motivating force behind their collection.

A Community Archives is not a standalone entity. While the term might, at first glance or to the uninitiated, appear to refer to a physical place or to the collections, Community Archives are, in fact, a system. At the simplest level, that system involves three key components: the archival records, the organisation which collects, manages and makes the archives accessible, and the community which both creates them and uses them. This concept of a system is captured well by the recordkeeping continuum theory.

From one perspective, a Community Archives can be seen as existing entirely in the fourth dimension - the system for "building, recalling and disseminating 
collective memory" (Upward, 1996, p. 9). The archives themselves are on the recordkeeping axis; the organisation which supports them, on the identity axis. Their role in culture and society is represented on the evidentiality axis as the evidence of the past which builds collective memory. The transactionality axis is where the archives are made accessible to society.

The continuum model can also be viewed from the perspective of the individual archive within the Community Archives, in which case the archival record continuum crosses all dimensions. Viewed this way, the original document creation takes place in the first dimension; that organisation or individual's capture of it into some recordkeeping system (whether a subject-classified file or a shoebox) occupies the second dimension; the recordkeeping regime of the organisation or individual (say, its filing system or collection of shoeboxes and envelopes) occupies the third dimension; and its transition to the Community Archives, where it joins the records of other organisations and individuals to provide a collective memory of the activities and roles of individuals and organisations (McKemmish, 1997), represents the fourth dimension.

Using the recordkeeping continuum model, community archives can therefore be viewed in a number of different ways, all of which contribute to understanding their place in recordkeeping and in society. The model helps explain the complexity, the interactions and the interdependencies of different factors within the system which comprise a Community Archives.

Dearstyne and the American archival organisations, whose work informs the methodological framework used in this research, do not explicitly situate local archives within a societal-recordkeeping system as the records continuum theory does, but their identification of a number of factors required for maintenance of community archives indicates that they also see it as a system. Within their essential pre-requisites and checklists, there are also dependencies and interrelationships similar to the flexible boundaries in the continuum model. The recordkeeping continuum makes the concept of a system explicit and also models archives and their role in a social and recordkeeping system. The continuum theory is used as the theoretical framework for this study because it 
locates elements, such as those required under Dearstyne's system, but makes it even clearer how they relate to evidence, collective memory and society - and hence their importance.

In addition to conceptually representing the place of the record in society, the continuum model emphasises the evidential nature of the record and the fact that recordkeeping actions occur even once a record has reached the fourth dimension. Description of archives, for instance, which captures contextual and other information necessary to ensure that reliable, authentic, meaningful and accessible records will continue to exist over time, is a recordkeeping process (McKemmish, Acland, Ward, \& Reed, 1999, p. 8). While continuing to emphasise the value of records as evidence, continuum theory strengthens notions of their ongoing 'recordness' and the fact that, even when archives are removed from their original creators, they continue to gather evidence (and therefore reveal value) of their life as records.

\subsubsection{Evidential theory}

A key responsibility in the maintenance of community archives is ensuring their integrity as records so that they endure as evidence of the activities of the creator. At a basic level, this requires their physical preservation, to which conservation or preservation techniques and technologies are applied. Maintenance of their value as archival records, however, requires adherence to practices and standards which preserve, in archival theory terms, their evidential value.

The importance of archives as evidence is one of the key concepts in archival theory, documented in an undiminished line from archives pioneers such as Hilary Jenkinson to the continuum theory. Jenkinson wrote that:

The aim of the Archivist is to hand on to future generations the documents confided to him with no diminution in their evidential value; accordingly he has to guard against the destruction not only of those elements whose value as evidence is obvious to him but also of those whose value he does not perceive. (Jenkinson, as cited in Cox, 1996b, p. 52) 
The key principles underlying evidential value are provenance and original order. While concepts of provenance (or respect des fonds) date back to 1841 in France, and original order to Prussia in 1881, these two principles were first clearly defined as archival theory by Muller, Feith and Fruin in 1898 (Schellenberg, 1956, p. 176). The principles are aimed at preserving the records as evidence of the activities of the creator, which is the unique contribution of archives to history, identity and accountability.

Provenance is defined as the "relationships between records and the agencies or individuals that created, accumulated and/or maintained those records in the conduct of personal or corporate activities" (Bettington, et al., 2008, p. 636).

Original order can be defined as the "sequence or grouping in which archival records were originally accumulated or kept by their creator". This definition is followed by the critical explanation:

Maintaining the original order preserves the context of their creation and the authenticity of records. It also provides valuable evidence about the organisation and/or person who created the records. (Bettington, et al., 2008, p. 635)

\subsubsection{Theoretical conclusions}

This study is based on the premise that, if the mission or role of an organisation is to preserve and make accessible archival records, it should have in place all the factors necessary to ensure that this responsibility can be met. Archival theories aimed at preserving the evidence or 'recordness' of archives (including provenance and original order), and modelling the complexity of the system of which they are part (the records continuum theory), therefore provide the essential theoretical and conceptual foundations against which to assess Community Archives. Informed by archival theory, standards and practices have been developed to guide archival work and these shape the propositions underlying this research. 


\subsection{Methodological framework}

A methodological framework for the study was developed using guidance produced for local history archives in the United States. The process of its development is explained in detail in Chapter 3. This framework then shaped the semi-structured interviews with case study participants and underpinned analysis and interpretation of the findings.

\subsection{Thesis overview}

Following this introductory chapter, Chapter 2 provides context for the research by critically reviewing relevant concepts, experiences and commentary from archival literature and pertinent organisational reports, policy and other documents.

Chapter 3 outlines the research design and the methodology used. It sets out the propositions underpinning the methodology, describes participant selection, data collection and analysis criteria and processes, and development of the methodological framework used for these.

Chapters 4 to 7 present findings from the case studies in narrative form, in order to paint a picture of the realities of four different Community Archives in New Zealand for the reader. The Archives are run by committed and enthusiastic people and the author believes it is as important to understand the human factors involved in maintaining community archives as it is to understand the technical ones, therefore the story of these individuals must be conveyed for the Community Archives 'system' to be understood. Individual case studies are then summarised in word and table form, and the findings on factors required for maintenance ranked according to likely contribution to sustainability.

Chapter 8 contains the results of cross-case analysis. It compares the four cases, discusses similarities and differences relating to each factor, and considers possible reasons for these and implications. It also includes a comparative sustainability ranking for the cases and an analysis of the relationship of the factors to the records continuum model. 
The final chapter answers the research questions and shares the conclusions the researcher has reached as a result of the study, relating them to archival theory and literature. The implications of the findings for management of community archives in future are discussed and recommendations made for further research.

\subsection{Conclusion}

The aim of this thesis is to explore how sustainable Community Archives in New Zealand are, by establishing the characteristics required for maintenance over time and studying four Community Archives to determine how well they meet these maintenance requirements. Analysis of findings from the case studies allows some conclusions to be drawn about the contribution of various factors to sustainability. On the basis of these, a number of strategies which might enhance sustainability of Community Archives are put forward. As little research has been carried out in this area, it is hoped that the results will prove useful to both policy makers and archivists in future. 


\section{Chapter 2}

\section{Literature Review}

\subsection{Introduction}

A literature review was carried out with three key aims in mind. Firstly, to better understand the social and cultural context of community archives, particularly the nature of community, heritage and identity, and to describe the context of Community Archives in New Zealand. Secondly, it was important to learn more about the requirements for maintenance of community archives over time and the experiences of custodians in meeting these requirements. Here the work of informed and critical writers on archives, texts on archival practice, and policies and programmes in jurisdictions similar to New Zealand's were considered relevant. Finally, further investigation into the application of archival theory was considered important, in order to understand its value to community archives.

\subsection{Social and cultural context}

This section looks at the social and cultural context for community archives. Key to understanding this are concepts of community, heritage and identity, cultural well-being and social capital.

\subsubsection{Community}

In a study on Community Archives, it is important to understand the implications of the community dimension and what distinguishes a Community Archives from others.

Use of the term community tends to suggest that communities are naturally existing entities which can be easily defined. Rather, community is an ambiguous term and communities are complex, ill-defined associations of 
people bound by some sense of shared identity. They involve individuals identifying with a collective but also with other individuals with whom they feel an affinity (Thompson-Fawcett \& Freeman, 2006). New Zealand society is diverse, containing many different and overlapping communities, each with their own character. Within a community, which might define itself by a physical space, there will also be many other communities (Thompson-Fawcett \& Freeman, 2006). As well as being a group defined by a common bond or interest, a community implies psychological connections. Psychological connections include membership (the feeling that one has invested a part of oneself and has a right to belong), influence (the feeling that one can be influential within a group), integration and fulfillment of needs (where people meet the needs of others as well as themselves) and shared emotional connection (a shared history, shared events) (Freeman, 2006, p. 16).

These characteristics of community are important to consider when studying Community Archives, as those involved in their establishment and maintenance will share the characteristics of the community, or communities, from which they spring and also form a sub-community of their own.

\subsubsection{Heritage and identity}

Whether they are held within a library, museum or dedicated Archives, community archives are not simply passive collections of documents, but archival records arising out of a community and whose collection, maintenance and use involves that community. They therefore play an important role in defining and preserving our sense of identity. The life of a community is represented by the records of multiple layers of actions and interactions among the people and institutions within it (Bastian, 2003, p. 5). Furthermore:

The relationship between communities, memory, and written records is complex and multifaceted. The reflective, reinforcing, and remembrancing roles that historical records play in the construction of community memory support the evidential, authenticating, and factual roles. Vital to all such roles must be the ability of the community to access the records to build and defend that memory... The critical importance of an archive as both a physical and spiritual "house of memory" in which records are united and stored is underscored when considering the dilemmas 
faced by communities whose archives are lost. (Bastian, 2003, p.

6)

'Heritage' is a term which, like 'community', is widely and sometimes loosely used. Its importance is not questioned, however. It is also generally accepted that it cannot be separated from the interrelated concepts of memory and identity (McDowell, 2008, p. 49). Heritage is a form of collective memory. It is a social construct in which values and meanings are attributed to past events, materials or places and to the representations created from them. Values are placed on the artefacts by people, who view heritage through many different lenses (Graham \& Howard, 2008, p. 2). It is shaped in response to the demands of the present and subject to constant revision and change. An important element of heritage, therefore, is the ability to constantly re-read texts to meet changing societal needs around identity and meaning (Graham \& Howard, 2008). The role of Community Archives (and, indeed, any Archives) in this function, as preservers of original records which remain connected to their provenance and context over time, is evident. The archives allow a community to revisit and redefine its heritage in search of identity, by finding new meanings in the same records.

While, in an increasingly pluralistic and globalised world, many communities (such as gay or ethnic communities) assert a heritage and identity which does not relate to a specific locality, accounts of memory still tend to centre on place. At the same time, although there has been a growth since the 1960's in forms of individual heritage such as genealogy, heritage has become more public and tends to refer increasingly to what is held collectively (Graham \& Howard, 2008). Guelke and Timothy (2008) have described how, as a subset of heritage, family history relates not only to personal identity but also to major geographical themes such as location, immigration and ethnicity (Guelke \& Timothy, 2008, p. 1). Individual memory is one aspect of collective memory and a variety of narratives and discourse bind people into a collective identity, creating a sense of community. Furthermore, in modern society, collective memory becomes mediated, or indeed only possible, through the evidence of archives (Meethan, 2008). 
The importance to wider society of the archives of individuals has also been addressed in archival literature. McKemmish explains that personal records are evidence of our lives, our identity and our place in the world. By caring for such records and making them accessible, Community Archives help ensure that "evidence of me" becomes "evidence of us" (McKemmish, 1996, p. 29).

In particular, community archives are important because they represent underdocumented and often powerless elements of society (Cox, 1994). Research in the United Kingdom also found that, through community archives, heritage and history are "re-balanced in favour of under-voiced communities" (Flinn, 2007, p. 165). Some writers argue that one of the responsibilities of the archivist is therefore to reflect the diversity of the community in their collecting (Jimerson, 2009).

Community archives remain connected to the community out of which they arise. There may be many and varied ways of maintaining this connection but, in the majority of cases, for the archives to be recognised as heritage they must remain physically as close as possible to their point of origin (Strachan, 1983; Taylor, 1982).

\subsubsection{Cultural well-being and social capital}

In New Zealand, the Ministry for Culture and Heritage (2008) links cultural well-being directly to identity. It describes culture as the foundation-stone of identity and values, and beliefs and identity as the glue for cultural well-being.

Under the Local Government Act, one of the roles of local government is to promote the cultural well-being of communities, now and for the future ( Local Government Act 2002). The Ministry for Culture and Heritage has defined cultural well-being for the purposes of the Act and states that it includes:

protecting and interpreting our past, linking us to who we are today and to our future. It is about providing our communities with an ability to access a wide range of media such as libraries, archives and museums for information, learning and pleasure. (Ministry for Culture \& Heritage, c.2005, p. 5) 
Furthermore, organisations such as historical societies, museums and pioneer villages run by volunteers have been described by the Ministry's Chief Executive as playing a key role in the creation of cultural well-being: "such places are repositories of community memory and fulfil a very real social and cultural need...their impact can be far greater than their ostensible museological or economic development purpose" (Matthews, 2005, p. 4). Research in the United Kingdom also concluded that Community Archives make a significant contribution to cultural capital, in a way that is not usually observed in the mainstream heritage sector. In addition to their heritage role, their grass-roots nature empowers participants and encourages a sense of belonging to the community (National Council on Archives, 2007b).

Many Community Archives are voluntary organisations. Such organisations are also an important source of social capital, defined as "those features of social life that enable participants to act together more effectively to pursue shared objectives" (Dollery \& Wallis, 2003, p. 88). Local government has been shown to have a particularly valuable role in social capital development because it is embedded in the local community along with the voluntary organisation. It is able to link these organisations with external networks, allowing them to acquire skills and resources to participate in networks beyond their communities, while maintaining their personal networks (Dollery \& Wallis, 2003, pp. 95-97).

\subsection{Community Archives in New Zealand}

To provide context for the individual case studies explored in the research, this section looks at how Community Archives fit into wider archives sector and gives an overview of the history of their development and their current status.

\subsubsection{Framework of archival institutions}

Archival institutions can be divided into two main categories: public and private.

Public records are those over which government legislation exercises control. These are created by the legislative, executive, and judicial branches of the New 
Zealand Government, including state enterprises, crown entities, state and integrated schools, universities and public hospitals and by local government, including council-controlled trading and other organisations (Public Records Act 2005). Public Archives are therefore institutions which hold only records of enduring value from these bodies.

Private records are everything else. In the Public Records Act a private record is defined as one "not created in, or received by, a public office or local authority, and that is not a Minister's paper" (Public Records Act 2005, Section 4). Private Archives are therefore organisations set up to maintain records created by any non-government body, including those which collect from a wide range of private individuals, businesses or other organisations. Private archives may be maintained by the creating organisation itself, held within museums, libraries or other publicly-funded bodies, or held by incorporated societies and other private entities.

The sector can also be sliced another way - in-house or collecting institution and these cut across the public/private categories.

An in-house Archives is maintained by an organisation for the purpose of keeping its own archives. Acquisition is restricted to records generated by the parent organisation, or by other closely associated bodies or people (Bettington, et al., 2008, p. 211), and there is an unbroken chain of custody. For example, a local authority may move selected records which are deemed to have permanent value to a purpose-built repository, and introduce different management and access regimes, but they remain the records of that local authority and it continues to have responsibility for their maintenance and use.

By contrast, a collecting Archives is an organisation (or part of an organisation) which has, as its principal function, collecting the records of a variety of organisations, families and individuals. These are sometimes also called manuscript collections or manuscript libraries (Bettington, et al., 2008, p. 211). A well-known New Zealand collecting archives is the Alexander Turnbull Library, which collects the records, personal papers, photographs and other 
original documentary material from many different organisations and individuals of importance to New Zealand's culture and heritage.

These different types of Archives can be shown diagrammatically in the following way:

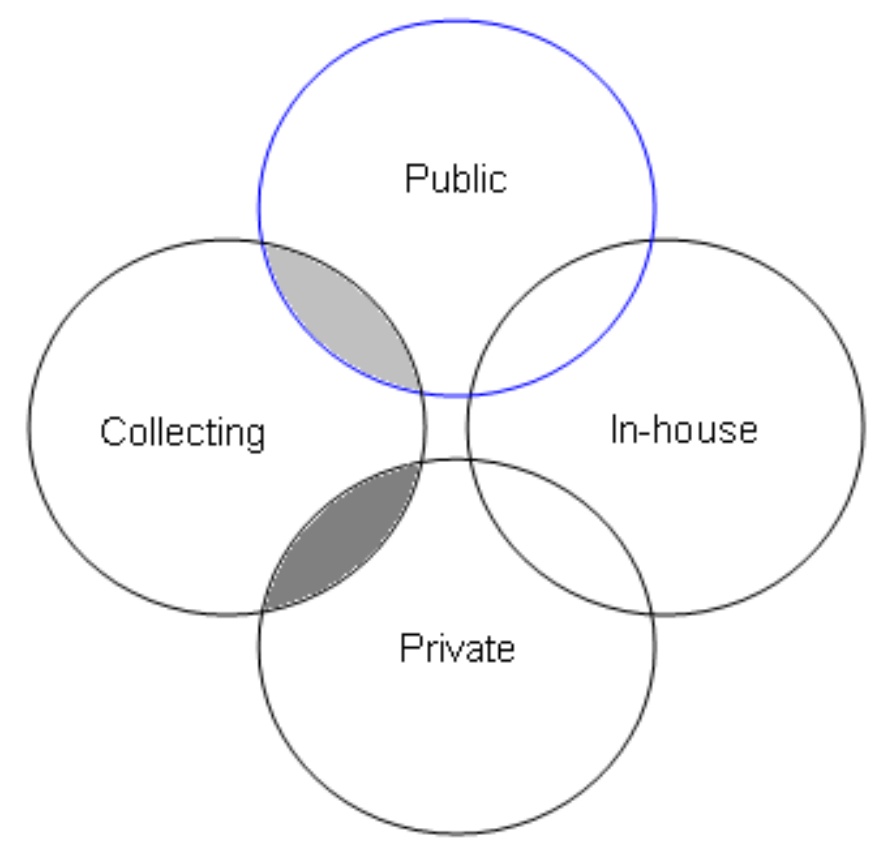

Figure 2: Model showing types of Archives

Community Archives fit into the intersection between private and collecting institution categories and, occasionally, between public and collecting institution categories. The latter situation may occur when a private Archives holds local government records or when a collecting Archives is wholly funded by a public authority.

\subsubsection{History of Community Archives}

In the 1970's there was a change in the nature of archives collecting, as New Zealand academic historians began to focus on their own country and, worldwide, there was a growing interest in social history. There was also increasing interest in genealogy, evidenced by the formation of the New Zealand Society of Genealogists in 1968 and a Federation of Family History Societies in 1974 (New Zealand Society of Genealogists, 2007). As a result, Archives increased the scope of their collecting activities to take in the records of community 
organisations (Sanderson, 2007). At the same time, there has been a growing interest in local history and identity amongst ordinary New Zealanders, inspiring the birth of grass-roots Community Archives.

While there has been no study of Community Archives in New Zealand, a reasonable picture of their origins and nature can be gained from articles and published conference papers over recent years. A report on the establishment of a Community Archives in the tiny settlement of Tinui bears witness to the 'emotional' involvement of the community in its archives. The writer describes how the Tinui Archives started as a community trust to preserve its country store and a Community Archives grew out of it, arising "individualistically out of a sturdy sense of local identity" (Davis, 1987).

The story of the establishment of a Community Archives reported in Archifacts in 1980 contains a number of elements which are common to the history of many:

Begun in 1955 as a result of interest throughout the Province with the oncoming centennial in 1959. . . It began as a $10 \times 3.6$ metre shed on $\mathrm{Mr}$ Norman Brayshaw's property to house predominantly his collection of photographs. .. In 1959 he was offered by the Land Registrar in Blenheim 20,000 land title documents. . . These he sorted into land allotment areas which then served as the basis for filing the other records as they came in later. The Archives are, consequently, arranged mainly in geographical form. . . As people came to learn of and respect the Society's attempt to preserve the Provincial history locally rather than centralized in Wellington. . . records came into the second shed he had built and by the mid 1960s both sheds were full (McNamara, 1980, p. 345).

The North Otago Museum provides another case study. It arose out of a strong sense of parochialism, and community involvement is evident from the day it opened in 1987, when local genealogists assisted with the move to new premises. After that, not only were services provided to school students, but the students assisted with sorting and cataloguing (McCulloch, 1998).

The last few years have also seen the development of strong Maori archive centres, some of which meet the definition of Community Archives used in this study (a number of others called 'Archives' are more like resource centres, 
bringing together copies of materials in other institutions for use by iwi). This has been described as a consequence of increased awareness of information resources, a desire to develop tribal capability but also of a certain dissatisfaction amongst Maori with what they see as inappropriate handling of cultural materials in institutions (Wareham, 2001, p. 44). The Ratana Church and Movement Archives, which opened at Ratana Pa in 2004, could be considered a Community Archives, with its volunteer-driven gathering of archives, photographs and oral histories relating to the Church and Movement and its plans for sharing this through education programmes (Collier, 2004).

\subsubsection{Community Archives today}

Community archives, often dating back to the nineteenth century, are held in many institutions throughout New Zealand (Archives New Zealand, 2008). These institutions vary in size and type, from large organisations, such as museums, to small, standalone, voluntary ones.

It is not easy to obtain an accurate picture of the Community Archives population in New Zealand, however. One of Archives New Zealand's purposes under the Public Records Act is to support the safekeeping of private records (Public Records Act 2005). In line with these requirements, it has developed a community archives function and declares, in its 2009-2012 Statement of Intent, that it "provides leadership, training, and support for community archival activities across New Zealand" to ensure archives are managed so they can remain within the community (Archives New Zealand, 2009c, p. 26). In spite of this, nowhere does it define a Community Archives and, in fact, there would appear to be considerable confusion over what constitutes one. For instance, the Community Archives Survey Report undertaken in 2007 includes institutions such as the Auckland Regional Office of Archives New Zealand, Department of Internal Affairs-Births Deaths \& Marriages, local authority Archives and many school Archives (Archives New Zealand, 2008) - all of which are public offices and subject to the Public Records Act.

What the survey does suggest, however, is that a high proportion of Community Archives are voluntary or within the local government sector. A total of $22 \%$ 
are clearly the direct responsibility of local government $(15 \%$ in "local authority" and 7\% in "public library" institutions) and this may be significantly larger if even some of the $30 \%$ in "museum or art gallery" are councilcontrolled. Another $30 \%$ are held by a "voluntary organisation" (14\%) or "historical society" (16\%), the latter likely to be also a voluntary organisation (Archives New Zealand, 2008, p. 10).

The finding that a large proportion of Community Archives are held within museums is born out by a survey undertaken for Museums Aotearoa in 2009. It indicated that $36.9 \%$ of museums categorised themselves as having "archive" as their primary purpose. The significance of museums to the community archives sector is further born out by the finding that, in terms of holdings size, $29 \%$ of museums cited photographs or archives and manuscripts as their top collection categories; and 37\% listed photographs or archives and manuscripts as the second largest holdings category (New Zealand Tourism Research Institute Auckland University of Technology, 2009). Both surveys allowed participants to choose more than one category, so conclusions cannot be drawn from it as to relative funding and governance (for instance, a voluntary historical society may also run a museum). As the Tourism Research Institute report states, however, the relative proportion for each category still gives a "good indication" of the situation (New Zealand Tourism Research Institute Auckland University of Technology, 2009, p. 20). Furthermore, the predominance of photographs, archives and manuscripts, and printed materials in museums highlights the breadth and depth of community archives they hold but also "reflects the fact that museums may exist where there are no libraries or official archives" (New Zealand Tourism Research Institute Auckland University of Technology, 2009, p. 7).

Statistics from the Tourism Research Institute also support the Archives New Zealand finding that many Community Archives are supported by local government. It found that, in terms of governance, $18 \%$ of museums are controlled by local government but $29 \%$ rely on local government for funding, the difference probably being accounted for by museums which categorised themselves as "being governed by independent boards or trusts". 
Identifying with 'community archives' may well be part of a world-wide trend. Crooke has noted that connecting with community has become fashionable, to the extent that, "in public policy, community is an ideal that should be strived for". She suggests that the term may be used simply because of its ability to promote a "positive regard for the organizations, policies or programmes to which it is applied" (Crooke, 2008, pp. 417-420). In the same spirit, the title 'community archive' may also be applied by Archives themselves or their governing bodies when, in fact, they are simply local collecting institutions with no community involvement.

Amongst other goals, this study aims to present a clear definition of community archives in order to provide some clarity for users, funders, policy makers, archivists, students and the people of New Zealand.

\subsubsection{Concerns about sustainability}

Evidence of concern about the sustainability of local archives collections in New Zealand dates back to the early 1970's. In 1978, Dr Wilfred Smith, in his report on the state of Archives in New Zealand, suggested the concept of regional Archives, because many organisations did not have the archival expertise and the facilities required to care for their archival holdings. While such archives should be near the people to whom they were of most interest, he believed it was essential to have adequate facilities and archival expertise provided by professional archivists to advise and assist smaller repositories (Smith, 1978). In the years following the report, the Archives and Records Association of New Zealand (ARANZ) devoted considerable energy to the issue of how to preserve local archives and keep them close to the people to whom they most mattered. In a 1983 issue of the ARANZ journal devoted to regional Archives, Stuart Strachan emphasised that New Zealand was in serious need of a strong local archives service to take care of local archive needs.

In the absence of these [strong units of local or regional government] the archives function has tended to be assumed by related but not primarily archive institutions, such as libraries, museums and historical societies, in which archives exist tenuously as an appendage to very much larger book and artifact collections. These commonly lack trained staff, properly 
supervised and serviced reading rooms, adequate finding aids, repair facilities, and are short of space. (Strachan, 1983, p. 8)

Regional Archives, collecting non-government records, have never developed in a systematic way in New Zealand, resulting in a continuation of the situation Strachan warned about. Consequently, local archives are collected by museums, libraries, historical societies, councils and other community groups and many still fit the description given by Strachan in 1983 of lacking trained staff, properly supervised and serviced reading rooms, adequate finding aids and facilities.

Today, in New Zealand, many small Archives are run with minimal resources by low-paid or voluntary workers who lack professional knowledge or experience; many have no guaranteed budget and an uncertain future (Sanderson, 2007). According to the survey by Archives New Zealand, 40\% of Community Archives have no paid staff and funding is seen as a major challenge and a priority for one third (Archives New Zealand, 2008, pp. 8, 28). In addition, 35\% have no qualified staff - with Archives New Zealand noting that, for many organisations, 'qualified' simply means having "some form of training (informal or formal)", generally acquired through workshops or seminars (Archives New Zealand, 2008, pp. 29, 30). In fact, as the survey included many local-authority, government and other non-community Archives which are known to have paid staff, the situation is probably worse for Community Archives than the statistics suggest.

Specific examples of the limitations of many Community Archives which, it could be argued, mitigate against their sustainability, can also be found in the New Zealand literature.

Two comments by an historian involved in a community effort to establish a heritage centre show an understanding of factors which should be considered in establishing a Community Archives but also of the fact that most of her fellow committee members did not share this understanding: 
Arrangement and description and making the archives available is going to be another puzzle altogether, and I am not quite sure if my fellow committee-members quite understand yet what that may entail.

(Butterworth, 2001, pp. 5-6)

While she saw a need to collect records of important local businesses:

It may be an uphill task persuading the committee of this, however, as they do not tend to think of business and industry as being historical, especially when the businesses were quite recent. (Butterworth, 2001, p. 6)

There is also evidence that Community Archives within larger organisations are subject to the funding constraints and changing priorities of their funders. For instance, the history and community nature of the archives held by the Whakatane Museum were outlined in a conference paper (Jordan, 2005) but in early 2006 these Archives were closed to the public and all staff left. The Archives remained closed to the public in 2010.

These examples illustrate some of the factors which indicate that certain structures for Community Archives may not be conducive to meeting a community's desire to preserve and make accessible its history. The question is, how can these factors be more clearly defined and help to provide us with a way forward.

\subsection{What constitutes sustainability for Community Archives?}

"Whatever the motivation behind the idea of establishing an archive, it is important to ensure that the concept is sustainable" (Bettington, et al., 2008, p. 33). These are the cautionary words on collecting archives, of which community archives are a subset, in the key archival textbook for Australasia.

The problem of sustainability of Community Archives is not confined to New Zealand. Community Archives in North America, for example, face similar challenges. In the face of a burgeoning community archives movement in Canada, a number of archivists and academics expressed concerns about their sustainability, going so far as to suggest that there was a need to limit their 
development since they did not have the basic resources to support themselves. Because they had taken on the role of "memory management", a job requiring an adequate level of funding, it was argued that it may have been best to stop providing support to unsustainable Community Archives (Millar, 1998, p. 132). Bruce Dearstyne, referring to surveys conducted in the United States, notes that they provided "evidence of how easy, and common, it is to underestimate what it takes to manage historical records in a responsible manner on a sustained basis" (Dearstyne, 2000, p. xiii). He found that many Community Archives in the United States have insufficient resources to fulfill their archival responsibilities and carry out their archival work in a "minimally acceptable way" (Dearstyne, 2000, p. xiii). There is a lack of skilled professional staff, secure climate-controlled storage space and preservation work, while unprocessed backlogs and lack of finding aids mean collections are inaccessible and unused.

If sustainability for Community Archives means having in place the factors necessary 'to keep or maintain [the archives] at the proper level or standard', what are those factors and how can understanding them help ensure sustainability?

Research indicates that there is a general consensus on the factors which need to be present in order to ensure that Community Archives are sustainable. There is considerable professional literature on the requirements for managing archives but archivists and archival organisations in the United States have outlined elements which must be in place specifically to maintain community (or local history) archives over time. A pamphlet produced by New York State Archives (1988) entitled Ensuring a usable past for your community provides a checklist of ten factors to be evaluated to determine how well records are being collected, preserved and made available. Dearstyne (2000) covers essential requirements extensively in his book, Managing historical records programs: A guide for historical agencies, outlining pre-requisites for successful archives programmes, basic elements for programmes and providing a checklist for reviewing programmes. The Society of American Archivists (1994) has produced 
Guidelines for the evaluation of archival institutions, describing a basic level of resources or activity for each of the fundamental aspects of archival operations.

Other literature, from archival texts on theory and practice to articles by archivists and academics on the maintenance and survival of Community Archives, accords with the requirements set out by New York State Archives and Dearstyne. In addition, as the importance of community archives is realised by government and non-government organisations, reports and standards issued by them pick up similar elements. The key themes which emerge are discussed below and grouped in line with the United States publications, which represent guidelines and assessment criteria for Community Archives that have been in place for many years.

\subsubsection{Governance}

Governance, organisational setting and the mandate of Community Archives may be a factor in their sustainability. Governance is listed as one of the basic elements of a local history records programme by Dearstyne (2000), who describes operating authority and mission statement as the foundation of any programme, determining its basic direction. Society of American Archivists' guidelines highlight the importance of this by stating that there should be "explicit documentation of the legal status and authority" and a "formal statement of purpose" for any Archives (Society of American Archivists, 1994, statement 1). There should also be a clear understanding of the difference between governance and administration, and Archives staff involvement in the planning and evaluation of the Archives' objectives. Furthermore, placement within a parent institution should contribute to the Archives' goals and objectives, a point which is relevant to Community Archives situated within larger organisations (Society of American Archivists, 1994).

The community archives sector is characterised by a relatively high number of organisations run by volunteers. One of the defining features of such organisations is that their success depends very much on the quality of their leadership (Dollery \& Wallis, 2003). The issue of dependence upon a small number of passionate individuals has been explored by Flinn et al. (2009) and 
they conclude that, while being able to draw on this commitment and enthusiasm is an enormous advantage, it means that individuals can be exhausted and lack the energy to face new challenges and contexts. Furthermore, "one of the most dangerous times for the long-term sustainability of a community archive is in the period after its original driving force moves away or passes on" (Flinn, et al., 2009, p. 80). Their research highlighted the complex and difficult relationship between sustainability and autonomy for Community Archives; autonomy is what sustains those running the Archives, and a key part of the sense of community ownership and engagement, but independence sometimes has to be compromised to obtain the funding necessary to ensure sustainability.

\subsubsection{Funding}

As might be expected, the level of funding has an impact on the ability of an Archives to resource other aspects of its programme. Both Dearstyne (2000) and Sanderson (2007) in New Zealand have noted that lack of funding is a significant impediment to a basic level of maintenance and the sustainability of small Archives. Under-funding can be partly due to a limited understanding of how resource-intensive archival work is (Dearstyne, 2000, p. 50). New Zealand's only survey of Community Archives adds to the picture painted by Sanderson, showing that funding is a major challenge and a priority for onethird of archival institutions (Archives New Zealand, 2008).

The number of voluntary Community Archives in New Zealand is especially relevant to issues of adequate funding. While researchers have found that voluntary organisations have a distinct advantage over other types of organisations, because of the huge amount that can be achieved by a small handful of committed volunteers, they have found that "voluntary failure" is particularly likely to result from the inability to generate adequate or reliable resources. (Dollery \& Wallis, 2003, pp. 59-63).

Society of American Archivists' guidelines state that "financial resources dependably available to the archives should be adequate to carry out its stated purpose" and, furthermore, that staff should have the opportunity to contribute 
to the budgeting process if the Archives are part of a larger organisation (Society of American Archivists, 1994).

\subsubsection{Skilled staff}

Archival records have two key characteristics: they provide evidence of activity and they are unique. The need to have confidence in the authenticity and integrity of archives means that they must processed according to archival principles. Many of the people who manage archives in small repositories, however, lack the necessary training and experience (Sanderson, 2007, p. 185). In order to adequately carry out their responsibilities in looking after archives, community archivists must first understand that the archives are records and recordkeeping systems, rather than artefacts or pieces of information, and that this determines how they are selected and managed (Cox, 1996b, p. 58).

Dearstyne also emphasises that archival work must be carried out in accordance with "professionally sanctioned practices" (Dearstyne, 2000, p. xiv) but notes that there is a lack of skilled staff in the area of community archives. The New York State Archives (1988) guidance also addresses this issue, by asking Community Archives to check whether they have the training, experience and expertise to care for records. The Society of American Archivists' guidelines specify that there should be sufficient staff to manage the holdings and provide services but also goes so far as to say that every Archives should have at least one person on their staff with professional competence gained through education or experience. This should then be supported by continuing professional training and development (Society of American Archivists, 1994).

One of the key skills of the archivist, but also one of the most challenging, is appraisal. Cox and Samuels describe this task of identifying records of enduring value as "the profession's first responsibility" (Cox \& Samuels, 1988, p. 29). As Randall Jimerson says, all other archival activities depend upon this ability to select wisely (Jimerson, 2009, p. 12).

The other core skill involved in ensuring that the evidential quality of archives is preserved is arrangement and description. Arrangement practices which do not 
adhere to the principles of provenance and original order put at risk the integrity and evidential qualities of the records. Description is important because it captures not only information about the records, but also the essential context which makes them meaningful (Milton, 2008, p. 263). Research into use of descriptive standards in New Zealand shows, however, that those in charge of describing archives are not necessarily trained archivists and that there is a lack of theoretical knowledge (Delaney, 2009, pp. 46, 49).

\subsubsection{Preservation}

The uniqueness of archives means that a high value must be placed on preservation (Sanderson, 2007). Preservation can be simply defined as the "ongoing care of archives so that they survive into the future" or "everything that contributes to the physical well-being of the collections" (Hadlow, 2008, pp. 87, 88). Dearstyne has noted, however, that with local archives collections, lack of appropriate storage conditions and preservation activities "may accelerate the demise of the very records dedicated people have worked so hard to save" (Dearstyne, 2000, p. xiii).

The two aspects of preservation - facilities (including premises design and construction, environmental conditions and security) and operational activities (including handling, packaging, basic conservation, security, disaster recovery) - are mentioned separately by Dearstyne (2000), but both under basic elements required for an historical records programme. In New Zealand, the booklet, Managing and preserving community archives (National Library of New Zealand, 2005), devotes one of its three main sections to this aspect. The New York State Archives' (1988) guide includes two items covering this area on its checklist for evaluating community historical records programmes, asking whether they have a secure facility and other necessary resources, and whether provision is made for preservation.

The issue of digital records preservation is particularly challenging, something which Dearstyne makes explicit by heading up a checklist relating to preservation of electronic archives with a question about whether those running 
the Archives "understand the similarities, and the differences, between traditional records and electronic records" (Dearstyne, 2000, p. 155).

\subsubsection{Archival practices}

Management of archives is governed by well-developed theory and standards designed to preserve the integrity and evidential value of the archives and to make them accessible. These relate particularly to the selection, or appraisal, of records and to their arrangement and description. Dearstyne describes arrangement and description, however, as "one of the most misunderstood archival functions and probably the one that is most often botched" by historical records programmes (Dearstyne, 2000, p. 84).

The New Zealand guide, Managing and preserving community archives (National Library of New Zealand, 2005), places considerable emphasis on the importance of the core archival tasks of acquisition, accessioning, appraisal, arrangement and description and finding aids. The requirement to follow basic archival standards for the processes and documentation around activities is also emphasised by Sanderson (2007). Dearstyne covers archival tools and practices under two of his essential operational elements: "a systematic approach to appraisal and selection of records" and "appropriate finding aids and provisions for access" (Dearstyne, 2000, pp. 177-178). The New York State Archives' (1988) guidance to Community Archives on evaluating programmes contains three points relating to this area. Community archives are advised to check whether they have written acquisition policies, accessible finding aids and "archival programs" (New York State Archives, 1988). If not, it is suggested that they should systematically transfer their archives to other repositories for preservation. The Society of American Archivists' (1994) guidelines also emphasise the importance of appraisal, documenting the acquisitions process and provenance, arranging in accordance with the principles of provenance and original order, and having a system of finding aids that reflect current professional standards.

At the highest level, collection policy may have a significant impact on sustainability. Eleanor Adams, writing about museums, refers to the fact that 
many seem to be inherently unsustainable organisations, partly because of unconstrained collecting (Adams, 2010, p. 11). Similarly, with archives, one of the major problems with archival collecting policies is that they are often too broad and cover "anything and everything to do with their subject" (Henry, as cited in Abraham, 1991, p. 45).

\subsubsection{Community engagement}

A good understanding of users, generating public support and connection with the local community are essential to survival. Those who fund an Archives need to see that it has value to the community to justify ongoing investment (Sanderson, 2007, p. 178). The Wairarapa Archive in New Zealand, for instance, has an overarching goal of having its archives used by the community, thus ensuring its support. Strong political support would appear to be largely a consequence of this strategy. (Winter, 2000). Dearstyne (2000) also covers community engagement in his list of basic elements required for a successful programme, when he talks about the need for a continuing campaign for public awareness. The New York State Archives' (1988) guidance to Community Archives asks them to consider whether community groups take an active interest in, and provide support for, programmes, and whether they actively promote use.

Community engagement may include involvement in determining what is to be collected by the Archives (see 2.5.4 for a discussion of appraisal). Andrew Flinn (2008) asserts that ensuring that the Archives more fully represent society requires openness and transparency about the reasons for selection of the archives which are collected. Two writers, in the context of multicultural archives, have suggested an even more radical approach with their model of "participatory archiving" (Shilton \& Srinivasan, 2007, p. 98). This involves the community in appraisal so that archivists take community understandings of the records into account when assessing records, resulting in stories of value to the community itself being collected. Their aim of working with the community on arrangement and description is to ensure that the community's understanding of provenance and record creation, and its practices, preferences and beliefs, are incorporated into arrangement and description (Shilton \& Srinivasan, 2007). 
Where a community is still 'alive', engagement becomes even more essential and may require archivists to turn traditional concepts of archives management upside down. An interesting example from London Metropolitan Archives involves a community's collection being only on loan to the Archives and the establishment of an advisory group to assist in planning events around the collection (Hopkins, 2008).

\subsubsection{Collaboration}

Most Community Archives value their independence highly. Researchers have found that custody and ownership of collections is a key concern for Community Archives and, while some may be interested in exploring partnerships with mainstream heritage organisations, they wish to participate and work very much on their own terms (Flinn, et al., 2009, pp. 80-81).

While Dearstyne does not list collaboration as one of his essential pre-requisites or basic programme elements for local history Archives, its value in improving the administration of historical records is mentioned several times, it is included in his checklist for self-assessement and an appendix is devoted to co-operative approaches. He recommends that organisations do not automatically assume they must begin collecting themselves; if they are unable to meet the prerequisites for a collecting programme, they should consider co-operation (for instance, sharing collecting responsibilities, storage and/or staff and expertise) or co-ordination (facilitating collecting of their community's archives by another institution) as an alternative (Dearstyne, 2000).

A number of other writers refer to the value of collaboration in sustaining Community Archives. The positive impact collaboration has had on three Community Archives in Canada is described by Laura Millar (1999), with examples of an institution holding records until they can be looked after by the community while the community group provides funding for arrangement and description, preservation of data archives, and cost-shared facilities. The National Council on Archives (2000) in the United Kingdom has identified working collaboratively as a key strategy to strengthen Archives and believes 
that joint projects by repositories could have major benefits. Its 2007 research found that heritage organisations and Community Archives gained mutual benefits from working together. It also found that, although Community Archives did not wish to be dependent, formal agencies could help ensure their future; some local authorities helped to support and link together community archives groups while others provided repositories and access services for their collections (National Council on Archives, 2007b). Furthermore, this research resulted in production of a guide for Community Archives, urging them to identify potential benefits and look for local links and partnerships (National Council on Archives, 2007a).

Collaboration in collecting is an area which has been frequently advocated as a way of fulfilling archival responsibilities to preserve documentary heritage (Abraham, 1995; Cox, 1996a; Cunningham, 1998). Documentation strategies recognise that one Archives cannot collect everything and that a multiinstitutional, collaborative approach is required (Bettington, et al., 2008, p. 166). While implementing a documentation strategy has proven to be unrealistic for most Archives, the underlying concept of representing a sector, society or community is important and elements of the strategy process are feasible. Dearstyne sees co-operative collecting as an alternative to a documentation plan (Dearstyne, 2000, pp. 69-71).

The issue of managing digital archives is one where collaboration may be particularly required in future because of the costs and technical challenges of managing sustainable digital archives (Lavoie, et al., 2008). In describing a digitisation project involving local heritage organisations, Yeates and Guy (2006) noted that a collaborative institutional infrastructure was one of the three factors which seem essential for creating sustainable digital information and finding aid services.

\subsubsection{Dynamic approach}

A dynamic approach means a commitment to growing and changing with the times. This is the term used by Dearstyne for one of his "essential prerequisites 
for responsible historical records collecting" (Dearstyne, 2000, p. 23). Planning for the future is a key part of this, and is one of the recommendations made to Community Archives in the United Kingdom by The National Council on Archives. In its Helpsheet: Engaging with wider agendas, it highlights the importance of having clear objectives and plans for achieving them (National Council on Archives, 2007a). The Society of American Archivists (1994) also emphasises this in its Guidelines for evaluation of archival institutions, where it states that planning is the "best means for the profession to fulfill the archival mission".

One of the biggest changes of recent times is the move into the digital age. The digital world now "permeates the archival profession" because of its dual commitment to preserving electronic or digital archives and to using digital applications for access and outreach (Jimerson, 2009, p. 319). Evolving to meet this changing world requires development of practices and models to deal with digital archives and to meet users' expectations that information will be available electronically. In Australia, Cunningham talked about the need for collecting Archives to "embark upon a process of reinvention" to ensure that they were able to preserve and provide access to the country's documentary heritage, particularly in light of increasingly fragile or unreliable recordkeeping systems and practices (Cunningham, 1998, p. 33).

This call is just as relevant to New Zealand and to the subset of the collecting archives sector represented by Community Archives.

\subsection{Community archives and archival theory}

Many Community Archives value the records they collect largely for their informational or artefactual value. In Richard Cox's words, there is a tendency for collecting Archives to "collect them, hoard them, touch them and otherwise regard them like museum artifacts" (Cox, 1996b, p. 52). Whether they are personal papers, records of clubs and societies or local schools, however, the archives collected by community organisations are all records. What happens to 
them should therefore be considered within the framework of records and archives theory.

\subsubsection{Life cycle theory}

Community archives are collected records, therefore the custodians are not the creators of the records they hold, and there has also often been a significant break - sometimes of chasm-like proportions - in maintenance of the material as records. Collecting Archives generally have no influence over the creation and maintenance of the records they acquire and frequently do not pro-actively identify records as being worthy of permanent retention before they are transferred to their custody. In many cases, records are 'rescued', 'discovered' or 'dumped', long after the entity which created them has ceased to exist.

The life cycle model in archival theory assumes that records have come to the end of their life as records when they become archives. Schellenberg described records management as being concerned with "the whole life span of most records", whereas archives were consigned to the "heaven" of an archival institution, if they were worthy of a life after death (Schellenberg, 1956, p. 37).

Given the description above of the acquisition process for community archives, the life cycle model is one which would appear to apply well in the collecting Archives context, where records are "static and self-contained in terms of content, structure and context” (Bettington, et al., 2008, p. 152).

\subsubsection{Continuum theory}

While it is acknowledged that the life cycle theory may, on the surface, still appear to be valid for collecting Archives, in the last 15 years a new theory has been gaining credibility in the recordkeeping world and its relevance to community archives must be considered.

The continuum theory arose out of a need to conceptualise and manage the modern (and, particularly, the electronic) recordkeeping era. There was initially considerable debate about its relevance to collecting Archives, to the extent that 
a whole issue of the Australian Society of Archivists journal was devoted to the question (Archives and Manuscripts, 1996, Vol 24, No. 1). Continuum theorists found it difficult to see how archivists in collecting Archives could play a role in post-custodial recordkeeping strategies, assuming that they had to be involved at the records-creation stage. In response to the arguments of archival thinkers such as Terry Cook (2000), however, the theory has come to accommodate the place of collecting Archives in the recordkeeping continuum.

The records collected by a Community Archives are conceptually placed in the fourth dimension of the continuum, where they are part of an overall system which enables them to function as "accessible collective memory". As records:

Their evidential qualities are seen as integral to...their role in the formation of individual, group, corporate and collective memory and the shaping of identity, and their value as authoritative sources of information. (McKemmish, 2001, pp. 352-353)

In the continuum theory, while a record's content and structure can be seen as fixed, it is "always in a process of becoming" (McKemmish, 2001, p. 359). Records continue to acquire meaning, even in the purely archival fourth dimension, as they gather information relating to context and use over time (Cook, 2000). Archivists are, therefore, active participants in recordkeeping and archive-creating processes. In McKemmish's words: "They become Terry Cook's "active shapers" of the archival heritage, "intervening agents" who need to be conscious of their own historicity in "the archive-creating and memoryformation process" (McKemmish, 2001, p. 349). The continuum concept of recordkeeping responsibility emphasises that all recordkeeping professionals, including archivists, share a common goal of delivering frameworks to enable access to useable evidence of activity (McKemmish, 2001, p. 338).

The implications of the continuum theory are that, while the archives might appear to be 'dead' or 'static', they are not; their life as records continues. Not only is their life up until the point they are received relevant to a community archivist, but community archivists should understand that they change and add to the value of the record by contributing their research knowledge (Cook, 2000, p. 11), as well as through activities such as appraisal, processing, description, 
and creating metadata for access. These key aspects of the nature of the archival record can be ignored in the community archivist's focus on the informational or artefactual nature of the archives.

\subsubsection{Evidentiality}

As Glenda Acland has explained:

The pivot of archival science is evidence, not information. Archivists do not deal with isolated and free-floating bits of information, but with their documentary expression....A change in the traditionally perceived archival mindset is needed here to manage the records and their continuum, not the relics at the end stage in the record life cycle. (Acland, 1992, pp. 58-59)

An understanding of the quality of 'recordness' and the significance of context is essential in helping users understand the archives. In relation to personal correspondence, for instance, McKemmish has called for greater understanding of the way letters function as both documents (information) and records (evidence of relationships and activities) and how "their informational value is dependent on their evidential value" (McKemmish, 1996, p. 36).

The continuum model emphasises that records cannot be categorised as representing either evidence or memory, but that they represent both. "It is their evidential nature that distinguishes them from other forms of recorded information, and enables them to play their particular role in forming memory and shaping identity" (McKemmish, 2001, p. 352).

Both the life cycle and the continuum theory assert that what constitutes evidence is not only the record, but also its context. Both theories, therefore, require the community archivist to treat the archives they hold as records with on-going evidential value after they are transferred to their custody - not simply as information or artefacts. The continuum theory adds to the life cycle theory's concept of evidence, however, the growing layers of metadata which gather around the archives. Community Archives need to ensure that contextual, structural and other information about records, including informatinon created as they manage them, is retained along with the records. 


\subsubsection{Appraisal}

Appraisal, or the selection of records of ongoing value, is one of the core skills of the archivist. Traditionally, under the records life cycle model, appraisal started once the active administrative use of the records was completed and this is particularly the case with collected archives. The approaches to appraisal which result from this model focus on the physical records first and then ask questions about the content and context - and hence the value - of those records, following the archival theories developed by writers like Schellenberg (Bettington, et al., 2008, p. 157).

A relatively new theory about appraisal, which may be particularly relevant to community archives, is the concept of macroappraisal. This takes a more holistic approach than traditional appraisal at the record level and considers, rather, the purpose, function and mandates of the record creator (Bettington, et al., 2008). Terry Cook explains that macroappraisal is "a provenance-based approach to appraisal, where the social context of the record's creation and contemporary use...establishes its relative value" (Cook, 2005, p. 128). Richard Cox (1996b) describes it as a move from acquiring interesting documentary materials based on examining records as they turn up, to focusing on what should be documented and the evidence of that contained within the archives.

A related concept is that of the documentation strategy. This aims to ensure that a core set of documentation relating to an area of interest is captured and retained. The Society of American Archivists defines it as "a methodology that guides selection and assures retention of adequate information about a specific geographic area, a topic, a process, or an event that has been dispersed throughout society" (Pearce-Moses, 2005). Documentation strategies recognise that one Archive cannot collect all the records relating to a topic, theme, industry or area and that a multi-institutional, collaborative approach is required (Bettington, et al., 2008, p. 166). Cook has specifically linked the value of macroappraisal and documentation strategies in his praise for the Minnesota Method, which he describes as combining "the best elements of collection policy and documentation strategy with macroappraisal...emphasizing the 
latter's priority-setting and functional analysis" (Cook, 2005, p. 143). While it is accepted that most Archives, and least of all Community Archives, do not have the resources to carry out the activities required for a full documentary strategy (Abraham, 1995), the concepts underlying the approach could be applied to foster collaboration with other institutions in building meaningful and useful community archives. Those key concepts include understanding the community which an Archives serves, analysing institutional holdings, preparing collection development plans and appraisal policies, and co-operating with other repositories.

As Terry Cook reminds archivists, through selection of records "we are doing nothing less than shaping the future of our jurisdiction's documentary heritage" (Cook, 2005, p. 103). Because the aim of a Community Archives should be to reflect the memory of the community in the archives in as balanced a manner as possible, selecting archives on the basis of an understanding of the recordcreating community and targeting specific records creators is valuable (see also discussion of "participatory appraisal" in 2.4.6).

\subsubsection{Theoretical conclusions}

While seeing the archives from these theoretical perspectives may be challenging in the community archives environment, one reason more effort may not be devoted to it is that community archives are not generally seen within this paradigm; rather they are seen from the perspective of the life cycle model, in which archives are essentially 'dead' records. Another may be that very few Community Archives have qualified staff likely to be conversant with archival theory.

Understanding and incorporating new theoretical concepts, along with those which have stood the test of time, into management of community archives would contribute to maintenance of the 'record' value of the archives. Ultimately, this will preserve and enhance their societal value and their ability to function as memory and heritage for their communities. 


\subsection{Conclusion}

The literature indicates that there is no dispute over the value and importance of Community Archives. Repeated reference to certain factors also reveals a large degree of consensus as to the key requirements for their maintenance and sustainability. These include tangible factors, such as funding and sound archival practices applied to management of the records, as well as more intangible factors. When the United Kingdom National Council on Archives (2007b) undertook research into the nature of Community Archives, it concluded that, while the "lifeblood" of Community Archives was enthusiasm, they also need volunteers, users and funding.

The next chapter describes the research design and methodology applied to this study. It also explains in detail the development of the methodological framework used for analysis of the findings. 


\section{Chapter 3}

\section{Methodology}

\subsection{Introduction}

Understanding (and sharing) the reality of Community Archives in New Zealand is one of the most important goals of this research, as no in-depth study has previously been undertaken into the issues related to their maintenance. The research therefore takes a qualitative approach. In addition, what the literature highlights is that Community Archive organisations, of whatever size, are complex systems of organisational structure, people and external influences as well as the collected records and the meanings they carry and gather. They are social constructs and, as Gilliland and McKemmish (2004) suggest, as a consequence it is impossible to state that there is one, objective reality. A study of the components (or factors) which make up the community archives phenomenon is therefore best approached by applying an interpretivist paradigm, which is based on the social world being constantly interpreted or constructed by people (Gilliland \& McKemmish, 2004, p. 166).

The researcher's role was that of an outside observer but informed by a background of working in the archives and records management field, including establishing and managing a 'community archives' programme under the umbrella of a local authority Archives and providing consulting services to Community Archives. Such a background had two key advantages: it enabled a certain empathy with the subjects of the study and sufficient familiarity with the field to ensure reliable identification of areas for exploration, particularly in the interview process. 
While it could be considered that the researcher might be influenced by preconceived ideas of requirements for sustainability of community archives, any such influence was minimised by:

a) developing the sustainability factors used in the methodological framework from a thorough literature review, and

b) using triangulation of the cases studies and data sources within case studies to build a coherent justification for the factors during analysis (Cresswell, 2003).

As with all interpretivist research, however, an element of subjectivity in data collection and analysis cannot be avoided.

\subsection{Research design}

\subsubsection{Research question}

The primary question posed by this research is: how sustainable are Community Archives in New Zealand?

In exploring this question, three subsidiary questions are asked:

- What factors need to be present in order to maintain community archives over the long term?

- How well do four Community Archives in New Zealand exhibit these factors?

- What changes might be required to enhance the sustainability of Community Archives in New Zealand?

\subsubsection{Research strategy}

Case studies were selected as the research strategy because these are particularly valuable in situations where "knowledge is shallow, fragmentary, incomplete or non-existent"; in-depth understanding of individual cases contributes to an understanding of the important aspects of a new research area (Punch, 2005, pp. 147-148). Furthermore, the environment surrounding community archives is an important part of their experience and case studies are appropriate for studying situations where behaviours cannot be manipulated and context is particularly 
relevant (Yin, 2003). Case studies also allow retention of the "holistic and meaningful characteristics" (Yin, 2003, p. 2), something which is valuable in a field where there is little existing research in New Zealand.

In their examination of archival research, Gilliland and McKemmish (2004) describe the value of comparative case studies as being that they allow the complex detail of particular cases to be understood, comparison of one situation to others and, sometimes, transfer of understandings gained in one instance to another. Carrying out case studies of a number of Community Archives provides a picture of the manner in which a variety of these Archives in New Zealand experience and exhibit the factors generally considered essential for maintenance and sustainability.

Interviews were chosen as the primary data source because these provide the participants' interpretations of situations and events. What is presented in this thesis is, therefore, essentially the researcher's interpretation of their interpretations (Walsham, 1995, p. 78). The triangulation made possible by use of a variety of data sources (interviews with funder, archivist, community representative, observations, documents and online resources) within each case study, however, ensures as accurate, meaningful and complete a picture as possible is obtained. It also minimises the impact of gaps in any one form of data, provides consistency checks and adds to the credibility of the final conclusions (Patton, 2002, p. 556).

Although a case study strategy does not allow generalisation of results to the entire community archives sector, it does allow what Stake calls "naturalistic generalization" to take place, where the reader is enabled to arrive at their own conclusions through a well-constructed, vicarious experience (Stake, 1995, p. 85). Such generalizations are "tendencies rather than predictions" but provide explanations from empirical interpretive research which may be useful in looking at other organisations and contexts in future (Walsham, 1995, pp. 79$80)$. 


\subsubsection{Propositions}

A number of propositions informed the research design and shaped data collection and analysis.

The first proposition is that Community Archives are both a system in themselves and part of a wider recordkeeping and societal system (as shown by the records continuum model). In this system, the institutions, the evidentiality, the records containers and the purpose (see section 1.6.1 for detailed explanation) are all components which need to be maintained across time.

The second proposition is that there are certain factors, commonly accepted in archival literature and theory, which are required to maintain community archives. These factors, which are dealt with in more detail in Section 4 of this chapter, can be grouped under the following categories:

1. Appropriate governance

2. Adequate and secure funding

3. Skilled staff

4. Preservation of the archives

5. Application of accepted archival practices and tools

6. Community engagement

7. Collaboration

8. Dynamic approach

Evidence of how sustainable a Community Archives is likely to be would, therefore, be found in the degree to which factors considered essential to its maintenance are present.

The research methodology relates data collected through case studies to each of the propositions (Yin, 2003, p. 26).

\subsubsection{Criteria for interpreting the findings}

As a Community Archives is a system, rather than a discrete entity, sustainability depends on a number of factors being maintained over time. 
Therefore, the number of these maintained, or the degree to which they are maintained, in the case studies provides an indication of likely sustainability. The criteria for interpreting the findings were:

- Can a characteristic displayed by the Archives be aligned with one of the factors identified as essential for maintenance in Proposition 2? If not, is it a characteristic which nevertheless has an impact on sustainability?

- What do the characteristics of each factor suggest about the contribution this factor is likely to make towards sustainability?

- How do these factors align with the records continuum model, and what does this tell us about the importance or impact of any factor?

- What patterns emerge from the findings to provide insight into the issues associated with maintenance and sustainability of Community Archives?

\subsubsection{Unit of analysis}

The unit of analysis used for this study is the organisational entity which holds and manages the community archives. These are existing Archives which meet the definition of Community Archives used by the study and which have been in existence for a reasonable length of time.

\subsubsection{Case selection}

Four cases were selected. Restriction of the study to four cases limits generalisability of results, but "purposeful" selection ensures that a range of organisational circumstances are analysed, allowing common themes and issues to be identified. Organisations were selected on the basis that they would contribute to an understanding of the problem and the research questions. The goal was not to select typical organisations but, rather, to select ones which were information-rich and offer insights into factors required for sustainability of Community Archives (Patton, 2002, p. 40).

Using a multiple-case replication design approach, two groups were identified within the four case studies, on the basis that either (a) similar results were predicted (literal replication) or (b) different results were expected but for predictable reasons (theoretical replication). Yin (2003) considers that two 
individual cases within a subgroup are sufficient to allow for literal replication within the subgroup and theoretical replication across the two groups. On that basis, two voluntary Community Archives with no paid staff (and no connection to a larger organisation) were selected and two Archives with one or more paid staff (and part of, or associated with, larger organisations) were selected. Across the four cases there is also a mix of institutional type with which the community archives are associated, namely museum, city council/library and historical society. Within the subgroup of Archives employing staff and part of, or associated with, larger organisations, there is also a difference in the organisational structure and therefore the degree of control and authority exercised by the principal funder/governance body. It was hypothesised that the influence of these different structures might provide useful insights.

Potential participating organisations were initially identified using the Directory of archives in New Zealand (Archives New Zealand, 2009b), with crossreference to The Community Archive online database more recently established by Archives New Zealand (Archives New Zealand, 2009a). The definition of community archives developed for this study was applied to eliminate many organisations listed in these sources, as not all organisations which call themselves 'Community Archives', or are considered by Archives New Zealand to be 'Community Archives', meet the definition used in this thesis. Particularly useful data contained in the Directory of archives in New Zealand included the brief descriptions of the Archives and the organisations' statements on "archives held", "collecting interests" and "significant collections", while the quantity of original records given provided an indication of the size of collections. From The Community Archive, the "number of collections" and their descriptions were most useful. (An Archives which stated that it held only one collection closed many years ago, for instance, would be rejected on the basis that it was unlikely to provide useful insights into the issues faced by Community Archives.)

This initial selection was further refined based on the researcher's own working knowledge and on information provided by New Zealand archivists. This fleshed out understanding of the scope, depth and type of archives collected and the way the Archives operate, to ensure that only those which have in the past, 
or do currently, fit the definition of Community Archives used in this research were selected. Descriptions of the history and operations of local Archives which have appeared in New Zealand archival literature and the organisations' websites were also used to build up a sufficient picture on which to base selection.

The 56 organisations initially selected were then categorised into two types: voluntary, or part of a larger organisation (generally local authority or councilcontrolled) and with paid staff. These were ranked from 1-3 in terms of usefulness (based on the quality of available information) and those ranked 3 were 'short-listed'. In the final selection, consideration was also given to selection of Archives from both the North and South Islands, accessibility and willingness of the individuals to participate in the research.

\subsubsection{Individual participant selection}

Within each case, individuals were selected to represent different perspectives on the Community Archives. The archivist, a representative of the funder and a community stakeholder were selected as they play key, but different, roles in the maintenance of Community Archives and therefore have different knowledge, views and experiences.

For each of the four cases the archivist, or individual operationally in charge of the Archives, was identified first.

In the two cases where the Archives was part of, or associated with, a larger organisation, a representative of the governance body was selected because, although external to the actual Archives, the governance function can have a profound effect upon the Archives. This individual was identified by the archivist, but it was specified that they should be the person with most direct responsibility for decision-making on funding and governance issues relating to the Archives.

To understand the community context, it was important to speak to people with an interest in the Archives but not involved in its running. The researcher was 
largely reliant on the archivist's recommendations in identifying the community stakeholder in each case although discussions took place to ensure that as much as possible they represented an 'outside' view. Requirements given to archivists were that the individual must have some engagement with the Archives (representing a group or as an individual); they should not be a researcher only; and, although they may be a member of the society in the case of historical societies, they should also represent other community interests. It is acknowledged that this method of selecting the community stakeholder participant is not perfect. Those selected were well known to the archivist and there was therefore potentially a risk that they would more favourably disposed (or less critical) than the general community. It did mean, however, that they knew a reasonable amount about the Archives. (As an alternative, it would have been possible to select a community representative almost at random (say, a local Rotary Club member or a local public library user), but the risk was that they would know nothing about the Archives and would be able to contribute little to the study.

All individual participants in the case study had to agree to be involved before the study could proceed. If one participant had not been willing, the organisation would have been rejected as a case.

In a small population of Community Archives such as in New Zealand, it was decided that the anonymity of case study organisations should be preserved. Organisations and individual participants are therefore not named, although the type, setting and operations of the Archives are described in such a way as to ensure the context is clear to readers. Presenting the context, describing what the Archives are like and the roles of key participants is essential to interpretation and understanding of the cases and, hence, to their value as case studies.

\subsubsection{Ethical considerations}

Human Ethics Committee approval for the research was received before commencing fieldwork. Individuals invited to participate were sent an information sheet outlining the project, their involvement and the process. It 
was also explained that information would be treated anonymously and confidentially and that they would receive a copy of the case study related to their Archives, along with a summary of the findings, at the conclusion of the research. Signed consent forms agreeing to take part in the research were received from all before site visits and interviews were conducted.

\subsection{Data collection}

\subsubsection{Preparation}

The primary data-gathering tool was the interview. Individual participants in each organisation were invited to take part in the study, with contact made by email, telephone or mail, depending on the most effective mode for each. They were also provided with the information outlined above in 3.2.8.

An interview guide was prepared, with the same framework of questions for each individual participant within a case study (see Appendices A, B and C). Interviews were semi-structured, with questions grouped around the factors identified from the literature review as being key requirements or influences on the ability of community archives to be maintained over time (see Table 1). A number of prompts were included relating to each factor so that different perspectives on the same issue could be explored. The interview guide was pretested with a nearby Community Archives to ensure that the line of questioning was likely to reveal information which would be useful to the study. Results from this interview were used only to refine questions for the case study interviews. One learning from this pre-test was that valuable information can emerge over coffee after the interview - and that the researcher should have pad and pen discretely placed alongside the coffee cup!

Participants were asked in advance to provide copies of documents such as policies, procedures, standards, governance and funding documents, and outreach materials. The aim was to collect as many key documents as possible before the site visit to enable some advance preparation to be carried out and possibly allow testing during the visit to determine to what extent any policies or 
stated actions are actually carried out. No documentation was provided before visits, however.

It was initially intended to interview the archivist first, in order to understand the core operations before proceeding to other contextual interviews. This proved to be not always possible because of the commitments of interviewees but it is not considered that it had any impact on the data collected.

\subsubsection{Interviews and site visits}

Visits were made to the site of each Community Archives to conduct interviews, to observe aspects of operations, such as facilities, user interface and outreach, and to collect additional information if possible.

Face-to-face interviews were conducted with two or three individuals at each Archives, depending on the size and structure of the organisation. Up to two hours was allowed for each interview and, in practice, they ranged from 33 to 90 minutes. Questions were open-ended so that interviewees were encouraged to share their experiences and views on issues or challenges, as well as knowledge of the organisation's history and information about current operations. The interviewer aimed to tease out causes and impacts as well as motivations, attitudes, beliefs and interpretations behind the surface realities or facts. Interviews were recorded for later transcription.

A guided tour of the Archives' facilities was requested for each organisation and information gathered and recorded in note form as the visits proceeded. The researcher acted as a complete observer during site visits in order to gain a firsthand impression of the facilities, how the Archives are set up, the way archives are cared for and used, and how services are provided. Photographs of facilities, storage methods and archives were taken during visits to supplement other methods of data collection but also to provide graphic illustrations of the characteristics of Community Archives for readers of the thesis, to aid their understanding of the findings. 
Documents collected included policies, procedures, standards, governance and funding documents, and outreach materials. These were later supplemented by review of the internet sites of the organisations, and documents found on other sites such as news and government regulatory bodies.

\subsection{Methodological framework}

A methodological framework for the study, consisting of a set of factors considered essential for the maintenance of community archives, was developed from the literature review. From this, a sustainability model was created outlining the characteristics of an Archives likely to be sustainable and its opposite, an Archives unlikely to be sustainable.

There is considerable professional literature on the requirements for managing archives but archivists and archival organisations in the United States have outlined essential elements which must be in place specifically for maintaining community, or local history, archives. Key sources used were a pamphlet produced by New York State Archives (1988) entitled Ensuring a usable past for your community, which provides a checklist of ten factors to be evaluated to determine how well records are being collected, preserved and made available, and Dearstyne's (2000) Managing historical records programs: a guide for historical agencies, which outlines pre-requisites for successful local history archives programmes and basic programme elements. The framework for this study has therefore been adapted from guidelines and assessment criteria for Community Archives developed by the American archival profession.

\subsubsection{Factors required for maintenance of community archives}

From Dearstyne and New York State Archives a set of factors required for the maintenance of community archives was developed. In some cases, two elements from the source publication have been combined into one, where it was considered that conceptually they were similar or interrelated enough. Table 1 sets out these factors, and their sources. 
Note: Dearstyne has two lists, one he describes as "The essential prerequisites to effective historical records collecting and maintenance work" (Dearstyne, 2000, p. 23) and another he describes as further elaboration of this and calls "Basic elements of historical records programs" (Dearstyne, 2000, p. 175). In Table 1, unique elements from both have been included. Items followed by a simple number are taken from the "basic elements" list and items followed by a number and 'a' from the "essential prerequisites" list.

Table 1: Factors or elements required for maintenance of community archives

\begin{tabular}{|c|c|c|}
\hline & New York State Archives, 1988 & Dearstyne, 2000 \\
\hline Governance & & $\begin{array}{l}\text { Operating authority and mission } \\
\text { statement [1] }\end{array}$ \\
\hline Funding & & $\begin{array}{l}\text { Adequate, continuing financial support } \\
\text { [2] }\end{array}$ \\
\hline Skilled staff & $\begin{array}{l}\text { Do staff have training, experience and } \\
\text { expertise needed? [6] }\end{array}$ & Sufficient, qualified staff [4] \\
\hline Preservation & $\begin{array}{l}\text { Secure facilities \& other resources } \\
\text { needed to care for records? [7] } \\
\text { Adequate provision for preservation to } \\
\text { ensure survival? [9] }\end{array}$ & $\begin{array}{l}\text { Secure storage and other facilities [3] } \\
\text { Preservation of records and/or their } \\
\text { information [8] }\end{array}$ \\
\hline $\begin{array}{l}\text { Archival } \\
\text { practices }\end{array}$ & $\begin{array}{l}\text { Written acquisition policies? [3] } \\
\text { Archival programs for preservation of } \\
\text { records? [4] } \\
\text { Produce \& make known finding aids? [8] }\end{array}$ & $\begin{array}{l}\text { A systematic approach to appraisal and } \\
\text { selection of records [6] } \\
\text { Appropriate finding aids and provisions } \\
\text { for access [7] }\end{array}$ \\
\hline $\begin{array}{l}\text { Community } \\
\text { engagement }\end{array}$ & $\begin{array}{l}\text { Does the community take active interest } \\
\text { in, \& provide support for, programs? [2] } \\
\text { Actively promote use? [10] }\end{array}$ & $\begin{array}{l}\text { Promoting use [9] } \\
\text { Continuing campaign for public } \\
\text { awareness [10] }\end{array}$ \\
\hline Collaboration & $\begin{array}{l}\text { Co-ordination and co-operation among } \\
\text { programs? [5] }\end{array}$ & \\
\hline $\begin{array}{l}\text { Dynamic } \\
\text { approach }\end{array}$ & $\begin{array}{l}\text { Is significant documentation identified } \\
\text { and collected? [1] }\end{array}$ & $\begin{array}{l}\text { Planning and balanced program } \\
\text { administration [5] } \\
\text { A dynamic approach }[7 a]\end{array}$ \\
\hline
\end{tabular}

(Numbers in square brackets are the 'checklist' numbers used by the authors.) 


\subsubsection{Maintenance requirements}

Using detail from the sources represented in Table 1, summarised characteristics required for maintenance of Community Archives were developed for each factor. A single, specifically New Zealand addition was made to this list - the Archives New Zealand Storage Standard - because it is relevant to Community Archives as well as government organisations and is referred to by many Community Archives. This summary is shown in Table 2.

While the requirements for maintenance are clearly explained, it is also acknowledged that some terms used (such as "adequate") are not exact and are therefore open to a level of interpretation. 
Table 2: Key requirements for maintenance of community archives

\begin{tabular}{|c|c|}
\hline Factor & Requirements \\
\hline Governance & $\begin{array}{l}\text { - } \quad \text { Defined legal status, authority and purpose } \\
\text { - } \quad \text { Clear mission, goals and objectives } \\
\text { - Clear and ongoing commitment to maintenance of the Archives } \\
\text { (Dearstyne, 2000, p. 22) }\end{array}$ \\
\hline Funding & 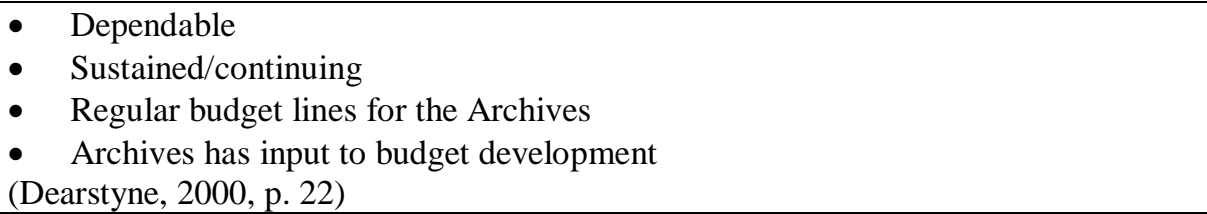 \\
\hline Skilled staff & $\begin{array}{l}\text { - } \quad \text { Sufficient numbers (at varying levels) to carry out the work } \\
\text { - Sufficient, and at least one, qualified through education or experience to carry out } \\
\text { professional tasks } \\
\text { (Dearstyne, 2000, p. 22) }\end{array}$ \\
\hline Preservation & $\begin{array}{l}\text { - } \quad \text { Conditions meet Archives NZ Storage Standard minimum requirements } \\
\text { (Archives New Zealand, 2007) } \\
\text { - } \quad \text { Appropriate storage facilities, including security, fire protection, climate control, } \\
\text { - } \quad \text { Apace } \\
\text { - } \quad \text { Appropriate research and work facilities, including space } \\
\text { - } \quad \text { Basic conservation needs met } \\
\text { - } \quad \text { Preservation requirements guide handling and use } \\
\text { (Dearstyne, } 2000, \text { pp. } 23,176,178 \text { ) }\end{array}$ \\
\hline $\begin{array}{l}\text { Archival } \\
\text { practices }\end{array}$ & $\begin{array}{l}\text { - Archives selection guided by a clear documentation objective, collection policy } \\
\text { and appraisal methodology } \\
\text { - } \quad \text { Archives arranged and described in accordance with professional standards } \\
\text { - System of finding aids to enable retrieval } \\
\text { - Open for research regularly and research services promoted and provided } \\
\text { (Dearstyne, 2000, pp. } 63-78,177-178 \text { ) }\end{array}$ \\
\hline $\begin{array}{l}\text { Community } \\
\text { engagement }\end{array}$ & $\begin{array}{l}\text { Offers varied outreach activities e.g. articles, talks, exhibitions, tours, research } \\
\text { services } \\
\text { (Dearstyne, 2000) } \\
\text { - Community groups take an active interest in, and provide support for, } \\
\text { programmes } \\
\text { (New York State Archives, 1988) }\end{array}$ \\
\hline Collaboration & $\begin{array}{l}\text { Co-ordination and co-operation among historical records programs to ensure } \\
\text { systematic documentation of community's history } \\
\text { (New York State Archives, 1988) } \\
\text { - Co-operates with other repositories to achieve goals, e.g. in collection, services, } \\
\text { expertise, preservation, public programmes } \\
\text { (Dearstyne, 2000, pp. 204, 211) }\end{array}$ \\
\hline Dynamism & $\begin{array}{l}\text { - Committed to growth, in terms of collections and users } \\
\text { - Commitment to changing, including incorporating new archival practices, } \\
\text { technologies } \\
\text { Planning to ensure forward movement toward defined goals, with a balanced } \\
\text { program } \\
\text { (Dearstyne, } 2000, \text { pp. } 23,29,177 \text { ) } \\
\text { - Significant documentation of the community is identified and collected } \\
\text { (New York State Archives, 1988) }\end{array}$ \\
\hline
\end{tabular}




\subsubsection{Sustainability model}

If sustainability means the ability to maintain at a proper level, over time and for future generations, then Community Archives which possess the factors considered essential to the preservation of community or local history archives should be more sustainable.

Having defined the characteristics required for maintenance of Community Archives (Table 2), the other end of the spectrum can be defined as the opposite, or a lack of, those characteristics. No attempt was made to describe the spectrum of characteristics in between.

Community Archives are systems and, at a high level, the three key aspects which need to be sustained can be divided into:

- the organisation (Can the infrastructure (people, buildings, etc) which has responsibility for the archives be sustained?)

- the archives (Can the archival records, and their evidential value, be maintained at the proper level or standard over the long term?)

- the community connection (Can the organisation maintain its relevance and engagement with the community over time?)

To reflect this, the factors were then grouped according to whether they related to the organisation, the archival records or the community connection.

The resulting model, showing characteristics of Community Archives more likely to be sustainable and those less likely to be so, provided the framework for assessment of the individual Archives' positions in relation to the different factors during the analysis phase of the research. This model is presented as Table 3. 
Table 3: Characteristics indicating likely sustainability of community archives

\begin{tabular}{|c|c|c|c|c|}
\hline & Factor & Absent or low = unlikely to be sustainable & 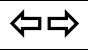 & Present = likely to be sustainable \\
\hline \multirow{5}{*}{$\begin{array}{l}\mathrm{O} \\
\mathrm{R} \\
\mathrm{G} \\
\mathrm{A} \\
\mathrm{N} \\
\mathrm{I} \\
\mathrm{S} \\
\mathrm{A} \\
\mathrm{T} \\
\mathrm{I} \\
\mathrm{O} \\
\mathrm{N}\end{array}$} & Governance & $\begin{array}{l}\text { - Unclear legal status, authority/responsibility and purpose } \\
\text { - } \quad \text { Unclear, ill-defined mission, goals, objectives } \\
\text { - } \quad \text { No long-term commitment from governing body }\end{array}$ & & $\begin{array}{l}\text { - } \quad \text { Defined legal status, authority and purpose } \\
\text { - } \quad \text { Clear mission, goals and objectives } \\
\text { - } \quad \text { Clear and ongoing commitment to maintenance of the Archives }\end{array}$ \\
\hline & Funding & $\begin{array}{l}\text { - } \quad \text { Fluctuates unpredictably, multiple sources, large proportion ad hoc } \\
\text { - } \quad \text { Core funding at risk } \\
\text { - Archives funding not clearly 'ring-fenced' } \\
\text { - } \quad \text { Archives has no input to budget it receives }\end{array}$ & & $\begin{array}{ll}\text { - } & \text { Dependable } \\
\text { - } & \text { Sustained/continuing } \\
\text { - } & \text { Archular budget lines for the Archives } \\
\end{array}$ \\
\hline & Skilled staff & $\begin{array}{l}\text { - Insufficient staff to manage collections and meet service } \\
\text { expectations } \\
\text { - } \quad \text { No staff with education/experience to carry out professional tasks }\end{array}$ & & $\begin{array}{l}\text { - Sufficient numbers (at varying levels) to carry out the work } \\
\text { - Sufficient, and at least one, qualified through education or experience } \\
\text { to carry out professional tasks }\end{array}$ \\
\hline & Collaboration & $\begin{array}{l}\text { Does not co-operate with other Archives to achieve collection } \\
\text { goals } \\
\text { Does not co-operate with other Archives to achieve other goals }\end{array}$ & & $\begin{array}{l}\text { Co-ordinates \& co-operates with other Archives to ensure systematic } \\
\text { documentation of community's history \& achieve collection goals } \\
\text { Co-operates with other repositories to achieve other goals e.g. } \\
\text { services, expertise, preservation, public programmes }\end{array}$ \\
\hline & Dynamism & $\begin{array}{l}\text { - } \quad \text { No commitment to growing collections or users } \\
\text { - } \quad \text { No awareness of need to keep evolving } \\
\text { - } \quad \text { No clear direction or plans for the future; unbalanced programme } \\
\text { - } \quad \text { Passive, reactive collectors }\end{array}$ & & $\begin{array}{l}\text { - } \quad \text { Committed to growth, in terms of collections and users } \\
\text { - } \quad \text { Commitment to changing, incl. adopting new practices, technologies } \\
\text { - } \quad \text { Plans to ensure progress toward defined goals; balanced programme } \\
\text { - } \quad \text { Identifies and collects significant documentation of the community }\end{array}$ \\
\hline $\begin{array}{l}\text { A } \\
\text { R } \\
\text { C } \\
\text { H } \\
\text { I } \\
\text { V }\end{array}$ & Preservation & $\begin{array}{l}\text { - } \quad \text { Storage facilities will/may lead to deterioration or loss of archives } \\
\text { - } \\
\text { - } \\
\text { - }\end{array}$ & & 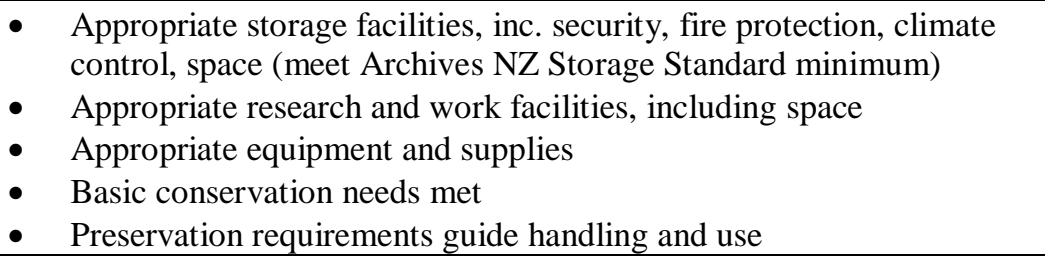 \\
\hline $\begin{array}{l}E \\
S\end{array}$ & $\begin{array}{l}\text { Archival } \\
\text { practices }\end{array}$ & $\begin{array}{ll}\text { - } & \text { No, or very simplistic, collection policy } \\
\text { - } & \text { No understanding of appraisal principles; no appraisal done } \\
\text { - } & \text { A\&D does not follow principles of provenance and original order } \\
\text { - } & \text { Description does not preserve integrity, security, ensure access } \\
\text { - } & \text { Few, or no, publicly accessible finding aids } \\
\text { - } & \text { Little access for research e.g. access by request only } \\
\end{array}$ & & $\begin{array}{l}\text { Archives selection guided by a clear documentation objective, } \\
\text { collection policy and appraisal methodology } \\
\text { - Archives arranged and described in accordance with professional } \\
\text { standards } \\
\text { - System of finding aids to enable retrieval } \\
\text { - Open for research regularly; research services promoted and provided }\end{array}$ \\
\hline $\begin{array}{l}\mathrm{C} \\
\mathrm{O} \\
\mathrm{M}\end{array}$ & $\begin{array}{l}\text { Community } \\
\text { engagement }\end{array}$ & $\begin{array}{l}\text { - } \quad \text { Passive relationship with the community, no outreach activities } \\
\text { - } \quad \text { No support from other community groups }\end{array}$ & & $\begin{array}{l}\text { - Offers varied outreach activities e.g. articles, talks, exhibitions, tours } \\
\text { - } \quad \text { Community takes active interest in, provides support for, programmes }\end{array}$ \\
\hline
\end{tabular}




\subsection{Data analysis and interpretation}

Analysis of the data involved writing a detailed description of each case study, followed by further analysis to distil the themes within individual cases, then comparison of themes across the four case studies.

\subsubsection{Preparation}

Interviews were transcribed and field notes typed up. Data were then organised according to type i.e. interviews, field notes, documentation and photographs, within each case study.

As the cases were pre-structured, pattern coding started during data collection (Miles \& Huberman, 1994, pp. 83-84). The first application of real coding, however, started during transcription, when content relating to factors considered essential for maintenance of community archives was often immediately apparent. Other potentially relevant factors also appeared, were tentatively named and highlighted. As these recurred in subsequent interview transcriptions, naming and coding was refined.

\subsubsection{Individual-case level analysis}

The decision was made to write narratives of the case studies first, before representing coded data in summarised form. Given that little has been written about Community Archives in New Zealand, it was considered particularly important to present pictures of the Archives in their settings, using the "thick description" advocated by Geertz (Patton, 2002, p. 438). This approach would engage readers and enhance understanding of the reality and context of the cases, but also allow readers to draw their own interpretations about the meaning and significance (Patton, 2002). (To further facilitate reading, cases have been given names: Case 1 is called Hilltown; Case 2, Plainstown; Case 3, Seatown and Case 4, Clifftown.)

These narratives represented the first level of analysis. The aim was to distil what interviewees talked about and group it under appropriate themes, or 
factors, using analytic induction (Patton, 2002, p. 454). Transcripts were reviewed thoroughly and pattern coding continued to reduce large amounts of data to smaller analytic units and to lay the ground work for later cross-case analysis (Miles \& Huberman, 1994, p. 69). The danger of naming and assigning codes to the data too early was avoided by returning to the research question, which stated clearly that one aim of the research was to determine if there were factors present other than those derived from the literature. Throughout the analysis, the factors were also looked at critically to ensure that there was not a need to break them down further to be useful. Evidence from the case studies was mapped to the factors identified in Proposition 2, while characteristics considered relevant but which did not map to these factors were considered for inclusion as new factors. Findings were constantly checked against the original transcripts and other data to ensure that the researcher was not captured by the themes and that only the data from the participants provided the linkages to the factors (Patton, 2002, pp. 468-476).

Once drafts of the case narratives had been completed, copies were sent to all interviewees, asking them to check for inaccuracies or to advise the author of significant information which they felt was missing. Feedback was positive, with some minor corrections made.

The characteristics supporting the factors for each case study were collated into a Microsoft Excel spreadsheet. A level of interpretation and induction was employed in this exercise to translate the evidence into brief statements encapsulating the essence of the characteristics. Any characteristic which supported more than one factor was replicated in each applicable one and the connection highlighted through coloured type. Further refinement of coding took place at this point and, particularly, adjustment of factors which appeared to be new. As analysis proceeded, it also became clear that some factors should be divided into sub-factors because different aspects could potentially have independent impacts on sustainability.

This summary data for each case was then placed alongside Table 3 showing the characteristics likely to make an Archives unsustainable (-) or sustainable (+). 
Characteristics from case studies were compared with those in this table and cases ranked for each factor as falling within one or other of these categories or somewhere in the middle but trending more to one end of the scale or the other $(\diamond \Longleftrightarrow$ ). If the majority of a factor's characteristics aligned with a category (for example with 'less likely to be sustainable') it was assigned that category (for example, given a -). Later, a '0' was added when it became necessary to assign a value to factors which appeared to have no impact either way. This assessment was necessarily interpretative, as no exact measures can be assigned.

The summarised data for each case study were then amalgamated into a single spreadsheet for two key reasons: to standardise language and allow alignment of characteristics where possible in order to facilitate the next stage of cross-case analysis. Care was taken not to allow the matrix to start manipulating the data, however, and to ensure that the proximity of one case's data to another's did not influence compilation, other than to assist standardisation of terminology and visual alignment of characteristics. There was frequent reference back to the transcripts and other documentation, and adjustment of the individual case narratives and summary findings to re-organise them for clarity and as factors and characteristics became clearer. This was particularly so for the additional characteristics/factors which emerged from the data.

A summary of the findings and analysis for each case study, including the ranking, was then extracted into a table for presentation with each case. Factors developed from sources for the methodological framework were displayed first, then additional factors which emerged from the data. The tables also show each factor's ranking as an indicator of sustainability. The coding applied for ranking is as follows:

$$
\begin{array}{ll}
+ & \text { a positive contribution to sustainability } \\
\Rightarrow & \text { trending towards a positive contribution to sustainability } \\
0 & \text { no influence either way } \\
\diamond & \text { trending towards a negative contribution sustainability } \\
- & \text { a negative contribution to sustainability }
\end{array}
$$

These summaries are then discussed briefly for each case study. 


\subsubsection{Cross-case analysis}

The single spreadsheet containing the summaries and rankings of the factors for all the case studies formed the basis of cross-case analysis. With the factors aligned across the cases, and the individual characteristics as much as possible also aligned, comparisons could be made looking across the spreadsheet.

Key similarities, differences and relationships between factors, and between organisations, highlighted by this comparison were then analysed. Finally, based on the analysis, factors were mapped to the records continuum model and the results interpreted.

\subsection{Conclusion}

This chapter has outlined the approach taken to the study, the research design and the development of a methodological framework. The following four chapters present the stories of the individual Community Archives studied, including case notes where these are pertinent to the study, summaries of the findings, and analysis using the methodological framework set out in this chapter. 


\section{Chapter 4}

\section{Hilltown}

\subsection{Introduction}

Arranging interviews for the first case study went like clockwork. All participants were keen to be involved despite busy work schedules, and most communication was efficiently conducted by email.

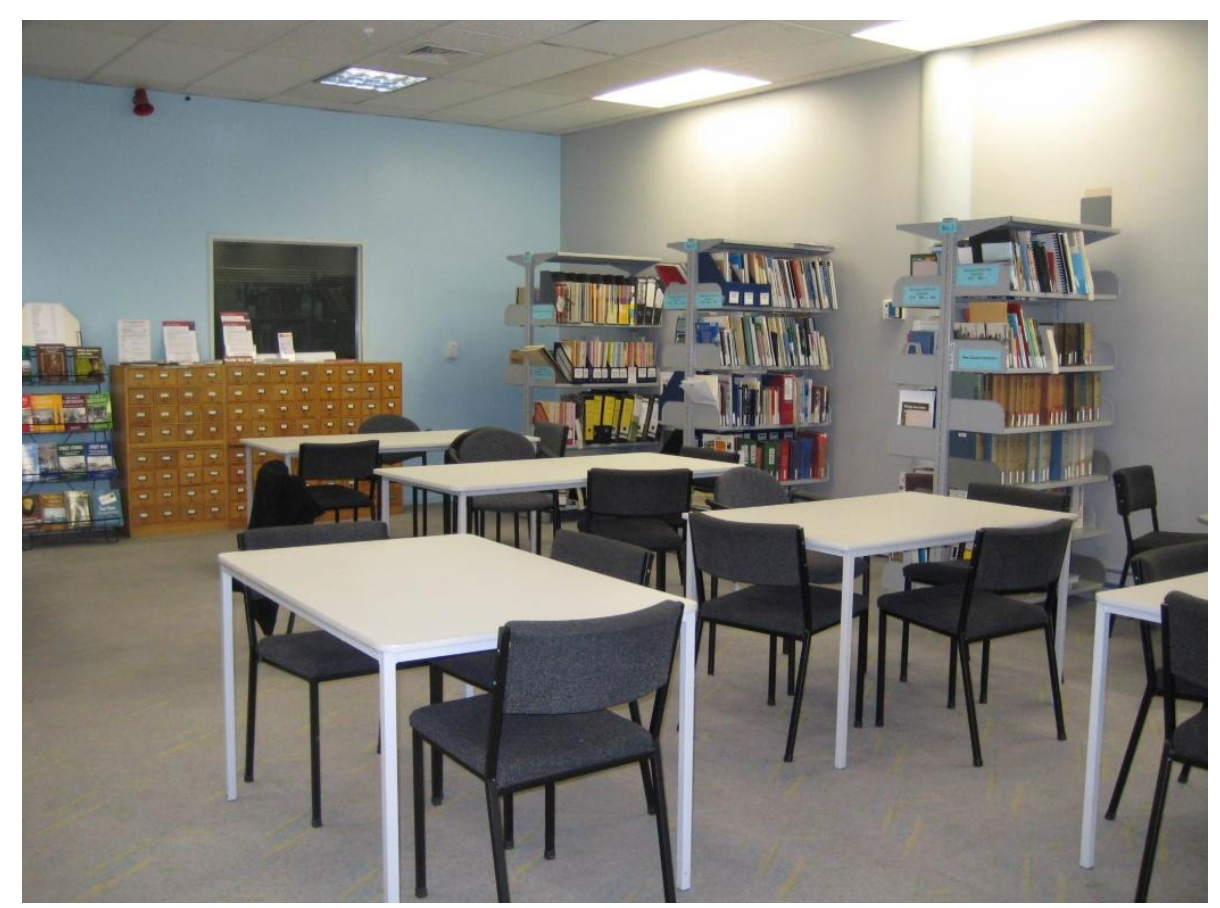

Figure 3: Hilltown - greeting the visitor, the reading room

\subsection{The Archives}

\section{Setting/description}

Large, plate-glass shop windows on the high street are the physical face this Archives presents to its community. It is situated in the heart of a town of around 20,000 people which is the main service centre for a large rural hinterland, a hub for government services and schools, host to a number of light industries and with a healthy cultural life, including a museum and art gallery. The town was founded in the 1850s and many descendants of early settlers still live in the area. 
At the Archives, visitors are welcomed into a large, light research room with a number of tables and chairs. A small library of local history resources, cabinets of genealogical resources and finding aids are at their disposal and the Archives' publications are proudly displayed on a stand. Assistance is at hand for researchers, with a staff member working in the reading room.

Behind this public area, one passes through a work area, down a corridor and into the stack room. The well-equipped archives storage area is clean, wellordered - and nearing full capacity.

\section{History}

The origins of the Archives lie in a 1989 government-commissioned community records search, which happened to be carried out by an archivist with local connections. A number of individuals, one of whom confessed that he "did not even know the word archive existed" before this, became excited by the project. A public meeting was organised by members of the local Historic Places Trust and it was decided to form an archives society. Using a certain amount of personal influence, premises were secured to store the records and the local authority agreed to take responsibility for the archives.

A number of factors appear to have inspired the establishment of the Archives: the passion of one or two key individuals, some of whom had previous involvement in local heritage activities (including establishing another small archives), their interest in the history of their own families, the lack of any other heritage facility in the town at the time and the community's desire to keep the archives of the area close to them. It was facilitated by the personal connections of some early players, who were prominent local politicians, businessmen or community leaders, by strong political support and the significant support of a local trust.

A succession of part-time, then full-time, archivists were employed from 1989, supplemented by volunteers and government-subsidised workers on employment schemes. In 1997 the current archivist was employed and the Archives moved to new and more-suitable leased premises on the main street of 
the town. Numbers of visitors increased dramatically, particularly after the move to new premises, as did accessions. Accessions have since tapered off, but not the numbers of visitors.

\section{Collections}

The Archives' collection policy is brief and general, simply specifying that it will "collect records relating to the region as a whole", with certain

broad types of records then listed. It also holds pre-1989 council records and provides research services to its parent organisation, but approximately $80 \%$ of the holdings are collected community archives. Although collecting is now relatively reactive (that is, collections are accepted only when offered), the collections are rich and varied as a result of this broad policy and community awareness.

The earliest archives date from 1860. Holdings are particularly strong in rural records, such as those from agricultural and pastoral societies, Federated Farmers provincial, branch and women's division, Country Women's Institute, dairy company and farms, but there are also business, church, lodge and community group records, collections of local photographers' work (both commercial and amateur) and school records. An example is records of a legal firm dating back to 1886 which include copies of outward letters written in Maori to Maori clients. The Archives also has a large collection of oral history recordings, made by volunteers and the Archives.

In addition to the school records, other government records, such as hospital board and land valuation records, are included as part of the community archives. These are retained on the basis that they are mainly of local interest or were saved by the Archives from destruction. In total (including the local authority's own records), the archives cover 700 linear metres.

\section{Governance/management}

Today the Archives come under the library and the archivist reports to the district librarian. The library manager in turn reports to a second-tier manager in the local authority who has responsibility for internal support services, 
community development, arts and culture, economic development and promotion, as well as the library and Archives. The council manager has a reasonable knowledge of the activities of the Archives but confesses to having visited only about 10 times in eight years.

The Archives are, however, relatively self-managing and the archivist has a significant degree of autonomy in terms of activities and spending of operational budget. Significant decisions, such as applying for Digital Strategy funding are made in conjunction with the library manager. Major funding or policy changes for the Archives would require approval of the elected council, on recommendation from management.

A, perhaps, unique aspect of governance is the relationship with the local archives society. While the Archives' staff are council employees, its overarching policy was written in conjunction with the Society and may not be altered without their involvement. While the Society now acts as a 'friends' group, there was initially tension with some members who considered that, because their work was the impetus behind establishment of the Archives, they should have greater control over it.

\section{Funding}

The Archives has a council-funded 2009 budget of \$248,900 (IT infrastructure not included), reflecting steady increases on the $\$ 90,000$ it received in 1999 . This is considered by all stakeholders to be relatively generous for an Archives of this size. Funding is allocated as a separate line item in the Long-term Community Council Plan (LTCCP) and appears secure, largely because of the esteem in which the Archives are held by council and community and the confidence in the archivist; "it's just taken for granted" that funding will be ongoing. On the other hand, the council manager is inclined to see it as being disproportionately well-resourced in comparison with the library, believing that backlogs of processing should be accepted as features of an Archives' existence.

The majority of digitisation work and some capital or equipment purchases are, however, not funded by the council. The Archives has tapped a number of other 
sources for projects, including New Zealand Digital Strategy funding for digitisation, community trust grants for shelving and equipment (generally applied for by the archives society) and some donations from the Society for materials. The cost of the publications produced by the Archives is born by the archives society, but they are also a source of profit for it - which, in turn, is used for projects for the Archives.

\section{Skilled staff}

The Archives are run by a number of paid staff; one full time archivist, one working 30 hours; an assistant on 24 hours and someone working on a digitisation projects for 10 hours a week. The Archives' policy statement specifies that a "professional archivist or librarian" must be appointed to care for the archives without, however, defining what a "professional" archivist is.

The archivist started as a volunteer with a keen interest in local history but with work experience in an unrelated field, and recalls that there was an emphasis on knowledge of local history when the vacancy for his job was advertised. He accepts that he may have initially been employed for his "attitude", as much as anything else. He does not have formal qualifications in archives, although he has undertaken many courses in aspects of archival work and been mentored by experienced archivists in the past. He is, therefore, relatively knowledgeable and experienced in managing archives. A local professional archivist is also on call to provide advice on, for example, particularly challenging arrangement and description issues. The part-time staff member working 30 hours has a library background.

There is no formal programme of continuing education, although the archivist does attempt to keep up with some reading and the local professional archivist also runs occasional, practical training courses for new staff or volunteers.

\section{Preservation}

The Archives' premises are temperature and humidity controlled and comply with Archives New Zealand's storage standard in all respects except for the requirement to have a disaster recovery plan. 
The majority of the collection, though not all, is boxed in archivally sound packaging of various sizes. Opportunities to recycle superior-quality containers from other institutions have been taken advantage of, but grants obtained through the archives society have also allowed specialised boxes for photographic materials to be made. Overall, the budget for preservation materials is considered adequate.

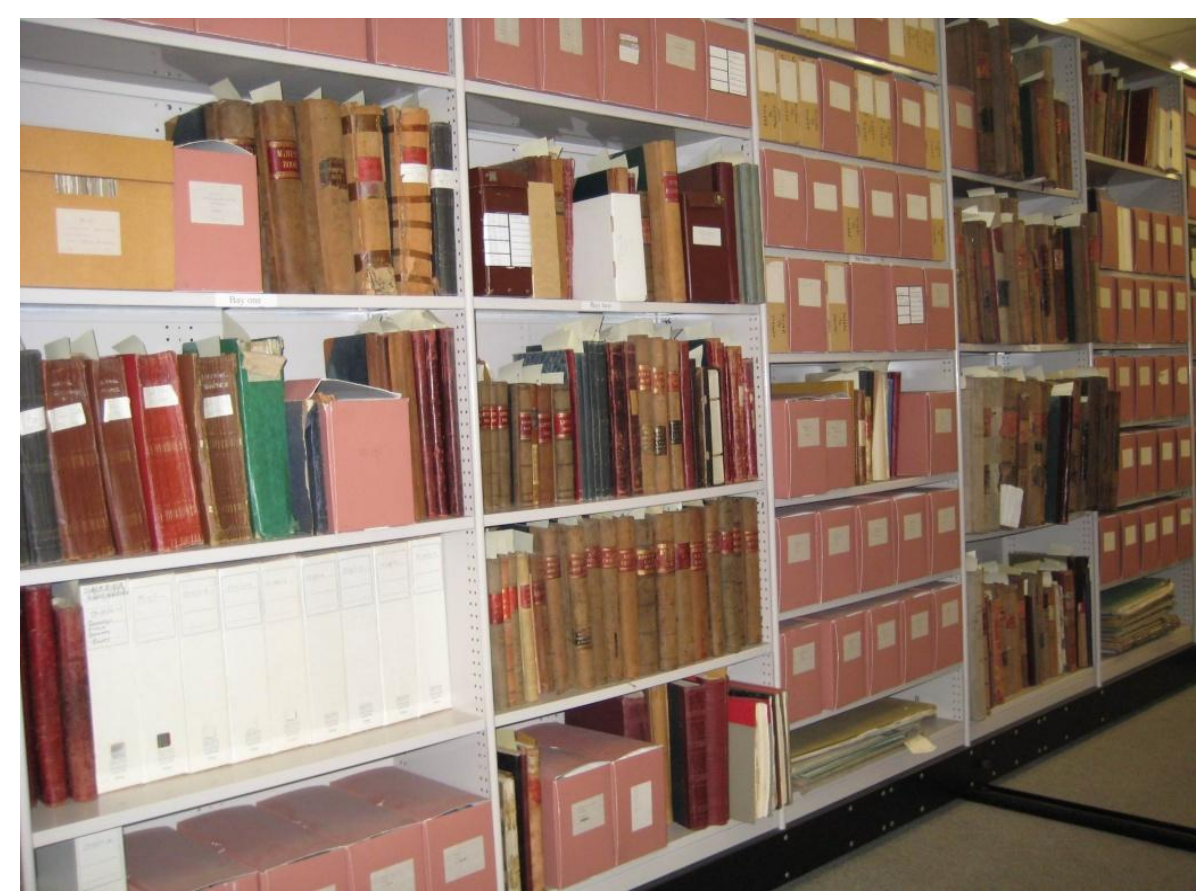

Figure 4: Hilltown - view of the stackroom

\section{Archival practices}

The Archives is guided by a brief but clear policy outlining its purpose, the framework for its operations, and responsibilities, although it has not been reviewed since establishment in 1989. This is supplemented by simple reference and acquisition policies. Apart from these, there is little documentation of procedures or standards used by the Archives.

Appraisal is informal and "just done from experience". The series system is used for arrangement and description, but the archivist is not confident that it is totally understood and there may be some "archivist-created series rather than creator-created" series. Access to item level is reasonably good but many collections are described at accession, rather than series, level. All information about the collections (around 50,000 entries) is entered into a computer database 
using library software similar to that used by some of New Zealand's largest collecting Archives. These finding aids are accessible on computer within the Archives reading room and also via the web.

\section{Community engagement}

This Archives has a close relationship with its community, responding to the smallest research requests as well as those of professional researchers, and everything in between. According to the archivist, "people feel they can just pop in". For example, "they'll come in and they'll say, my son's just bought a bike and it's got the name Sharland on it; was he a bike seller round here?" This degree of engagement and familiarity with the Archives has not just happened; it is the result of a conscious strategy and significant time and effort. From the outset, the Archives was determined that its focus would be use of the records, not storage. It also recognises that, even with promotion, only a very small proportion of its community will ever visit the Archives and that it must therefore give back to them in other ways. The sense of responsibility to the community extends to providing preservation advice (and even the occasional acid-free folder) to members of the public who wish to keep their own archives. It is acknowledged that, to a large extent, without community support the Archives would not survive. The archivist believes that even the location of the Archives is an important factor in this and fears that some of this connection would be lost if the Archives were moved and located behind the library, as has been considered.

This community engagement works on a number of levels. The archivist gives talks to community groups, old people's homes and schools. In addition, however, the Archives has a very active programme of working with both

primary and secondary schools on local research projects which fit with the curriculum. (One primary school teacher, who visited the Archives as a pupil himself, is now bringing his classes in to the Archives.) The results of these are then shared with the community, through publications or other outlets. The Archives has a publication programme focused on people, places or subjects of high local interest and a collection of local history stories, complete with images, is available on the Archives' website. The archivist has also kept up a 
regular column for the local newspaper for many years, as well as contributing feature stories connected to local events or to new acquisitions and has, in the past, provided history slots on the radio.

It was community engagement - a grass-roots desire to preserve their local history - which originally led to the establishment of an archives society and the Archives. The Society has been a significant part of the Archives' community engagement, particularly in the early days of its existence. The passion of its members for their local heritage has resulted in a long-term commitment by many people, who have applied their energy, skills, connections and influence to ensure its establishment and ongoing success. As the chairman describes it, there was a "community of responsibility". In the early days, members were also actively involved in archival work, assisting with accessioning, listing and other tasks, and undertaking oral histories; now they help launch books and provide funds, advocacy and other support. Volunteers continue to assist the Archives, working up to 20 hours a week doing things such as indexing or typing.

All case study participants share a sense, however, that this level of engagement may only be possible in a small centre (the Archives serves a total catchment of approximately 40,000 people), which identifies itself strongly as a community.

\section{Collaboration}

The Archives could be considered to have one formal collaborative 'partnership' aimed at furthering its objectives, and that is the publication partnership with the archives society, which is a separately and legally constituted organisation. While this group generally acts as a supporter, advocate or donor, if collaboration means a co-operative arrangement in which two or more parties work jointly towards a common goal, publication is an area in which collaboration could be considered to occur. There is a tangible, mutual benefit, with the Society totally funding publications by the Archives and bearing any financial risk, but also receiving the profits. In addition, both staff of the Archives and members of the Society may write for publications put out under the name of the Archives. (Although, it has to be noted that there is some lack 
of definition around roles in this example, with Archives staff who write for publications also being members of the Society.) Society members also assist with book launches and presumably derive some kudos in the community and personal reward from these.

Attempts have been made in the past to collaborate with other small Archives and territorial authorities in the region, to provide storage and services, but these have not been successful - generally because the other organisations wished to retain control of their own archives or keep them closer to users. The Archives does, however, provide storage for the archives of a heritage organisation in town, to ensure their preservation.

The Archives has an informal relationship with local genealogists which could also be considered a kind of collaboration. Based next door to the Archives, the genealogists benefit from accessing a free wireless network through the wall, but if they find information about local families they pass it on to the Archives, and they refer researchers on. The Archives has a key to the genealogists' rooms and sometimes also borrows resources.

\section{Dynamism}

There can be no question that this Archives is dynamic. It is very much focused on extending its outreach activities and is constantly exploring new opportunities and ways to reach users, engage the community and increase use of its collections. There is also a willingness to experiment.

Dynamism can be seen in its obtaining funding for digitisation through the Digital Strategy Fund (as it is not allocated by the council). The archivist has mounted images from the collection on the National Library's Matapihi and Archives New Zealand's Community Archive websites but has also shown creativity and a desire to be up with contemporary outreach trends by putting images on Flickr and creating a video to view on Youtube. The Community Archive is seen as an additional promotional channel but, while the archivist made a great effort to put digital images onto it for Archives New Zealand's 
launch, it was difficult, required a lot of personal time and is not likely to be continued in the near future.

No consideration has been given, however, to the possibility of accepting or holding digital archives, other than those the Archives creates itself through digitisation of photographs. In relation to digitisation, however, the archivist is very concerned about the increasing expectation that small Archives like this will digitise collections when there is little understanding of what is involved in such an exercise.

There appears to be no formal plan for the Archives over the next few years, either on the part of the council or the Archives itself.

\section{Other noticeable characteristics/issues}

What is immediately striking is that an enormous amount of work is done by the archivist in his own time. The council is proud of its Archives and appreciates that, because of the archivist's passion, "he spends a lot more time there than he's ever paid to be there". Many of the outreach activities and products which make the Archives successful are worked on by the archivist outside work hours. He also confesses, "In reality, I know we try to do too much, so that we over-extend ourselves and it would be easier to sort of pull back and do less, but the ongoing success of it is derived from doing that other stuff that builds up the support." This commitment is clearly part of the archivist's nature and personal dedication to the role.

Two potential issues regarding the future were touched on by the council manager, one being succession planning and the other possible local authority amalgamation. The first was mentioned as a concern, but no plans are in place to address it, largely because it would require more staff and financially this is not feasible. It is acknowledged that there is a significant reliance on the collection knowledge and memory of one person. Amalgamation is something which political trends indicate may one day be a possibility but all that can be said at this stage is that, in relation to the community archives, there is a clear sense that "the community wouldn't let them go". 


\section{Last words}

Reflecting on the future of the Archives, the chairman of the archives society initially commented, "I feel it's evolved in quite a miraculous fashion, really." He soon qualified this, however, saying:

I think fundamentally our success has really been the fact that we have been funded by the council to have professional archivists here. And if, in fact, you tried to exist on a voluntary basis we just would not have made the progress that we have had. We've identified that many of the original enthusiasts have departed, and they haven't been replenished, and I think under any normal community evolution there would have been real sort of atrophy in the whole thing. But the fact that we do have this professional and funded area of activity is quite critical to ongoing success.

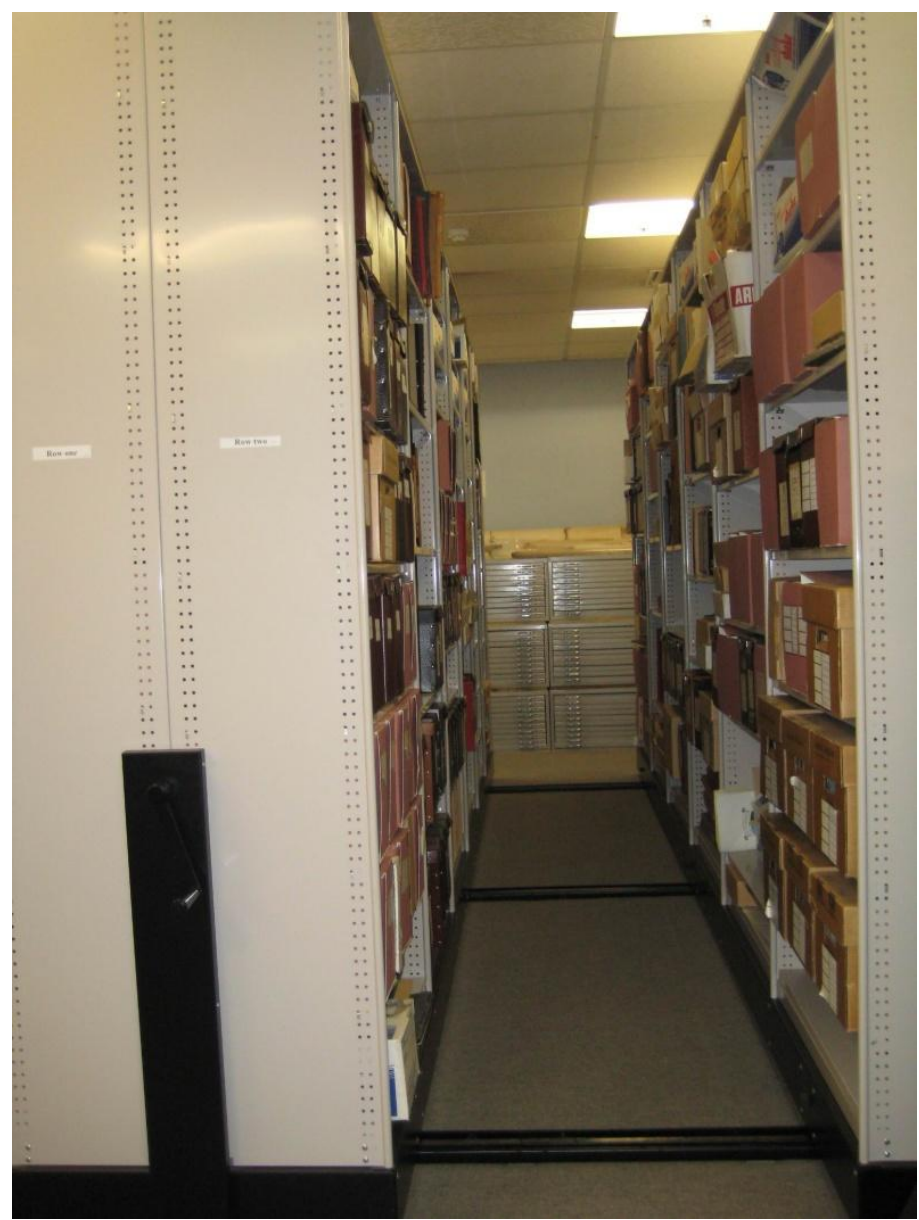

Figure 5: Hilltown - the archives stackroom

\subsection{Summary findings}

A summary of the findings for this case study is presented in tabular form below (Table 4), followed by discussion of each factor. 
Table 4: Hilltown - summary of characteristics

\begin{tabular}{|c|c|c|c|}
\hline & Ranking \\
\hline \multirow{7}{*}{ 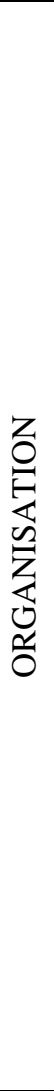 } & $\begin{array}{l}\text { Governance: } \\
\text { Structure }\end{array}$ & $\begin{array}{l}\text { Council function } \\
\text { Direct local authority control }\end{array}$ & + \\
\hline & $\begin{array}{l}\text { Governance: } \\
\text { Management }\end{array}$ & $\begin{array}{l}\text { Overarching policy document sets out roles, mission etc. } \\
\text { Archivist reports to librarian (third-tier manager) } \\
\text { Self-managing day-to-day } \\
\text { Significant expenditure decisions involve librarian } \\
\text { Major funding or policy changes require elected council approval }\end{array}$ & + \\
\hline & Funding & $\begin{array}{l}\text { Operating budget from council - } \$ 248,900(2009) \text { - trend to increase } \\
\text { Appears secure (in LTCCP) } \\
\text { Major projects funded from ext. grants or archives society donations } \\
\text { Publications funded by archives society }\end{array}$ & + \\
\hline & $\begin{array}{l}\text { Skilled staff: } \\
\text { Knowledge etc }\end{array}$ & $\begin{array}{l}2.5 \text { FTE (full time equivalent) paid staff } \\
\text { Archivist has no formal qualifications, but well trained } \\
\text { One part-time staff member with library qualifications } \\
\text { No continuing education programme }\end{array}$ & + \\
\hline & $\begin{array}{l}\text { Skilled staff: } \\
\text { Succession }\end{array}$ & $\begin{array}{l}\text { Archivist aged under } 60 \text { years } \\
\text { Dependence on knowledge and memory of archivist } \\
\text { No succession plan but aware of desirability }\end{array}$ & $\Rightarrow$ \\
\hline & Collaboration & $\begin{array}{l}\text { Formal collaboration - publication partnership with archives society } \\
\text { Informal mutually beneficial relationship with genealogists } \\
\text { Initiated (unsuccessfully) attempts to collaborate with other Archives }\end{array}$ & + \\
\hline & Dynamism & $\begin{array}{l}\text { Actively explores and extends outreach activities } \\
\text { Willing to experiment e.g. use of online social networks } \\
\text { Accesses new funding sources } \\
\text { Not preparing for digital archives } \\
\text { No formal plan for the future } \\
\text { Passive collectors - active in the past }\end{array}$ & $\Rightarrow$ \\
\hline \multirow{2}{*}{ 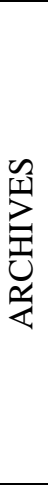 } & Preservation & $\begin{array}{l}\text { Adequate budget for preservation } \\
\text { Adequate space for storage, processing and research } \\
\text { Environmental conditions meet Archives NZ storage standard } \\
\text { Majority of collection in archival-quality packaging } \\
\text { Re-use of cast-off archival packaging }\end{array}$ & + \\
\hline & $\begin{array}{l}\text { Archival } \\
\text { practices }\end{array}$ & $\begin{array}{l}\text { Collection policy brief but clear (last reviewed 1989) } \\
\text { Reference and volunteer policies, but little documentation of } \\
\quad \text { standards/procedures } \\
\text { Appraisal process informal - 'just done from experience' } \\
\text { Series system used } \\
\text { Good item-level access but not for all collections } \\
\text { Finding aids on database and online }\end{array}$ & + \\
\hline$\sum_{0}^{己}$ & $\begin{array}{l}\text { Community } \\
\text { engagement }\end{array}$ & $\begin{array}{l}\text { Deliberate strategy to engage, be relevant, focus on use } \\
\text { Actively seek and develop multiple channels for engagement } \\
\text { Visible location an important factor } \\
\text { Volunteer commitment - sense of reward, pride in achievements } \\
\text { Policy cannot be changed without archives society agreement } \\
\text { Archives society funds publications and other projects } \\
\text { Informal, mutually beneficial relationship with genealogists } \\
\text { Belief that community would not allow the archives to leave the area }\end{array}$ & + \\
\hline \multirow{3}{*}{ 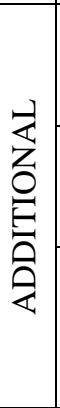 } & Archivist & $\begin{array}{l}\text { Enormous amount of unpaid time given by archivist } \\
\text { Personal commitment to role } \\
\text { Passion }\end{array}$ & + \\
\hline & Collections & $\begin{array}{l}\text { Local government records (parent-organisation) } \\
\text { Government records } \\
\text { Small number of secondary sources }\end{array}$ & $\Rightarrow$ \\
\hline & $\begin{array}{l}\text { External } \\
\text { support }\end{array}$ & $\begin{array}{l}\text { Uses Archives NZ free online database, but extra promotion only } \\
\quad \text { (difficult to use) } \\
\text { Mentoring, guidance from other archivists } \\
\text { Re-use of cast-off archival packaging }\end{array}$ & $\Rightarrow$ \\
\hline
\end{tabular}




\section{Governance: structure}

Coming under direct local-authority control and operating as a council function, this Archives is likely to be enduring because it is mandated under council policy, is included in public, long-term planning documents and subject to formal input through local authority processes.

\section{Governance: management}

Although significant funding or policy decisions require higher council-officer or elected-member approval, the archivist is responsible for management and decision-making on a day-to-day basis. The Archives' position is strengthened by the fact that its policy cannot be changed without consulting the archives society, which represents the community.

\section{Funding}

Operating budget comes from the local authority and is approved in the LTCCP. At nearly $\$ 250,000$ per annum, it is sufficient to fund 2.5 FTE (full time equivalent) staff, has shown a trend to increase over the past 10 years and appears secure. On top of this, the Archives also seeks funding from external agencies and a 'friends' of the Archives group is willing and able to raise additional funds for major projects and publications.

\section{Skilled staff: knowledge}

While the archivist has no formal qualifications, he is well-trained and other staff have also had some archives-specific training. Although there is no continuing education programme, the archivist appears to have sufficient knowledge to ensure that the archives are managed in such a way as to ensure the retention of their evidential value and, therefore, to sustain their record quality over time.

\section{Skilled staff: succession}

While the archivist is under the age of 60 years and shows no apparent signs of leaving, there is a dependence on his knowledge and memory of collections and little documentation of standards and procedures. With low staff numbers, there is no planning by the organisation for succession so there is a potential risk of knowledge loss in a future transition, although this is balanced by the continuity provided by council infrastructure and the presence of other staff with some familiarity with the operations. 
Collaboration

A successful collaboration is in place with the 'friends' group, which allows delivery of significant and noticeable output for the community, in the form of popular publications. By raising the profile of the Archives, expanding its capability to deliver to its community and building a committed core of stakeholders, this collaboration contributes significantly to sustainability.

\section{Dynamism}

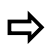

The archivist experiments with, and develops, new forms of outreach and proactively accesses new funding sources to achieve goals. There is, however, no formal plan for the future and no preparation for digital archives. This may lead to significant gaps in the collection's representativeness of the community in future.

\section{Preservation}

Environmental conditions for storage meet Archives New Zealand's minimum storage standard, the budget is considered adequate for preservation and the majority of archives are packaged in archival-quality materials. Consequently, the physical records have sufficient protection to ensure they are likely to endure over the long-term.

\section{Archival practices}

Policies are adequate, the series system is used for arrangement and description and accepted professional archival practices generally appear to be followed, ensuring that the integrity and evidentiality of the records will be retained. Finding aids are created on a database and available to the public via the internet and the Archives are open for a reasonable number of hours for research. Appraisal practices are not well developed, however, and there is little documentation of standards or procedures.

\section{Community engagement}

There is a high level of community engagement which is actively developed through outreach activities. Volunteers are involved with the work of the Archives and groups, such as school classes, are brought in to work on projects. The community has a sense of ownership which leads participants to believe it would not allow the archives to be alienated from them. 
Three other factors have been identified which potentially have an impact on sustainabilility.

\section{Character of the archivist}

The archivist has a passion and commitment which results in an enormous amount of unpaid time being given to the role. There is even a suggestion from council management that it is confidence in the current archivist which ensures continuation of the level of funding enjoyed by the Archives; indirect confirmation of this factor's contribution to the sustainability of the Archives. While it contributes to sustainability today, however, this situation carries the inherent risk that things might change with a different archivist.

\section{Collections}

The nature of the collections may also favour sustainability. The Archives is responsible for some of the parent-organisation's archives, which is likely to encourage on-going support because the organisation is required under the Public Records Act to maintain its archives to a certain standard. In addition, although technically not acceptable under the Public Records Act, it holds government archives which must also be protected and made accessible.

\section{External support}

The most likely potential source for institutional support from outside the parent organisation comes from Archives New Zealand. There has not, however, been a great deal of such support. The Archives has utilised its free, online database to make collections known to a wider public, largely to assist Archives New Zealand to launch the product, but few items are on it and the archivist finds it difficult to use. The support provided by the national institution can be interpreted as neither contributing nor detracting from sustainability. On the other hand, advice and training provided by other professional archivists has clearly raised the skills and knowledge of the archivist. 


\subsection{Conclusion}

Overall, this community archives exhibits sufficient characteristics in each of the required factors to indicate that it is likely to be sustainable. The majority of factors, both those identified as research propositions and new ones emerging from the case study, rank as either positive contributions to sustainability or trending towards positive contributions. 


\section{Chapter 5}

\section{Plainstown}

\subsection{Introduction}

At the request of the archivist, interviews for this case study were held at the home of the community stakeholder. Because of tensions around proposed developments, there is some friction among staff at the very small museum/Archives and the Trust. Even off-site, the archivist was guarded in her conversation and it was evident that she was carefully phrasing some of her comments.

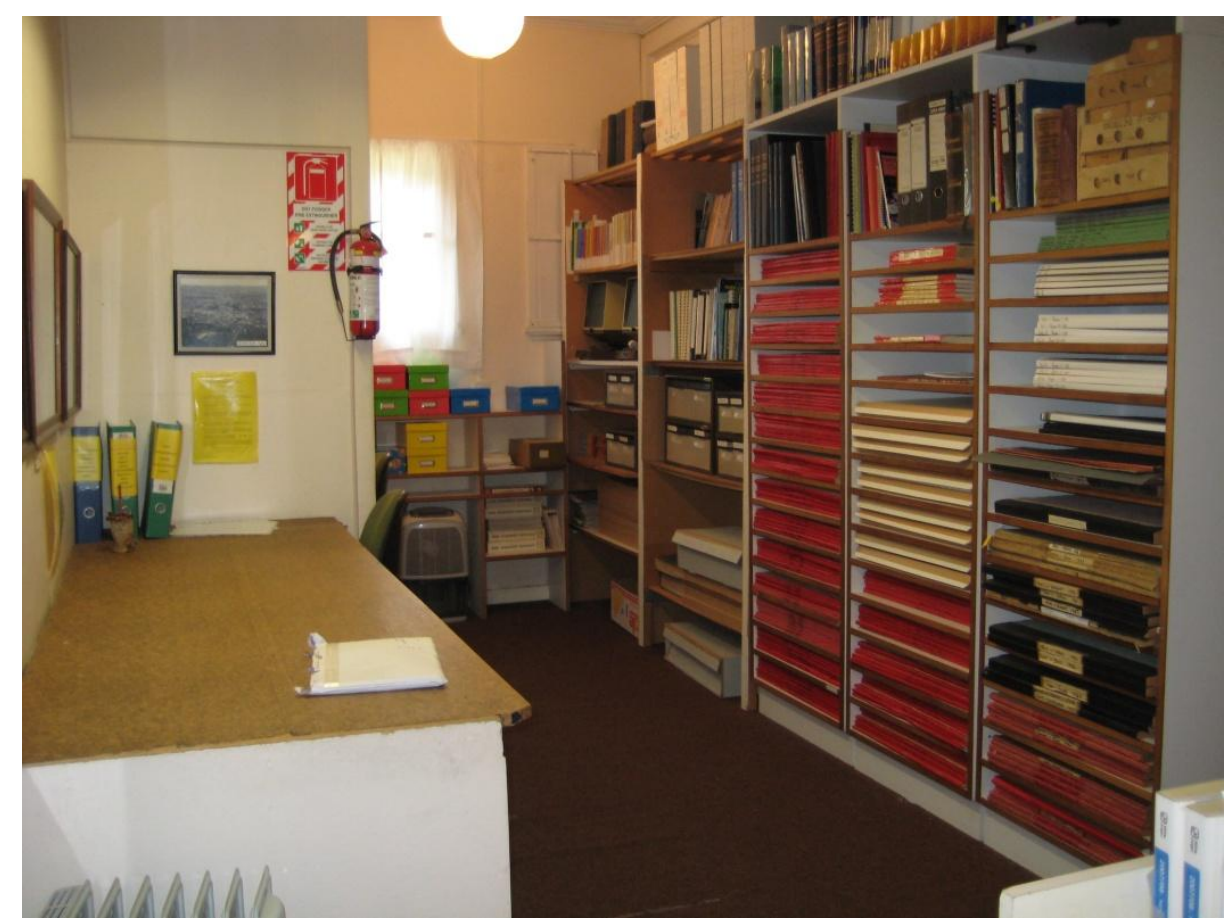

Figure 6: Plainstown - the reading room welcomes researchers

\subsection{The Archives}

\section{Setting/description}

Driving into town, one of the first non-commercial signs to catch the eye is a large billboard announcing 'museum and archives'. The Community Archives 
here is part of a museum, occupying a domestic-scale building that once housed a 1940's commemorative town library and ladies' restroom. The town itself is some distance from any New Zealand main centre and home to just over 5,000 people. It is an area rich in both Maori and early-European settlement history, with five iwi based in the district. None of these have a particular affinity with the Archives, although their presence can sometimes add a dimension to debates about its future. The strong Maori community has also had a significant impact on use of collections, some of which (albeit the mostly secondary, copied sources) have been heavily used for Treaty of Waitangi research.

The Archives is staffed two days a week but open to researchers only on Fridays from 10.00 am to $4.00 \mathrm{pm}$. It has a small reading room with a bench and handy reference sources, while the archivist works either in a combined processing/store room or at a table in the museum administrative area. The archivist sees her role very much as provider of historical information and will draw on published sources (such as newspapers), genealogical resources (particularly those created by the Mormons) and copies of archives from other repositories, as much as original records, to answer enquiries.

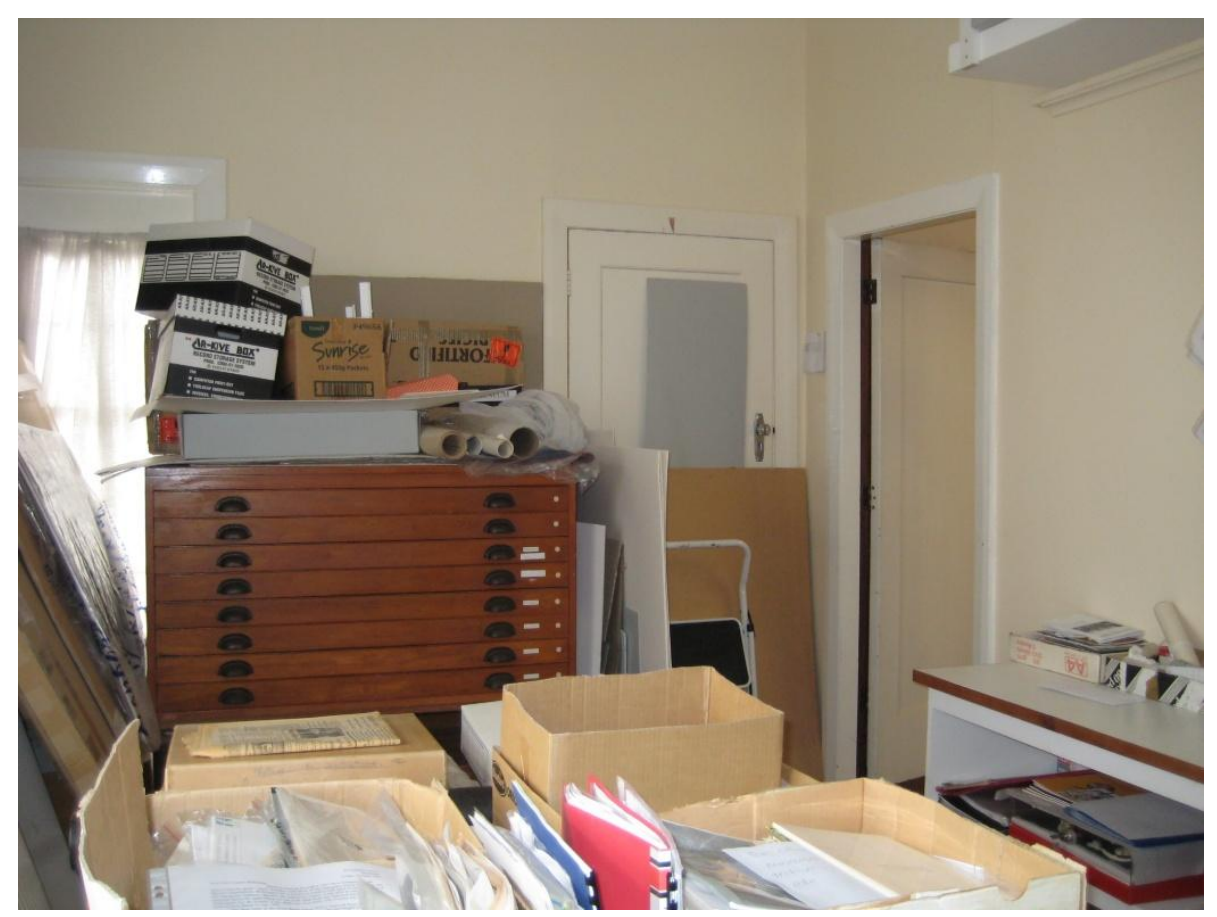

Figure 7: Plainstown - the archives processing room (and general storage) 


\section{History}

The Archives were effectively started in 1985 when a local and family historian, employed as a part-time museum assistant, decided that it was important to obtain copies of information pertaining to the area from remote national or other large repositories in order to bring it closer to the people to whom it related. Collection of family papers and other local records soon followed. At that time, the museum was run by the council. In the 1990's, however, the council sought to divest itself of direct responsibility for local heritage and in 1998 established a charitable Trust to manage the museum.

In recent years, the council has been leading a major project to develop a multimillion-dollar community and cultural centre, which will "bring new museum facilities, library, tourist I-Site, and café onto one site at the southern end of the township in iconic premises that speak eloquently of who we are" and "present an exciting new visitor experience where we provide the stories and treasures of our place and offer improved research facilities". It is understood at this stage that the archives may be removed from the museum and go into the library, although there has not been agreement within the current Museum Trust over this proposal.

\section{Collections}

The archivist estimates that approximately $60 \%$ of the collection is original records and $40 \%$ copies. Copied records include such things as church and school registers, Maori land court minute books and genealogical microfiche, which are useful as family and local history sources. Electoral rolls from outside the area fulfil the same purpose. Providing easy access to such resources has been seen by past and present archivists as a key role for the Archives and their acquisition is specified as a special category in the policy. Although many of these are now available in digitised form, the Archives keeps the copies for those who prefer to view them in hard copy rather than online.

The area from which original collections are drawn is geographically extensive. Holdings include archives from organisations such as the local branches of the Country Women's Institute, sports clubs, Masonic lodges and other community 
groups, a significant collection of local photography from a photography business covering three decades, family records and photographs. Early County Council records are also contained in the Archives. Oral histories have been recorded by volunteers and are also held.

Collections now come in largely by word of mouth, a legacy of past promotional activities. The number of collections or items being offered appears to have tapered off a little since the major redevelopment project started, however. The archivist wonders if this may be partly because it is controversial and potential donors are holding off, feeling there is uncertainty about what will happen to collections.

\section{Governance}

The museum (and hence the Archives) is governed by a charitable Trust Board established by the local authority as a 'council organisation' under the Local Government Act 2002. This means that the council has the right to appoint one or more trustees and has voting rights (as opposed to if it were a 'councilcontrolled organisation', in which case a council would have $50 \%$ or more of the trustees and voting rights). Under the terms of the deed, the Board has wide powers to manage the museum and enter into financial and other arrangements but all assets remain the property of the local authority. If the Trust were to wind up, however, it has absolute discretion to transfer all property to any organisation with "same or similar charitable aims" that it thinks fit. In the eyes of the Trust chairman, this governance arrangement has its pluses and minuses; the museum is, of course, beholden to the council to a certain extent, which limits its flexibility, but it also has free premises and an annual budget which, as he says, means “you don't have to be doing cake stalls every Friday on shop corners".

In its policy, the Archives is described in the following terms "The Archive is located at the Museum", implying a certain separate identity from the museum. The archivist reports to the museum's curator/manager, however. Her decision-making ability is limited to day-to-day archival 
functions such as acquisitions, appraisal, arrangement and description and reference enquiries.

\section{Funding}

The work of the Archives is funded operationally through the museum. The archivist has no input to, or control over, budget and seeks approval from the curator/manager to spend on regular operational items. Projects such as oral histories are carried out only if funding applications to external sources are successful. The council annual grant to the museum is around $\$ 100,000$, which is not large, but which the chairman considers generous, given the low socioeconomic nature of the area in which the museum is located. This funding is not guaranteed, however, so is always potentially at risk from changing priorities. The chairman acknowledges, too, that, with the new community centre project, it is likely that funding to the museum may be reduced. He believes that the museum trust should persist under the new structure, enabling it to continue to raise funds separately to meet its goals, to the benefit of all. In the past, it has raised, on average, $\$ 20,000-30,000$ per annum from outside sources.

\section{Skilled staff}

The Trust chairman believes it is important to have qualified staff but considers that the current archivist meets their criteria although she has had no formal training or education in archives. She came to the paid position through volunteering at the museum on Saturdays and with a previous background in administration. Driven by a need to have something to do when there were no visitors, she begged for a useful task to occupy her time and was given newspaper indexing: "where I think we mostly all begin". She works two days a week, which is never enough to get the work done. The Trust chairman agrees that more hours would be preferable; he feels there is currently not enough promotion of the Archives done.

While the archivist has no formal training, she does now have several years' experience. Training has been on-the-job, from people who worked with the archives but had no formal archives training themselves, although they had attended workshops held by the museum sector (largely focusing on care and 
handling). After five years, the archivist is feeling confident about her decisionmaking on what to keep and not to keep. A volunteer and local historian acts as a mentor and sounding board on difficult accessions. She does find it hard to get the training she feels she needs and is available (most often museum-related and through Te Papa's National Services) - largely, she suspects, because it is held in bigger centres and would involve travel and accommodation costs. One advantage the Trust chairman sees in being part of a larger organisation with more funding is that there may be more training opportunities for an archivist.

\section{Preservation}

Although the current premises are not purpose-built for archives, the main storage area is secured, with restricted access, and humidity is controlled by dehumidifiers set at $50-55^{\circ}$. This is critical, as summertime humidity generally ranges between $80 \%$ and $100 \%$, with an average of $90 \%$. Some of the collections stored in this room, however, are copied sources while the large photographic collection (mainly negatives) and some glass pate negatives are stored in the small washhouse at the back of the building, where the door is open much of the day and there is no temperature or humidity control. These materials are a source of major concern to the archivist for this reason and also because the boxes they are stored in are dusty and their contents often secured by deteriorating rubber bands. Processed archival collections in the climatecontrolled repository are well-packaged in acid-free boxes and/or tissue. Deteriorating photograph albums, particularly those with adhesive pages, are slowly being worked on. There is an awareness, too, that insufficient preservation measures are in place for oral history recordings, videos and digital media. Silverfish are periodically seen in the building and new damage by them detected, indicating that pest control is not adequately maintained.

Preservation measures are sometimes, of necessity, 'home made'. One collection which was full of silverfish, was collected, spread out on the floor of the garage at a private home for a few days "so that all the silverfish could walk away", then gathered up and taken to the Archives. Folded items were also ironed flat so they could be read. 


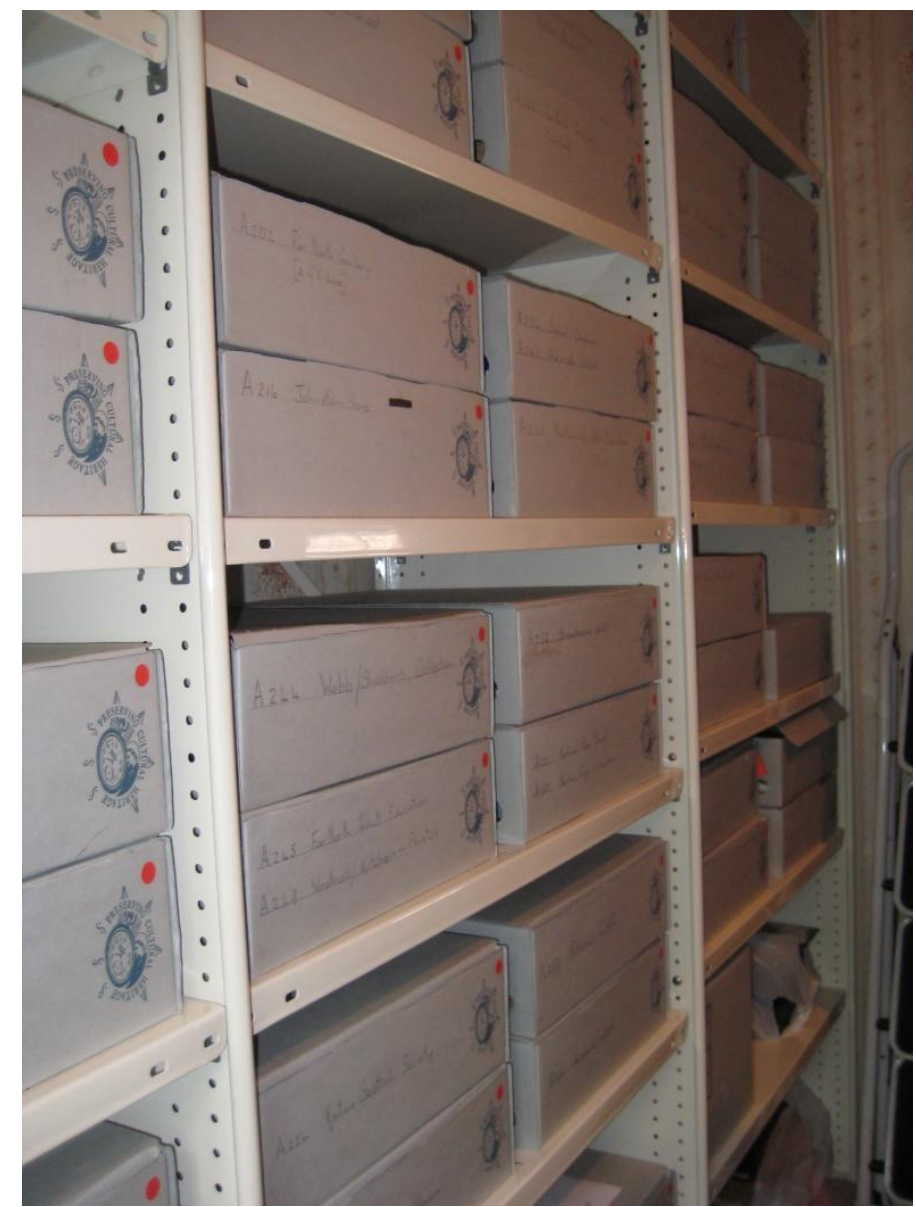

Figure 8: Plainstown - the main repository, with standardised archival storage boxes

\section{Archival practices}

The Archives is guided by a policy separate from that of the museum, which notes that specific emphasis has been placed "since 1991, on the development of a unit operating on archival principles and practices". The policy guides acquisitions and procedures for organising the archives but a number of its provisions (such as the archivist assisting with planning and evaluating services) do not appear to be being fulfilled. The archivist understands that initial procedures were largely developed through researching internet sources for templates and guidance. Appraisal is mentioned in the procedures as necessary to ensure appropriate material is acquired, the importance of preserving original order is referred to, and arrangement into series is mentioned but there is no detail or explanation of these key aspects of archival processing. While there is a checklist of tasks for the overall processing function, there are none for appraisal or arrangement and description. In fact, there is evidence that actions undertaken during processing may be at odds with professional practice. For 
example, when additional material is received from the same creating agency, it appears to be added to any earlier series and, if there is too much to box it with that earlier series, all is moved to a new series. There are also procedures for handling reference enquiries and dealing with researchers.

Access to archives is initially via card indexes to subjects and names. Printed catalogue sheets containing more detail are available for public use but restricted items are not included in the public catalogue. The archivist has her own copy which includes access restrictions on any items within a series, which she must check before making archives available. A computer program for archives has been purchased in the past, but the archivist was not involved in selection or set up. That system was mothballed after a period and another purchased for museum and archival collections but development of that appears to have halted, too, and there is still no access to collections via computer. Around 150 collections (including copies of holdings in other Archives) have been listed on the National Register of Archives and Manuscripts (now The Community Archive), but contributions stopped about the mid-1990s.

\section{Community engagement}

Although both the present and past archivists have spoken to community groups about the archives, the archivist is conscious "there's not a lot of people aware that they are there, you know." Those involved in genealogy have a high level of awareness, partly because the Archives work closely with the genealogical society. There has, however, been little promotion of the archives to the town recently. Despite this, there is a general sense that the community supports the museum as a whole which, of course, includes the archives.

One of the considerations for the Trust chairman, as the location of the archives is debated, is how much it should be considered only as a storage facility and the alternative possibility of it being developed into an exciting community research facility. One of his visions is of a place people would walk past and say "What are those people doing in there? Why are they looking through that material? What is so interesting about that? Should I be having a look in there? Does it cost anything to do that? Can I get a copy of that photograph - that's a very old 
photograph of my family's homestead in and that would be something nice on a Christmas card?"

He sees volunteers as a very important part of reassuring the community of its ownership of the archives. He recognises, however, that community engagement is to a large degree determined by the experience people have of the Archives, which is influenced by the attitude, knowledge and skills of the archivist. He does believe that the community's confidence in the Archives could change if they did not trust that this person was looking after their archives: "the archivist has a huge role to play in the protection of the heritage of any community".

The boundary between community and Archives is fluid in this situation, where the volunteer (and former archivist) acts as mentor to the archivist and also, in her role as a local historian, holds archives she has collected from the community at home until she has finished her research.

\section{Collaboration}

If the museum is taken out of the equation, the Archives does not formally work with any other organisation to further its aims. There has always been a connection with the genealogical society, however, which ran more as an historical society and met in the museum when first established. Many of its members became involved in such things as transcribing local cemetery inscriptions, and the results of this work are held in the Archives.

The new community facility project could potentially involve considerable collaboration (for instance, the library apparently holds some 'archives') but, as yet, this is an unknown quantity. The Trust chairman sees value in the Archives being located within the museum because archives provide good material for displays, which, in turn, increases interest in them. The archives could also generate revenue for the museum, through sale of photographic reproductions, for example. 


\section{Dynamism}

The project to incorporate the Archives in the new community facility is a major change on the horizon. The archivist has had no involvement in it, however, although the Museum Trust is a partner in the project. How it will affect the archives themselves is not clear as references in the project concept document are high-level and 'promotional' in style: "the new concept fundamentally shifts the idea of the cultural institution forward into the 21 st century to draws together information with collections and archives in an environment of optimised information technologies and supporting national strategies".

There is some resistance to the proposed changes but the chairman of the Trust sees many advantages to the project. In addition to purpose-built premises (which would enhance preservation), there would be increased pedestrian flow, opportunity for more changing exhibitions, increased revenue-raising opportunities (in which the archives are seen to play a key part), and an ability to create good educational programmes and increase the tourist dollar for the community.

The archivist is generally supportive of the proposal, although her wishes for the future focus more on improving access to holdings through better cataloguing. She also feels that a strong push to digitise archive collections for online access does not sufficiently take into account community sensitivities and privacy issues. The community stakeholder and volunteer sees no reason for the Archives to change the way it operates.

\section{Other noticeable characteristics/issues}

The Trust established for the proposed new community facility makes no mention of the community archives. According to the Trust Deed on the project website, the purpose of the Trust is " Providing, maintaining, resourcing and managing multi-purpose community facility buildings...”. In addition to the existing but refurbished community centre, the facility will offer "a new library, museum, service centre, I-site, technology centre, retail space, public meeting spaces, public toilets, including a comfortable, well appointed parents' room, and ancillary rooms and spaces - all designed specifically for the uses 
intended and with the flexibility to grow as community needs grow." The archivist believes that the new facility is being seen as more of "a large information centre", downgrading the significance of the archives. She has some concerns that, if the archives are transferred to the library, there will be no-one there trained or dedicated to working on them. A part-time archivist in the situation of this community archives has little ability to influence the direction, or even the policies, of the Archives.

There is, nevertheless, a very strong personal commitment to the role. Although the archivist is paid to work two, seven-and-a-half hour days, she frequently does more - appraising collections, talking to groups and processing archives in her own time. Because there is not sufficient time to do all the work required on the archives, the time she makes real progress is when she has to fill in for absentee museum volunteers and can do extra work on collections. "I really move ahead when I volunteer to work a weekend." The community representative (and former archivist) also believes one has to have a passion to do the job; that is the only way a person will "go the extra mile" - put in the extra time to do the indexing or conservation required to help people use the archives. Along with the Trust chairman, she agrees that the current archivist has that passion.

\section{Last words}

Like other case studies, those interviewed here strongly believe that the community archives should stay in the area. The words of the Trust chairman sum up their value to the area:

I think, in many respects, it is the unique part of a heritage - of the heritage of a community - because it is the actual records that you've got - it's the hard copy of where you've been and how you've got to where you are. And that, to me, is - in the world of education or in the world of knowledge - that is really, really important.

\subsection{Summary findings}

A summary of the findings for this case study is presented in tabular form below (Table 5), followed by discussion of each factor. 
Table 5: Plainstown - summary of characteristics

\begin{tabular}{|c|c|c|c|}
\hline & & & Ranking \\
\hline \multirow{7}{*}{ 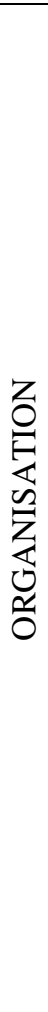 } & $\begin{array}{l}\text { Governance: } \\
\text { Structure }\end{array}$ & $\begin{array}{l}\text { Within Museum } \\
\text { Charitable Trust with 'council organisation' status under LGA }\end{array}$ & $\Rightarrow$ \\
\hline & $\begin{array}{l}\text { Governance: } \\
\text { Management }\end{array}$ & $\begin{array}{l}\text { Archivist reports to museum curator/manager } \\
\text { Separate identity within the museum, on paper } \\
\text { Decision-making limited to day-to-day functions } \\
\text { Archivist not involved in planning }\end{array}$ & • \\
\hline & Funding & $\begin{array}{l}\text { Operating budget from museum (small share of museum's annual } \\
\quad \$ 100,000) \\
\text { Funding not guaranteed } \\
\text { Archivist has no input to, or control over, budget } \\
\text { Approval of manager required for operational expenditure } \\
\text { Additional funds raised annually from external sources }\end{array}$ & 一 \\
\hline & $\begin{array}{l}\text { Skilled staff: } \\
\text { Knowledge etc }\end{array}$ & $\begin{array}{l}1 \text { paid staff, } 15 \text { hours per week only } \\
\text { Archivist has no formal qualifications or training } \\
\text { Training received on-the-job from former archivists with similar } \\
\quad \text { background } \\
\text { No continuing education programme }\end{array}$ & 一 \\
\hline & $\begin{array}{l}\text { Skilled staff: } \\
\text { Succession }\end{array}$ & $\begin{array}{l}\text { Archivist aged over } 60 \text { years } \\
\text { No apparent succession plan }\end{array}$ & $\diamond$ \\
\hline & Collaboration & $\begin{array}{l}\text { None at present but significant collaborative project imminent } \\
\text { Also potential risk, because outcome for Archives unknown }\end{array}$ & $\Rightarrow$ \\
\hline & Dynamism & $\begin{array}{l}\text { Plans for change driven by the governing body } \\
\text { Archivist has no plans to change the way things operate } \\
\text { No plans to implement new technologies, archival practices etc. } \\
\text { Passive collectors - active in the past }\end{array}$ & • \\
\hline \multirow{2}{*}{ 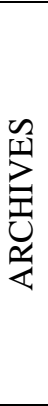 } & Preservation & $\begin{array}{l}\text { No separate budget for preservation } \\
\text { Only some collections in climate-controlled conditions and most } \\
\quad \text { at-risk media are not (high-humidity area) } \\
\text { Silverfish evident } \\
\text { Inadequate packaging of fragile collections (negatives, digital etc.) } \\
\text { Uncontrolled access to one collection storage area }\end{array}$ & 一 \\
\hline & $\begin{array}{l}\text { Archival } \\
\text { practices }\end{array}$ & $\begin{array}{l}\text { Collection policy } \\
\text { Appraisal process informal (quality unknown) } \\
\text { Good documentation of collections } \\
\text { No computerised finding aids or online access }\end{array}$ & • \\
\hline 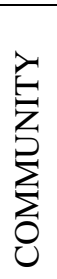 & $\begin{array}{l}\text { Community } \\
\text { engagement }\end{array}$ & $\begin{array}{l}\text { Small number of volunteers } \\
\text { Work with genealogists } \\
\text { Very little outreach because of time commitment } \\
\text { Use only by those who know ("word of mouth") } \\
\text { Strong belief archives must stay in the area }\end{array}$ & - \\
\hline \multirow{3}{*}{ 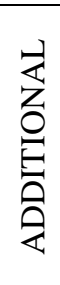 } & Archivist & $\begin{array}{l}\text { Additional unpaid time given by archivist } \\
\text { Personal commitment to role } \\
\text { Passion }\end{array}$ & $\Rightarrow$ \\
\hline & Collections & $\begin{array}{l}\text { Local government records } \\
\text { High number of secondary sources }\end{array}$ & $\Rightarrow$ \\
\hline & $\begin{array}{l}\text { External } \\
\text { support }\end{array}$ & $\begin{array}{l}\text { Museum training offered, but not readily accessible } \\
\text { Lapsed use of Archives NZ free online database }\end{array}$ & 0 \\
\hline
\end{tabular}




\section{Governance: structure}

The Archives is within a museum governed by a charitable trust which is constituted as a 'council organisation' under the Local Government Act. This is likely to ensure that the museum is sustainable, but not necessarily the identity of the Archives within it, even though it has a separate policy.

\section{Governance: management}

The archivist is not involved in planning for the Archives and decision-making is limited to day-to-day archival functions, which does not leave it in a strong position.

\section{Funding}

The operating budget for the museum is not large and the Archives has access to a small portion of this at the discretion of the museum curator/manager. The archivist also has no input to budgeting activities. Funding is not guaranteed and a significant portion of funds are raised each year from external sources to fund projects. This limits many activities, such as preservation, which have a significant impact on the sustainability of the actual archival records.

\section{Skilled staff: knowledge etc}

The Archives is run by a paid employee but at only 15 hours a week. The archivist has no formal qualifications, has learned 'on-the-job' and has no continuing education programme. While there are basic procedures to guide her, knowledge and skills are passed from one part-time archivist with no formal training to another. This lack of training affects the quality of core archival activities, such as appraisal and arrangement and description in particular, and does not meet the pre-requisites for a successful archives programme.

\section{Skilled staff: succession}

While possessing great energy and enthusiasm, the archivist is of an age where it can be assumed she may not continue in the role for long, and there is no indication that the organisation has considered succession. If transition to a new archivist is similar to last time, skill level may not increase. There is also a risk that knowledge of collections built up may be lost. 


\section{Collaboration}

The Archives has not, in the past, collaborated with other organisations to achieve its goals, but the forthcoming possible collaboration through the combined community/cultural centre has the potential to make it considerably more sustainable by providing better facilities, more support and more visitors. By the same token, it could also put the community archives at greater risk if custody is passed to people who know less about archival practices than the current archivist or if the archives are not seen as publicly appealing enough for the outreach focus of the new centre.

\section{Dynamism}

While the Archives has not, in the past, had the resources to develop and change to meet new needs, the involvement in the community/cultural centre has the potential to position it very differently within the community. There are also risks, however, as the location, leadership, resourcing and modus operandi for the Archives in such a situation are all unspecified. If the project does not go ahead, there is no impetus or capacity within the Archives to change. For instance, there is no preparation for collection of digital records, which could lead to significant gaps in the collective memory of the community in future.

\section{Preservation}

The archival records themselves are at considerable risk from inadequate preservation measures. While some paper collections are relatively wellhoused, appropriate regimes have not been put in place for more fragile media. Underlying pest-management and environmental control issues also put all collections at risk both long-term and short-term.

\section{Archival practices}

There is an awareness, expressed in policies and procedures, that there are unique requirements for the management of archives. It is not clear, however, that all tasks are carried out according to archival standards. Appraisal is very informal, which may put at risk the evidentiality of records, and the lack of computerised finding aids or online access for researchers means collections cannot be used except by those who already know of them. 


\section{Community engagement}

The Archives are relatively passive in their engagement with the community at this point in time. If this continued, it would be likely to impact on sustainability as collections would no longer come in, community support would drop and funders might question the value of their commitment.

Three other factors have been identified which potentially have an impact on sustainabilility.

\section{Character of the archivist}

The archivist has a passion and commitment which results in a significant amount of unpaid time being given to the role. This probably represents a large contribution to keeping the Archives going at this point. As in Hilltown, however, there is an inherent risk in depending on a single individual to this extent, enhanced, in this case, because of the archivist's age and low working hours.

\section{Collections}

The nature of the collections may also favour sustainability. The Archives is responsible for some of the parent-organisation's predecessor-agency archives, which should encourage on-going support as there is a legislative requirement for the local authority to maintain these records. On the other hand, the concentration on indexing and undertaking research on secondary, duplicated sources which are increasingly online may deflect time and effort from essential work on original collections.

\section{External support}

The majority of external support comes in the form of training opportunities, mostly offered through Te Papa National Services, but it is not often possible to take advantage of them because of cost and distance. Archives New Zealand has visited but its free online product to manage collections has not been pursued after a few initial collections were entered onto it some years ago. The conclusion is that national institutional support has had no impact either way on sustainability for the Archives. 


\subsection{Conclusions}

Overall, this Community Archives has over half its indicators negative or tending to detract from sustainability. The Archives may be at a turning point but, at this time, the lack of skilled staff (which impacts on archival practices) and preservation measures ultimately put the collective memory at risk through threats to the archival records and their evidentiality, and because of the lack of accessibility. 


\section{Chapter 6}

\section{Seatown}

\subsection{Introduction}

Initial contact with participants for Seatown was revealing. After an introductory phone call, correspondence was conducted by letter and final arrangements confirmed by further phone calls. The curator did not use email. The reply to an initial request to see any policies or procedures the Archives used when I visited was along the lines of "apologies for misleading you, but we don't do any of that so we're not appropriate for your study". Only after reassurance that I was interested in how things actually are for them, did the curator agree to participate.

Although an interview had been requested only with the curator, I arrived to find that another of the long-term volunteers (the treasurer) was also present. This made the interview more challenging in some respects (one person completing another's sentences, the interviewees talking to each other about things the interviewer did not understand, for instance) but it also had the unintended bonus of providing two points of view and providing a glimpse of some of the personal dynamics in the Society. The transcript of the interview with the curator therefore included comments interpolated by the treasurer. 


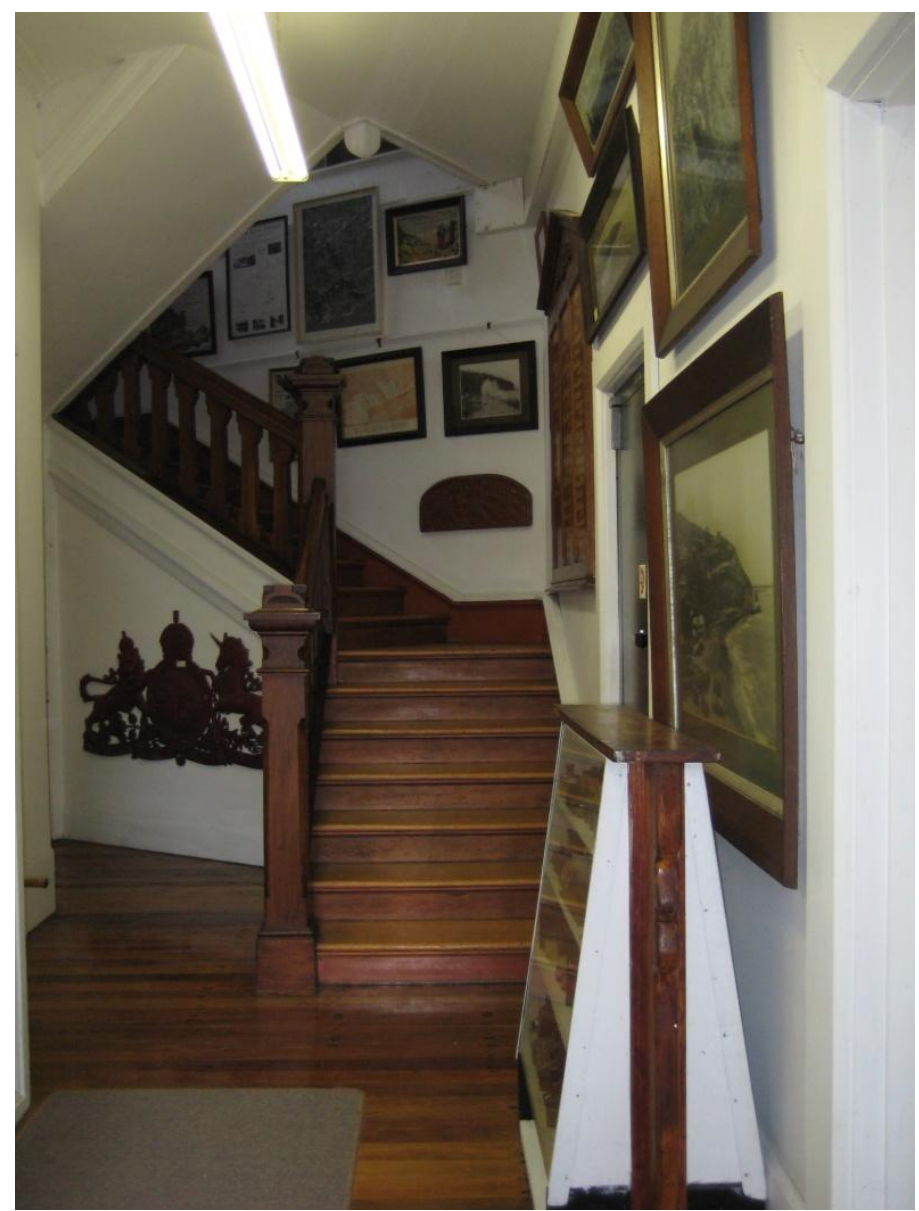

Figure 9: Seatown - entrance and stairs leading to the museum

\subsection{The Archives}

\section{Setting/description}

In the heart of a small seaside village, through the double wood and glass doors of the former council chambers proudly surmounted by the date "1907", are the museum and Archives of this historical society. The building, with its air of grandeur in miniature, is one of the last remnants of the early town, now amalgamated with a larger city. Either side of the wooden staircase are two vaults with massive steel doors, one containing valuable artefacts and the other archives. Upstairs, the museum collections take pride of place, dominating the space and bringing in visitors with their displays. These include everything from artefacts with a strong local connection to others with none at all; 30-40 old lamps, for instance, and a collection of foreign shells donated originally to the library by a local resident. 
The character of the community, currently numbering around 4,000 people, is changing rapidly. Young professionals with four-wheel drives whose children go to school in the city are moving in alongside those who are third or fourth generation residents. And, although the motivations are different, both the newcomers and the old-timers value the ability to get in touch with the history of their community - newcomers are excited to discover the history of the house they've bought which features in an old black and white photograph mounted on the wall, while the long-time residents want to share what makes their suburb unique and the stories of the people who have helped it to be so.

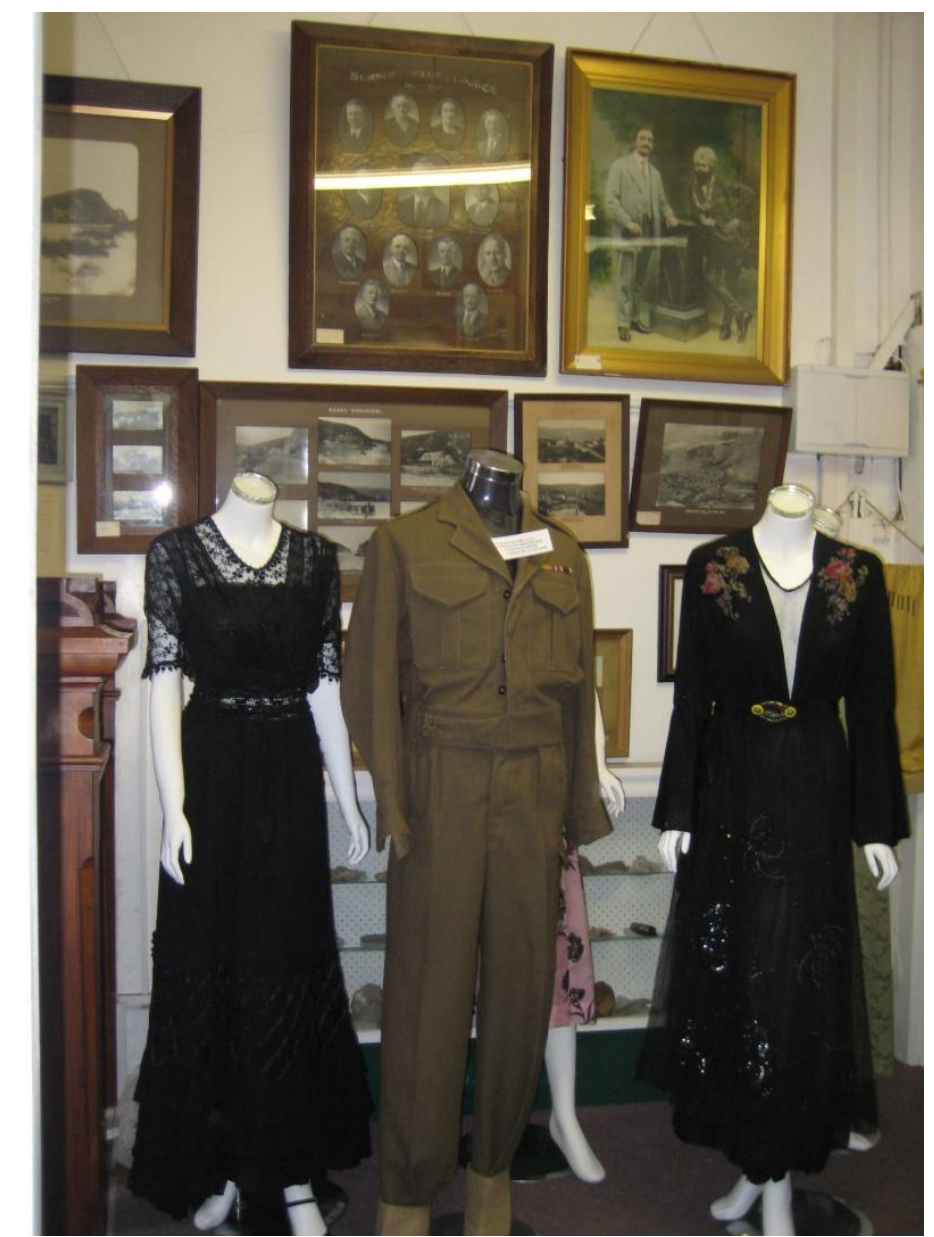

Figure 10: Seatown - costume display on the landing

\section{History}

The historical society was started in 1977 by the current curator, her husband and two other keen volunteers. Its establishment was inspired by a school reunion which left the curator and her husband with medals and books stored under their bed - a worry when they planned to go away for the Christmas 
holidays. The husband, who had worked for the abolished borough council, was now employed by the successor council and knew that the old borough chambers were empty. Back in 1949 he had fortuitously rescued the last load of old council records from the dump. Ordering the workers to take them back and put them in the concrete vault in the council offices, he rushed out to the tip to try and salvage earlier loads. He uncovered the borough seal, but was too late to save other records. In 1977, he had keys to the old chambers and knew those early council records were still in the vault. Soon, arrangements had been made with the community centre next door to lease the building and, as the curator says, it's grown "like topsy".

The Society now has several hundred members, organises events, produces a newsletter, carries out research, spearheads heritage projects in the village and lobbies council on heritage issues. The museum is at the heart of its activities, however, and this incorporates a significant collection of community archives.

\section{Collections}

A major part of the archival collection is still those rescued borough council records. Dating from 1889 to 1945 and including minute books, letter books, town clerk's files and electoral rolls, these have never been handed over to the current local authority for the area, which is required under legislation to maintain them. In addition to these, the Society holds the records of local organisations, both disestablished and extant, many of which have had a significant influence on the shape of the community. There are the records of a surf life saving club, for instance, coming up to its centenary. There are records of lodges, swimming, boating, rowing, golf and bowling clubs, the RSA, businessmen's and residents' associations, and the school, among others. A large collection of photographs of the area has also been gathered, some of which are original.

Secondary sources used for local history research, such as copies of land titles and photographs, newspaper clippings and family history information gathered from obituaries, cemeteries and other sources, command a significant amount of the attention of the Society's members. In the minds of the volunteers, these are 
not really distinguished from the archives and they feel some of their most important holdings are the copies of old land titles, because they are easier to access here than through the government department.

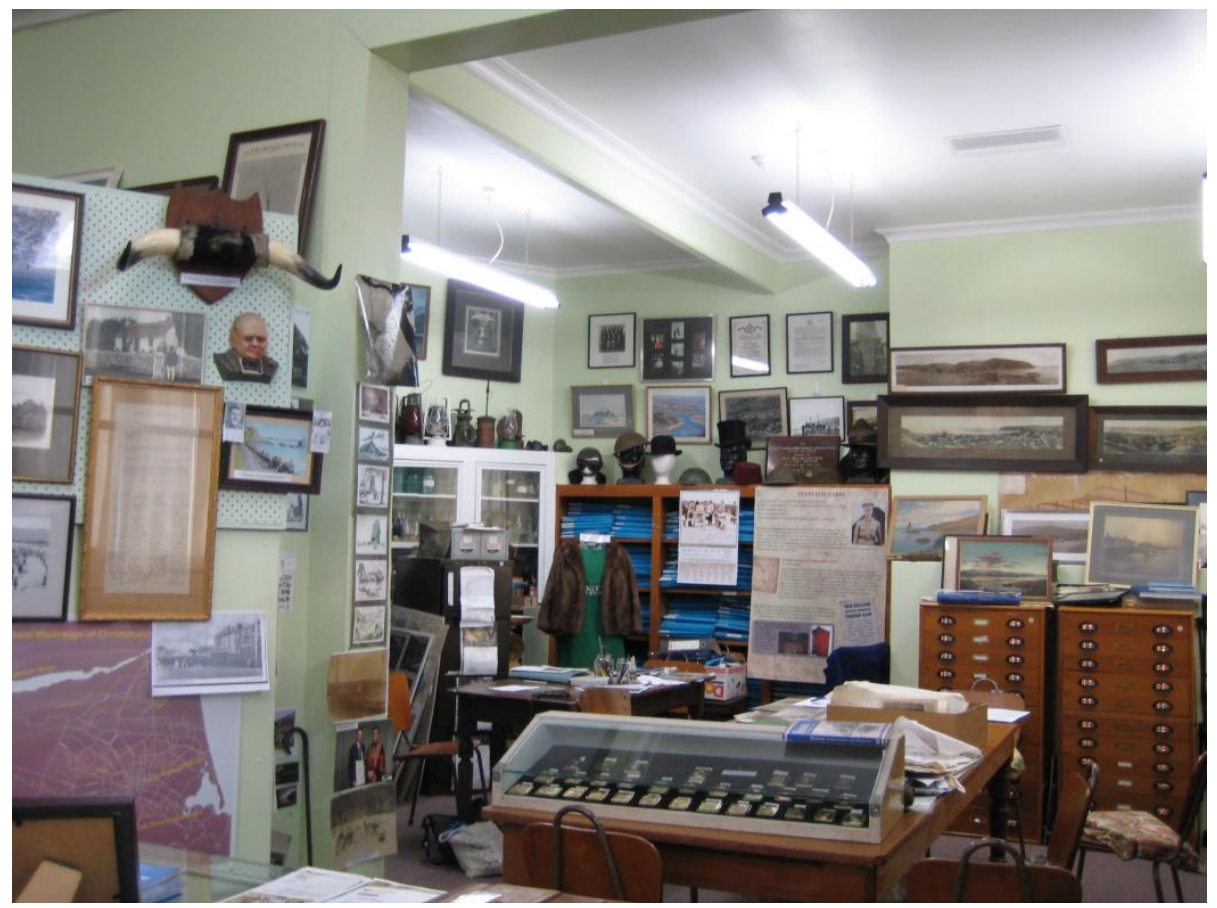

Figure 11: Seatown - museum looking toward the archives/research end of the room

\section{Governance}

The historical society is an incorporated society and registered charity. Its rules follow those of many small incorporated societies, but its aims and objects include one related to collection of archives: "to promote the preservation and safe keeping of records, photographs, artefacts and anything of an historical nature pertaining to the general area." The winding up clause is relatively standard, and as such would not appear to take into consideration the collecting nature of the organisation. It states that, in the event of winding up, "all assets must be realised and payment of all costs, debts and liabilities made first" and "surplus assets which may exist...shall be distributed to similar tax exempt organisations within New Zealand.”

Three volunteers do most of the work at the museum and Archives and two are also the Society's secretary and treasurer. The curator (and secretary), who has been involved since the historical society's inception, also has considerable 
influence over its direction. Members on the committee (which meets three times a year), all play a valuable part but are less involved in management and the work of the organisation.

\section{Funding}

The curator/secretary feels funding levels are quite adequate for their activities. The budget for an average year is about $\$ 5,000$ and the Society had just over $\$ 22,000$ in cash and investments in the bank at the end of its 2009 financial year. Money comes from subscriptions (approximately $\$ 750$ a year), which remain unchanged at $\$ 5.00$ since the day the society was formed, from small donations, occasional grants from pub charities, the community trust and the council. It has very few costs: a peppercorn rent is paid to the council for the lease on the building and, as the work is all voluntary, there are no wages or salaries. There has recently been a noticeable increase in costs, largely because of increased power usage following installation of a heat pump in the museum room, but previously members suffered through winters without any real heating. There is also a significant amount of in-kind support. For instance, when the fire brigade come to do an inspection they always ask if there is anything that needs moving, and offer their labour. Photographic reproductions are sold but that is the only 'sales' revenue and when last recorded in annual accounts (2006) amounted to $\$ 63$.

\section{Skilled staff}

Work on the archives is largely carried out by the curator and the treasurer, who have been there since day one. Others assist from time to time, though, particularly with indexing. Both the curator and the treasurer have had training in museums and archives work, largely preservation and disaster recovery related, although they are a little uncertain about which of the national institutions (Archives New Zealand, National Library or Te Papa) delivered it, as at various times all three have offered workshops. The Society has recently been sent copies of Managing and Preserving Community Archives and Caring for Photographs but when asked if these were useful the response was: "Well, yes, but you see our system is set in place." Workshops and training have sometimes been helpful but are generally viewed in the same light. One 
workshop on displays for instance, which they attended locally, they left at the first possible break: "we knew more than he did...We just thought, god, we could teach you things." In the past, one of the volunteers has attended museum seminars, which sometimes included information about archives, "but we really didn't learn any more from what we're doing." Nowadays, they occasionally call on the nearby Archives New Zealand branch for advice.

The curator and treasurer acknowledge that they're old-fashioned, but really don't see the place for a computer in the museum - either in terms of space or need. There is certainly awareness of aspects of preservation, the need for accessioning and clear donation conditions but two comments possibly indicate the extent of archival knowledge: “...really, archives is indexing in my book" and (in response to a question about whether any training has covered how to decide what to keep or how to organise archives), "the basic thing was, throw nothing out...the basic thing was you had to keep everything." This latter may, of course, reflect the fact that the trainer aimed to convey 'safe' messages to ensure that a little knowledge did not lead to irrevocable actions. As one of the oldest historical societies in the area, however, members do provide advice to others from time to time, suggesting that their practices may be adopted by similar organisations in the region.

\section{Preservation}

As described earlier, the museum and Archives are housed in converted, brick council chambers. The majority of the community's archives are stored in the vault. The former borough council records dating back to 1889 , however, are stored upstairs in a wooden cupboard and on wooden shelves. There is no airconditioning but temperature is less variable now that heating has been installed for the comfort of the workers. A large skylight in the original building has been removed (for security reasons) and the windows are covered by calico curtains. Fluorescent lighting is installed throughout the main museum/archives room. Many original watercolours and photographs are hung around the walls.

Community archives generally remain in the boxes in which they are received, securely taped up. If access is not required, this is how they stay. For instance, 
after a local school reunion, "they handed all the discs and everything they found to us and it's in a box for another 120 years or whatever". The council archives are loose and stacked on shelves, although the town clerk's files have been re-housed in modern (though not archival) file covers. Photographs are stored in drop files in four-drawer cabinets, along with newspaper clippings and other papers. Some are protected by plastic pockets but these do not appear to be archival. Concern to protect certain records is evident in the fact that visitors are not allowed to touch the early, tissue-leaved letter books and that there is no copying of these. To help with preservation, from time to time the society has received recycled archives boxes from larger organisations.

The Society is also running out of room to house its collections and, as long as the policy is to retain everything (whether directly relevant to the community or not), this may have an impact on storage conditions for archives in future.

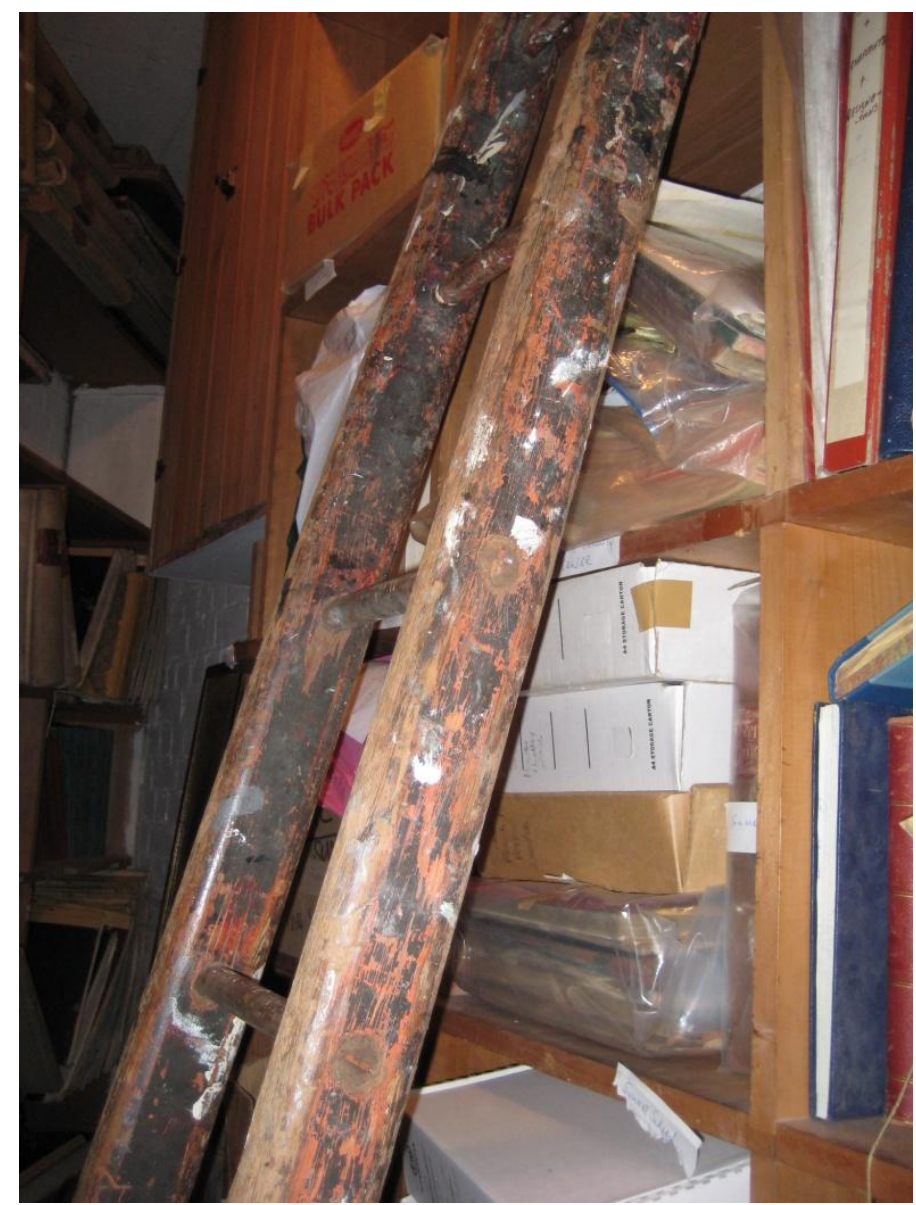

Figure 12: Seatown - records in the vault 


\section{Archival practices}

The historical society has no written policies or procedures for its archival work. Everything received is, however, recorded in "the big black book" and a letter acknowledging receipt is written. The letters are filed at the Archives and the book is kept at the curator's home so they have two records in the event of fire. This practice was suggested back in the early days by an authoritative person in the community who advised that they "couldn't go past that to be simple". There is, however, no formal donation agreement with conditions which would allow the Society to confidently dispose of items it has collected.

Records from organisations are not appraised or arranged and described according to archival principles. Photographs, for instance, are removed from their original context and filed by subject, along with other information, in drop files, although it is generally noted on the back of the photograph where they have come from. It's not clear what happens with some records or information, as a volunteer describes how "We've sometimes sorted out some papers into piles and then she [the curator] has then, in fact, tidied them all away." It appears that the council files may have had documents added to them on the same subject from different sources. Some collections also appear to be divided up into subjects and stored along with other material on the same subject.

There is no computer, finding aids are minimal, and there is total reliance on those who know the collections. Contents of the vault are listed only at organisational level, with general location, although the majority (but not all) of council records are listed by file or book. Brief details of 31 collections were entered on the National Register of Archives and Manuscripts (now The Community Archive) a number of years ago but they are not complete (for instance, only the borough council letter books are recorded, not files) and there have been no updates for some years; the volunteers find it frustrating having to fill in forms, measure collections and keep up with changing systems. The facility is open for research only two hours a week, or by appointment.

Records are held in storage for organisations still in existence and these and other records are readily lent out to those who need them, particularly if they are 
part of the organisation, though "they're not given just to every Mrs Smith or Jones". The writer of the surf club history, for instance, has council files relating to the surf club and surf club records at home in his garage; he'll return them when he's finished the history in 2011. He was not given any particular instructions as to handling or storage of the records because "they belong to them".

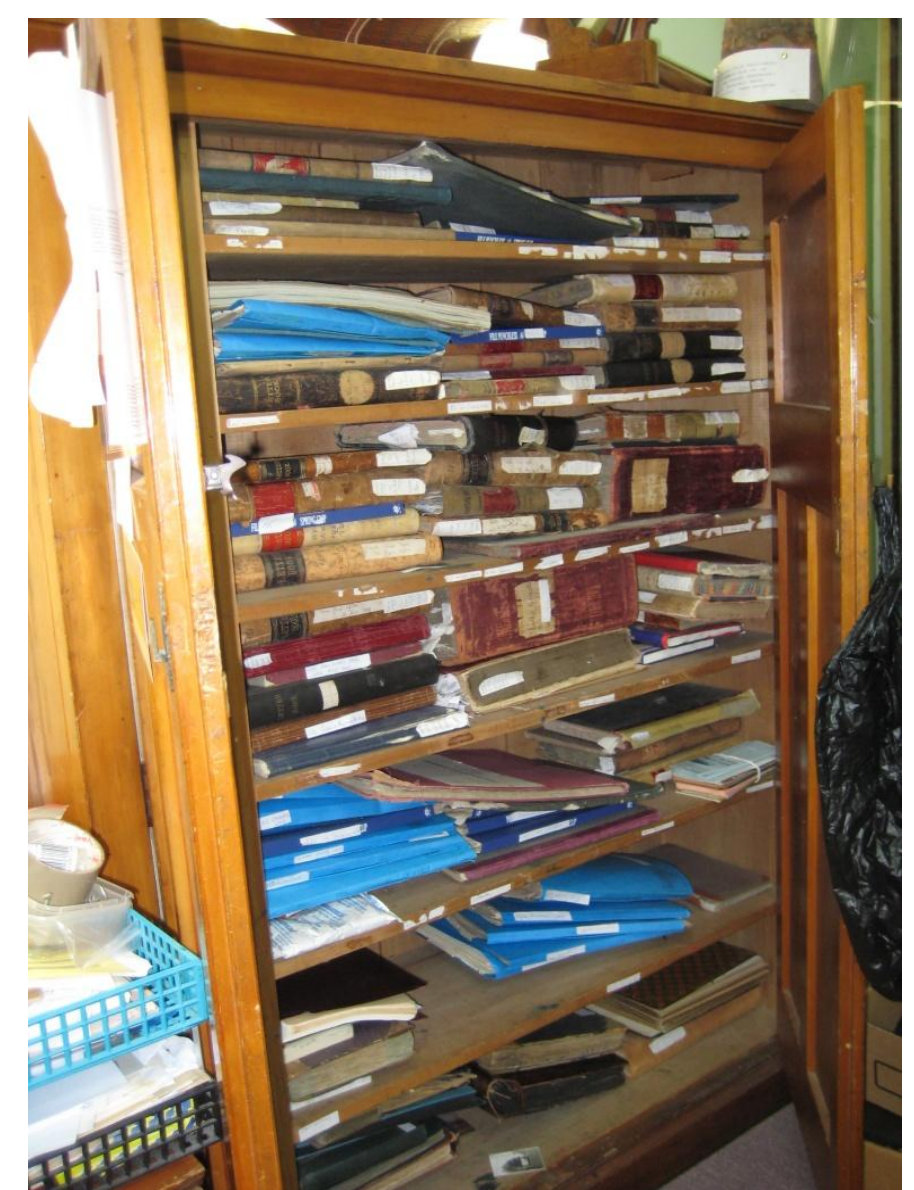

Figure 13: Seatown - early borough council records

\section{Community engagement}

The historical society has a large membership and many of its number are members of one or more other clubs and associations in the village: "all of us know somebody in every group here." This network, linking organisations in the village, means the Society feels that active promotion of its presence or resources is not necessary; all groups know about the Archives because it comes up in conversation, or because sooner or later their activities mean they seek information from it. Collections come in because somebody knows somebody and all clubs know it is a potential home for their records. Mostly, "word just 
gets around". Key members, like the curator, do, however, go out to speak to groups such as Probus, old people's homes and schools, taking along items from the museum like an old gramophone to entertain the audience.

In addition to the key workers in the museum and Archives, other volunteers collect newspaper clippings, index newspapers and build up local family history cards. From outside the Society, individuals such as the members of the fire brigade lend a hand from time to time.

\section{Collaboration}

The Society is very independent and likes it that way. There is particularly no inclination to collaborate with the current local authority, or even to ask for assistance: "We don't want to ask the council - we try to be independent... Because we don't want them interfering in the running of our group, do we?" It is acknowledged that holding the former borough records is a bone of contention with the local authority but, having rescued them, the Society has no intention of handing them over, even though it is aware of legislative requirements. It also has no trust in the council being able to care for archives or find information, as its officers regularly rely on the Society's volunteers to research land information issues. (Given that this service is provided free and is largely done from copies of old land titles, which the Society has collected and paid for over the years, it would appear that the council is receiving a good service.)

\section{Dynamism}

The key people running this museum and Archives are very happy with the way things are. They are confident that they are doing their best and that they way they have set up the operation works, and is therefore right, for them. They feel no need to change the way they operate and any plans are focused on projects such as creating temporary displays and enhancing permanent ones. A computer doesn't seem necessary although they have embraced the new technology available to create and sell digital copies of photographs to the public. These reproductions are made by commercial photographers and stored on discs. 
Although records on electronic media are stored in boxes along with other material from community organisations, the Society has not contemplated the possibility of holding digital archives or the issues around their management.

\section{Other noticeable characteristics/issues}

While there is a committee and a large membership for the Society, both the community stakeholder and the committee members interviewed expressed some concern for the future. The curator/secretary and the treasurer are aware that they are not getting any younger and worry that there is no-one in the wings to take over from them. They endeavour to involve younger people in their activities, but there is a sense that the young are not interested or do not have the time and passion to provide the commitment they themselves have given to the museum and Archives. The Society and users are very dependant on the knowledge of two or three individuals. The archives appear to be valued by the locals but whether this is enough to ensure their preservation within the community in future may become an issue. In the words of the community representative: "I don't think most of them realise how tenuous it is."

The volunteers bring enormous commitment to researching and looking after the collection: "we're very lucky because the people are dedicated". Involvement, in turn, brings great satisfaction and enjoyment.

It is noticeable that the archives are viewed principally as information sources for local history. They do fulfil this role, of course, but seeing them only in this light impacts on their care and handling as records.

\section{Last words}

For those intimately involved with the archives, the people they meet and the excitement of new discoveries are a great reward for their work:

We learn something every week - four generations, five, six generations my family have lived here and, boy, we always learn something... If you don't want to learn, you shouldn't be in this business. 


\subsection{Summary findings}

A summary of the findings for this case study is presented in tabular form below (Table 6), followed by discussion of each factor. 
Table 6: Seatown - summary of characteristics

\begin{tabular}{|c|c|c|c|}
\hline & & & Ranking \\
\hline \multirow{7}{*}{ 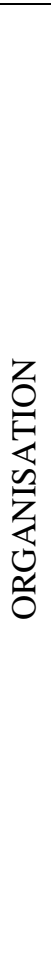 } & $\begin{array}{l}\text { Governance: } \\
\text { Structure }\end{array}$ & $\begin{array}{l}\text { Incorporated society, registered charity } \\
\text { Committee of volunteers } \\
\text { Historical society with a large museum } \\
\text { Society's rules do not well reflect activities/protect collections }\end{array}$ & $\diamond$ \\
\hline & $\begin{array}{l}\text { Governance: } \\
\text { Management }\end{array}$ & $\begin{array}{l}\text { Activities driven by the curator } \\
\text { Majority of work done by } 3 \text { volunteers }\end{array}$ & ك \\
\hline & Funding & $\begin{array}{l}\text { Subscription income supplemented by occasional grants, donations, } \\
\quad \text { small sales } \\
\text { Budget about } \$ 5000 \text { per annum (museum and Archives) } \\
\text { Peppercorn rental to local authority } \\
\text { In-kind assistance from community received }\end{array}$ & 一 \\
\hline & $\begin{array}{l}\text { Skilled staff: } \\
\text { Knowledge etc }\end{array}$ & $\begin{array}{l}\text { No paid staff } \\
\text { No volunteers with formal qualifications, little training } \\
\text { Lack of knowledge and 'don't know what they don't know' } \\
\text { Resistant to training }\end{array}$ & - \\
\hline & $\begin{array}{l}\text { Skilled staff: } \\
\text { Succession }\end{array}$ & $\begin{array}{l}\text { Archivist aged over } 70 \text { years } \\
\text { Young people not joining } \\
\text { Concern about future as volunteers age }\end{array}$ & - \\
\hline & Collaboration & $\begin{array}{l}\text { No collaboration with other organisations to achieve goals } \\
\text { Active resistance to local authority involvement }\end{array}$ & - \\
\hline & Dynamism & $\begin{array}{l}\text { No interest in changing the way they operate } \\
\text { No plans for future direction } \\
\text { No plans to implement new technologies, archival practices etc. } \\
\text { Passive collectors }\end{array}$ & - \\
\hline \multirow{2}{*}{ 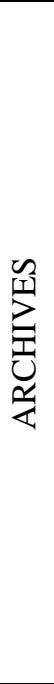 } & Preservation & $\begin{array}{l}\text { No environmental controls } \\
\text { Fragile paper items exposed to fluorescent light, low-level daylight } \\
\text { Boxed items not always inspected before storage } \\
\text { Digital media stored in boxes and not checked } \\
\text { Inadequate storage of fragile early council records } \\
\text { Little use of archival-quality packaging } \\
\text { Storage constraints put collections at risk in future } \\
\text { Unsafe access for retrievals (risk of dropping) } \\
\text { Re-use of cast-off archival packaging }\end{array}$ & 一 \\
\hline & $\begin{array}{l}\text { Archival } \\
\text { practices }\end{array}$ & $\begin{array}{l}\text { No written policies or procedures } \\
\text { Simple accessioning procedures; no formal donation agreement } \\
\text { No appraisal } \\
\text { No arrangement and description according to archival principles } \\
\text { Evidence of arrangement by subject, adding records to files } \\
\text { No computerised finding aids or online access } \\
\text { Archives lent to researchers with no instructions, monitoring } \\
\text { Open } 2 \text { hours a week, or by appointment, for research }\end{array}$ & \\
\hline 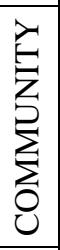 & $\begin{array}{l}\text { Community } \\
\text { engagement }\end{array}$ & $\begin{array}{l}\text { Occasional talks to community groups (particularly museum-related) } \\
\text { Use only by those who know by "word of mouth" \& informal } \\
\quad \text { networking } \\
\text { In-kind assistance from community received } \\
\text { Lobbying and projects for local heritage probably raise profile } \\
\text { Strong sense of ownership to extent of antagonism }\end{array}$ & $\Rightarrow$ \\
\hline \multirow{3}{*}{ 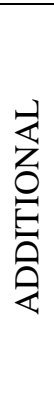 } & Archivist & $\begin{array}{l}\text { Dominant } \\
\text { Personal commitment to role } \\
\text { Passion }\end{array}$ & • \\
\hline & Collections & $\begin{array}{l}\text { Local government records } \\
\text { High number of secondary sources }\end{array}$ & $\Rightarrow$ \\
\hline & $\begin{array}{l}\text { External } \\
\text { support }\end{array}$ & $\begin{array}{l}\text { Resistant to offerings from national institutions } \\
\text { No inclination to use Archives NZ free online database } \\
\text { Antipathy to fulfilling requirements for Archives NZ directory etc } \\
\text { Advice from local Archives NZ branch } \\
\text { Re-use of cast-off archival packaging }\end{array}$ & 0 \\
\hline
\end{tabular}




\section{Governance: structure}

This Archives is run on a completely voluntary basis, with governance provided by the committee of its incorporated society. The content of the Society's rules potentially puts the preservation of the collections at risk, if winding up leads to inappropriate disposal.

\section{Governance: management}

In practice, direction comes from a small number of enthusiastic members and the curator in particular. Such a structure may contribute to making the Archives less sustainable because those with control over the direction of the organisation also tightly control day-to-day activities but do not have the skills and knowledge required for archival management.

\section{Funding}

The organisation has a very small income, derived largely from subscriptions, small sales, donations and occasional grants. It is not sufficient or reliable enough to support skilled, paid staff, or appropriate preservation measures, let alone significant outreach or online activities. This means that the archives, in particular, cannot be adequately maintained over time.

\section{Skilled staff: knowledge etc.}

As noted above, there are no staff knowledgable in the management of archives and there is resistance to learning such skills. This puts the archives physically at risk and threatens their evidential value, meaning that they are not likely to endure over time.

\section{Skilled staff: succession}

The age of the two key players in the Society is significant, as both are over 70 years of age. Members of the society are concerned that new people are not joining and being brought on to take over running the Archives and museum. This constitutes a considerable risk, both to the organisation and to the archives.

\section{Collaboration}

The organisation has no formal collaborative arrangements, which means that it is not able to fill the gaps in staff skills, preservation measures or other areas by utilising the resources or skills of others. 


\section{Dynamism}

While very committed to their mission, the key players do not wish to change the way they do things. Consequently, they are unlikely to reach new audiences, attract young people to take over from them, or be able to manage new archival formats. This puts both the organisation and the archives at risk.

\section{Preservation}

The Archives is lacking many basic preservation measures and practices, putting the archival records at considerable risk. There is also a lack of awareness that this is the case, so the situation is unlikely to change in the near future.

\section{Archival practices}

Work is not carried out according to basic archival principles and very few accepted archival practices are followed. This puts the integrity and preservation of the archives at risk, potentially limiting their evidential and collective memory value in future. Lack of finding aids also means that information about the collections is not readily available to researchers, with the consequence that a fundamental purpose of the archives cannot be met.

\section{Community engagement}

The fact that the organisation is run by volunteers indicates a level of community engagement. The Society has a large membership and there is a degree of awareness of the Archives through informal community networks, which is likely to help sustain the organisation in times of need. There is not the outreach into schools and promotion to new audiences, however, which might cement its place and value in the community long-term.

Three other factors were identified which potentially have an impact on sustainabilility.

\section{Character of the archivist}

The curator has a passion and commitment to her voluntary role but also dominates the work of the historical society. This means that a great deal has been achieved under her driving force, but the risk is that what and how things are done is not easily questioned. Consequently, actions taken with the archives, which may limit their ability to endure as archival records, appear to have been going on for some time. 


\section{Collections}

In a worst-case scenario, the nature of the collections may aid sustainability. The Archives holds the local authority's predecessor agency records, for which the current local authority has legal responsibility. While the latter shows no signs of assuming that responsibility, the requirements of the Public Records Act mean that it is unlikely to be able to ignore any threat of their loss in future.

\section{External support}

The Society appears to have been offered support through Te Papa National Services, Archives New Zealand and the National Preservation Office, although there is confusion over who offered what. Ad hoc advice from the local branch of Archives New Zealand has been appreciated, but members have not been interested in most training or written products. There is even a marked antipathy to attempts to involve them in updating Archives New Zealand products such as The Community Archive or Archives Directory, with this just seen as adding extra work for something they are not interested in. Such institutional support has, therefore, probably neither contributed to nor detracted from sustainability.

\subsection{Conclusions}

For this Community Archives a majority of factors rank as negatively contributing to, or trending towards a negative contribution to, sustainability. It is noticeable that all the factors directly relating to the archival records themselves, and those with the strongest indirect influence on the archives (funding and skilled staff), are negative. 


\section{Chapter 7}

\section{Clifftown}

\subsection{Introduction}

The curator at Clifftown found it a challenge identifying a community stakeholder to participate in the interviews. The person she believed most appropriate (a member of the Society but not a permanent volunteer, involved with many community organisations including one which has donated collections, and a descendant of one of the earliest Europeans to settle in the area) had also been involved in the difficult and sometimes acrimonious negotiations over splitting the records of one organisation (discussed below). She felt that this incident, though resolved, might "colour her attitude". It was only after reassurance that this kind of situation could only serve to shed light on the challenges of Community Archives that this interviewee was confirmed.

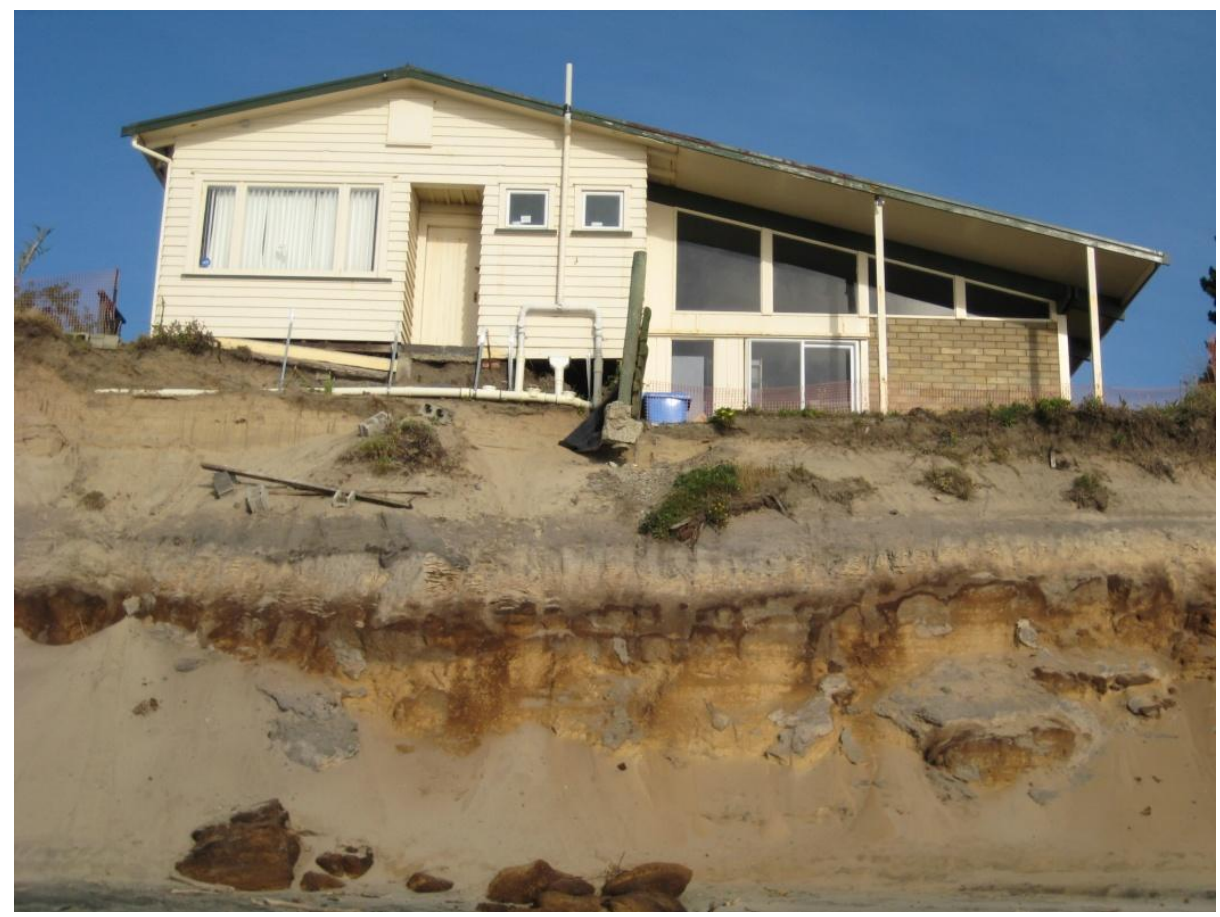

Figure 14: Clifftown premises 


\subsection{The Archives}

\section{Setting/description}

As a graphic metaphor for unsustainability, this Community Archives sits on the edge of a rapidly eroding sand cliff, looking ready to fall into the sea any day. The path, doorstep and service pipes have already gone. Fortunately (in a sense) the majority of the archives themselves have never been stored here because of lack of space, and plans are well under way for purchase and move to a new building.

For now, this historical society museum shares premises with the local I-site. It's in one of the earliest European settlement areas in New Zealand and, in a region where around $70 \%$ of the population is Maori, many families have a strong bicultural background. The area is relatively isolated but on an important tourist route and the historical society is located in one of two little villages which almost merge into each other and have a combined population of fewer than 500 .

Many tourists, including busloads full, stop at the I-site and visit the museum, especially to see videos of one of the historical tourist icons of the area. Its toilets also attract the passersby, who are then enticed to stop and browse in the museum for a moment. Visitor numbers to the historical society are therefore surprisingly large - around 10,000 per annum. The museum itself is small and local in nature, run entirely by a pool of 25 volunteers, but staffed from 9.30 to $4.30 \mathrm{pm}, 364$ days a year. One of its key roles is as an historical information centre.

\section{History}

The Society was originally a branch of a larger historical society, which was started in 1965 by a local historian and grew out of a project seeking the return of an historic building to the area. This branch was set up in 1973 but is now the only one left. From the beginning, it was interested in establishing a museum and local Maori were particularly keen to have a museum in this location. Looking for premises, a perceptive local councillor suggested "you should say 
you want an information centre, because information centres are the in-thing at the moment." Eventually, in 1988, the Society moved into the current building and established and ran the information centre, which was later handed over to the local council. Since then, the shared premises situation has been mostly successful; in return for peppercorn rental, security and visitors, there have been relatively minor drawbacks, such as having to share communication lines (although recently this has meant virtually no access for the Society, with the Isite offering internet access to visitors). Running an information centre did mean being open to the public seven days a week, which required a large pool of volunteers.

\section{Collections}

The collection began with a lot of photographs but, soon, growing numbers of volunteers raised awareness in the community and material began to be donated. Volunteers started bringing items in themselves. There were not many artefacts specific to the area, so the collection naturally tended towards the documentary. The collection doubled, however, when the librarian at a small nearby local library, who had collected a significant quantity of archives from the community, handed them to the historical society. This was motivated by a concern for their future as the library was being "handed over" to the larger council library network. The Society's objects, set out in its rules of incorporation, include statements that it will "collect, record, safeguard and publish information on the history, both social and cultural" and "collect and safeguard records and objects associated with such history."

The Society has collected the files of many small clubs, such as the tennis club, the Poultry Association and Lions Club, school records, small business and family or farm records, church newsletters and, of course, photographs. There are a lot of items, such as books, which it has accepted, aware that they are not really appropriate for the Archives or museum but it has been too difficult to decline offers from the community or make decisions about disposing of them once accepted. The community representative confirmed this challenge by sharing her understanding of what the Society collects: "Anything. Anything old." She gave as an example one of her possessions which will be given to the 
Society when it has new premises, "I've got the old family bible here...I don't want to keep it but I don't want to see it thrown away." There is no space to store collections at present, however, so there is no active soliciting.

The Society has also been building up and documenting family histories dating back to the 1820's, collecting copies and transcriptions of archives which are held in other repositories and gathering information about the area from many secondary sources to use as an information resource.

\section{Governance}

The Community Archives are part of an incorporated society, with over 100 members in many parts of New Zealand. The make-up of the Society's officers and members is bicultural, reflecting the community which surrounds it. The Society has an executive committee of elected officers headed by the Chairman, a local Maori awarded the Queens Service Medal for services to Maori and the community. In addition to the executive committee, there is a management committee of members which concerns itself with operational matters and is led by the curator.

The Society's constitution appears to sufficiently acknowledge its responsibilities and makes provision for collections by specifying that, in the event of winding up, "property must be given or transferred to another organisation that...has purposes similar to that of the organisation being wound up."

\section{Funding}

The Society has accumulated a healthy level of funds, largely as a result of donations and proceeds from the sale of a gifted deceased estate. Its annual operating budget is generally between $\$ 6,000$ and $\$ 14,000$. Membership subscriptions have been kept to $\$ 15$, which covers newsletters and postage, but other annual income for operating purposes comes from sale of publications and souvenirs, trip and activity fees, interest on investments and occasional fundraising efforts such as "big basket socials". Fundraising is difficult, however, in a small community which is not wealthy and where there are many 
competing good causes. Grants are applied for from time to time to fund publication projects and acquisition of such things as equipment, and a large grant was received initially to establish the information centre.

There is no local authority funding, other than the in-kind support currently provided through the shared premises. This benefit will also presumably disappear with the move to new premises and the organisation will be required to cover its operating costs for the first time. In addition, the accumulated funds are expected to be wiped out with purchase of the new building - and this money will only buy a shell; it is unlikely to extend to shelving, air-conditioning or the other requirements of fitting out an archives.

The community representative does not think the Society has enough funding to cover its activities, especially with the impending building costs.

\section{Skilled Staff}

The curator has a background as a librarian, including working in the New Zealand section of a large metropolitan library which has significant archival holdings, and attended some weekend training courses on archives in that role. In the 20 years since retiring and taking on the role as curator, however, there has been no training other than occasional workshops for museums (not specifically tailored for archives) offered by Te Papa. She knows the training has not equipped her to manage archives and is not confident to deal with appraisal decisions or arrangement and description. As a result, the majority of the archives are left relatively untouched. In general, the curator believes there is a lack of appropriate training available but also that no one- or two-day course, of the kind sometimes offered, would be sufficient to equip people to manage paper archives. Furthermore, she comments, thinking about dealing with digital records, "that's another ball game".

None of the other volunteers have had archival training and most are not interested; the majority are over 60 and a number over 80 years of age. 
The curator is also feeling ready to 'retire' now from this retirement project and does have concerns about finding an appropriate person to take the lead from here. The only one she can think of in the area would need to be paid because she is not of retirement age. Payment is impossible, however, unless the Society can find funding for such a position.

\section{Preservation}

Preservation of the archives has been a major concern to the curator for many years. The majority have been stored in a private home and a volunteer's garage, as there is no space in the information centre. The small number of very old records are stored at the centre, well-wrapped in archival tissue and in drawers, and some of the more recent records are relatively well-housed in the private home. Those in the garage, however, are exposed to dirt, insects and animals. No particular preservation measures seem to be in place for such things as oral history recordings on tape. In this high-humidity area, there is no climate control in any of the repositories - and it's unlikely that it will be able to be provided in the new building either. The curator is relieved that at least items will be brought together there in a clean environment and is keen, as a minimum, to provide good shelving appropriate for archives.

The budget for preservation/conservation materials is small - estimated around $\$ 500$ a year (although this could not be confirmed because it is not itemised in annual accounts) - and comes from pub charities grants. The Society has successfully picked up useful cast-offs such as waxed boxes from larger archival repositories, however, and many of the records in storage are kept in these.

\section{Archival practices}

The Society has a simple but clear collection policy and basic procedures are written down for functions such as dealing with donations and accessions, describing items, security management and research requests. Volunteers are trained in application of these procedures. Receipt of items (including copies and secondary sources) is recorded in accession registers. 


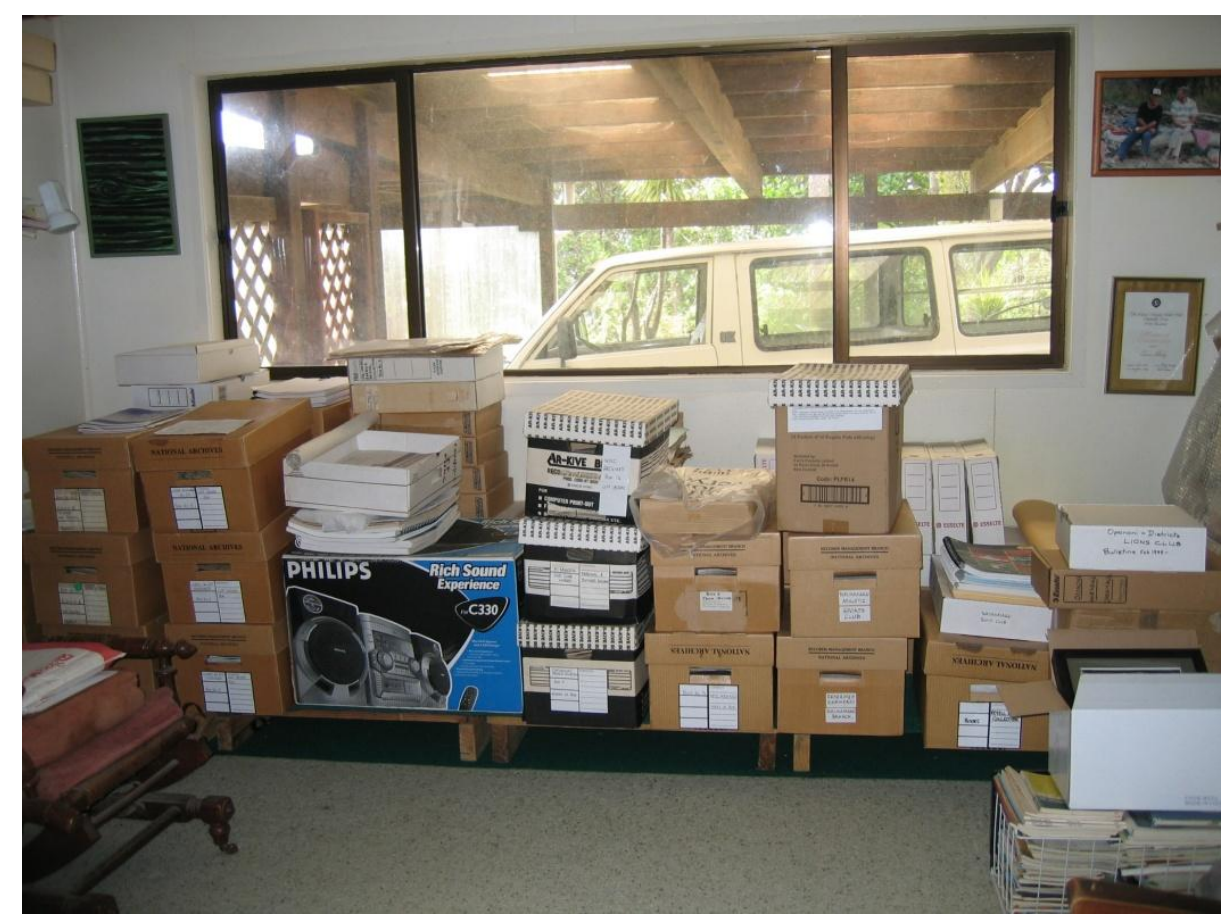

Figure 15: Clifftown - records stored in a private home

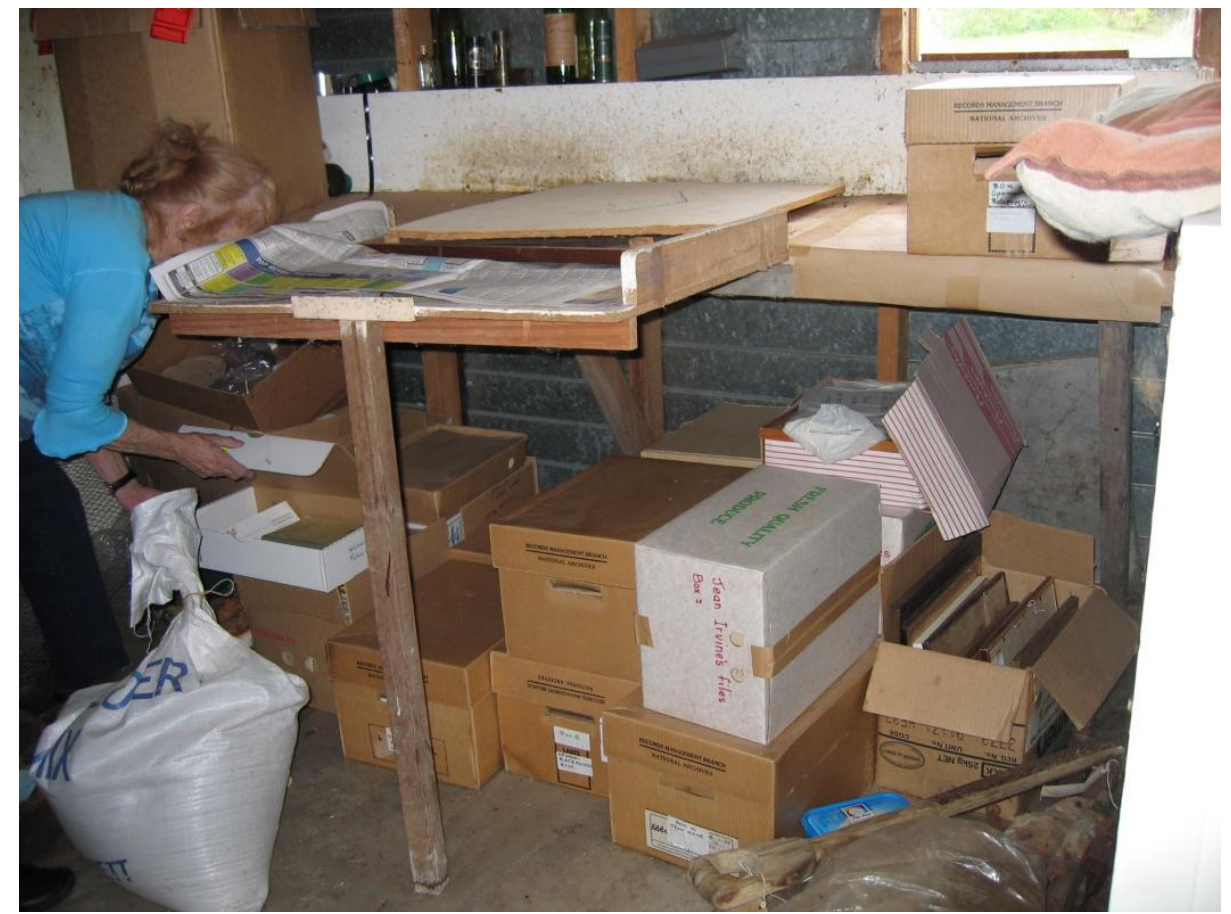

Figure 16: Clifftown - records stored in a garage 
When archives are offered, they are covered by an agreement under which the Society reserves the right to dispose of them if it does not need them, but this rarely takes place for fear of offending people in the small community or because of lack of confidence in making the decisions. Offers of items are seldom turned away, for the same reason.

There is essentially no appraisal or archival arrangement and description. When received, archives are generally described simply and sometimes wrapped in newspaper to keep the silverfish out. Sometimes they might be sorted into categories, for instance the papers of an individual might be sorted according to their business, family and other interests. No particular standards are followed. The curator would very much like to have the collection appraised and properly arranged and described when they move to the new building but is at a loss as to how to achieve this, knowing they do not have the knowledge to undertake such tasks.

There are no finding aids for the archives and locating something in the collection depends on a volunteer remembering that it might exist and looking up the basic lists and descriptive sheets. The Society is aware of The Community Archive provided by Archives New Zealand, but has entered only a single collection item on it, and that some years ago when it was the National Register of Archives and Manuscripts. This is the only item, therefore, discoverable by a wider public. Since the collections are stored away, however, this is generally not an issue because "it's just as though it did not exist, really".

A challenging archival issue has arisen in recent years, however, which illustrates the difficult position a Community Archives might find itself in from time to time. Possession of records from the closed branch of a nationwide organisation was disputed, although its acquisition was quite properly agreed and documented at the time. After continual pressure and threats, the collection was finally broken up and part sent to a museum closer to the individual who has an interest in them. 


\section{Community engagement}

Only about $25 \%$ of the Society's members live in the area but the large pool of regular and 'on call' volunteers, in such a small community, attests to a significant level of engagement. Between them, these volunteers commit at least 49 hours a week, year round, to working at the museum and answering enquiries, sometimes typing up responses to requests at home in the evening on top of that.

There is a sense, however, that awareness of the Archives in the wider community is low and also that the community does not care much about them. Unless there is a significant anniversary coming up, when locals might come and see what the museum holds, most of the interest and enquiries come from outside the area. Attempts to bring it to the attention of the community have included notices in circulars such as the school newsletter and displays at gala days. Teachers bring classes over to visit the museum, too.

On the other hand, because most of the Society's members are members of other local organisations, news of what is happening at the museum does spread informally.

\section{Collaboration}

A major collaboration to date has been with the I-site. Originally, of course, the Society set up and ran the information centre but of more recent years it has provided historical information, videos and a museum which have enriched the visitor experience of the separately managed I-site for many people, and in return received accommodation, services and visitors. The collaboration will cease this year, when both the I-site and the Society move to new premises. The Society explored the possibility of moving to the same new complex as the I-site for many months, but costs were too high and there was not enough space available. It also approached developers of a Maori museum being established nearby to explore the potential for working together, but this was turned down.

In a new collaborative venture, the Society has reached agreement with the local school to site a building on their land and, in return, has offered the possibility 
of work experience to students. The curator visited the Ministry of Education to discuss the proposal and their response was basically "great idea, we're all for community co-operation, and just make sure the school is happy". The other idea is to involve parents in work for the Archives, such as typing oral history transcriptions or catalogue information, while they wait for children to finish school. The Society's chairman (who has also been involved with the local school for many years) has always been keen on promoting more co-operation between the school and the community. It is an untried situation with some risks (such as security) and disadvantages (off the main road with none of the Isite traffic), but there are also advantages - and the Society does not have a lot of options.

The community representative is concerned, however, that separation from the I-site could be a significant loss to both organisations and that the area is too small for them to be separate.

\section{Dynamism}

The Society has been very creative in preparation for the move to a new building. It has worked hard for two or three years exploring options for new premises and been willing to take risks and consider new ways of doing things in order to ensure both the museum and historical society will continue.

On the specifically archival side, however, there is less change and little in the way of future plans other than new shelving and bringing the collection together. The curator would like very much to improve access to archives, though, and, while moving to new premises and bringing them all together would represent a challenge, commented that "at that point we will also start digitising everything."

\section{Other noticeable characteristics/issues}

Most of the volunteers are over 60 and some over 80. Apart from worries about continuing the museum and archives work at a reasonable level, there is concern about simply keeping up the number of volunteers. The community representative is concerned about the future of the Society if the curator and her 
husband stop doing the enormous amount of work that they do for it - "they've put everything into it". In her view, the curator is "fantastic" and suggested that she gives so much time to the Society that it has become "her life".

The community representative summed up the value to her in working with the historical society in the following words: "You meet up with all sorts of people world-wide, and that. And, actually, it does broaden your outlook on life."

Retaining the archives close to the community is of great importance to the Society. This is exemplified by the unwillingness to see the records of the local branch of an organisation be removed to another repository more than two hour's travel away.

\section{Last words}

The role of the historical society, and its value to the community, was described by the community stakeholder in these words - it is, and should be, she said:

Where people can come and look up all their past history - you know, family stuff, everything else. And I think it's great that there is somewhere where that stuff can be stored and you know that it's safe and it's there for people...you can go along and investigate for yourself without bothering anybody else. And the thing is, too, I feel that once you get there and start going through records, you forget where you are and forget to go home.

\subsection{Summary findings}

A summary of the findings for this case study is presented in tabular form below (Table 7), followed by discussion of each factor. 
Table 7: Clifftown - summary of characteristics

\begin{tabular}{|c|c|c|c|}
\hline & & & Ranking \\
\hline \multirow{7}{*}{ 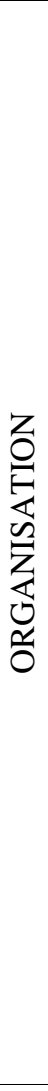 } & $\begin{array}{l}\text { Governance: } \\
\text { Structure }\end{array}$ & $\begin{array}{l}\text { Incorporated society, registered charity } \\
\text { Committee of volunteers } \\
\text { Historical society with a very small museum }\end{array}$ & $\Rightarrow$ \\
\hline & $\begin{array}{l}\text { Governance: } \\
\text { Management }\end{array}$ & $\begin{array}{l}\text { Activities driven by the curator } \\
\text { Executive committee for overall direction etc. } \\
\text { Management committee for operational matters, led by the curator }\end{array}$ & $\Rightarrow$ \\
\hline & Funding & $\begin{array}{l}\text { Operating budget } \$ 6,000-\$ 14,000 \text { per annum } \\
\text { Subscription income supplemented by sales, activity fees, fundraising } \\
\text { Peppercorn rental to local authority } \\
\text { Large projects/equipment funded from external grants } \\
\text { Significant costs looming with purchase of premises, loss of free } \\
\text { services }\end{array}$ & - \\
\hline & $\begin{array}{l}\text { Skilled staff: } \\
\text { Knowledge etc }\end{array}$ & $\begin{array}{l}\text { No paid staff } \\
\text { Curator with librarianship background but minimal archival training } \\
\text { Other volunteers have no training; most not interested }\end{array}$ & - \\
\hline & $\begin{array}{l}\text { Skilled staff: } \\
\text { Succession }\end{array}$ & $\begin{array}{l}\text { Archivist aged over } 70 \text { years } \\
\text { Dependence on knowledge and memory of curator } \\
\text { Serious concerns about future if the curator retires }\end{array}$ & - \\
\hline & Collaboration & $\begin{array}{l}\text { Major collaboration with the I-site to date } \\
\text { Has worked hard to form collaborations } \\
\text { New collaboration being planned with school } \\
\text { Link between Chairman's involvement with school \& Society's } \\
\text { activities }\end{array}$ & $\Rightarrow$ \\
\hline & Dynamism & $\begin{array}{l}\text { Creative and proactive in exploring options for new premises } \\
\text { Open to new ways of operating to make collaboration work } \\
\text { Passive collectors } \\
\text { No plans to implement new technologies, archival practices etc. }\end{array}$ & $\diamond$ \\
\hline \multirow{2}{*}{ 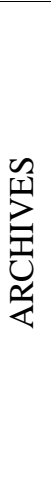 } & Preservation & $\begin{array}{l}\text { Preservation budget of around } \$ 500 \\
\text { No environmental controls in high-humidity climate } \\
\text { Very inadequate storage for the majority of archives } \\
\text { Re-use of cast-off archival packaging } \\
\text { Small number of very early archives well-packaged } \\
\text { Plans for significant improvement }\end{array}$ & - \\
\hline & $\begin{array}{l}\text { Archival } \\
\text { practices }\end{array}$ & $\begin{array}{l}\text { Clear and simple policies and procedures } \\
\text { Donation agreements signed } \\
\text { No appraisal } \\
\text { No arrangement and description according to archival principles } \\
\text { No computerised finding aids or online access } \\
\text { Breaking up of collections of a single provenance }\end{array}$ & - \\
\hline 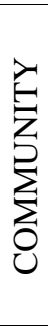 & $\begin{array}{l}\text { Community } \\
\text { engagement }\end{array}$ & $\begin{array}{l}\text { Very significant volunteer commitment } \\
\text { Low level of awareness outside this membership } \\
\text { Promotion largely by word of mouth, with occasional displays at gala } \\
\quad \text { days } \\
\text { School classes encouraged to visit } \\
\text { Link between Chairman's involvement with school \& Society's } \\
\text { activities } \\
\text { Belief that community has a right to have records relating to it nearby }\end{array}$ & • \\
\hline \multirow{3}{*}{ 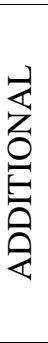 } & Archivist & $\begin{array}{l}\text { Commits an enormous amount of energy and time } \\
\text { Personal commitment to role } \\
\text { Passion }\end{array}$ & $\Rightarrow$ \\
\hline & Collections & Emphasis on secondary sources & 一 \\
\hline & $\begin{array}{l}\text { External } \\
\text { support }\end{array}$ & $\begin{array}{l}\text { Occasional museum-related training from Te Papa, but not readily } \\
\quad \text { accessible } \\
\text { No inclination to use Archives NZ free online database } \\
\text { Re-use of cast-off archival packaging }\end{array}$ & 0 \\
\hline
\end{tabular}


Governance: structure

This Archives is part of an incorporated society run on a completely voluntary basis, with governance provided by an executive committee. Relatively unusually for a small incorporated society, there is a separate management committee which concerns itself with operational matters. This structure allows influential locals on the executive committee to make an important contribution without feeling obligated to commit a great deal of time and, in this way, probably strengthens the Society and contributes to sustainability.

\section{Governance: management}

Day-to-day management is overseen by the management committee, with strong leadership provided by the curator. The museum and Archives are run by a large pool of regular volunteers.

\section{Funding}

The organisation has a small income, derived largely from subscriptions, small sales, donations and occasional grants. It is not, therefore, sufficient or reliable enough to support skilled, paid staff or appropriate preservation measures, let alone significant outreach or online activities. The Society has been spared rental and services costs to date, but this is likely to change once it moves to new premises. The cost of acquiring the premises will also use all its reserves, putting it in a more vulnerable position financially and negatively impacting on sustainability.

\section{Skilled staff: knowledge, etc}

The organisation is entirely run by volunteers with no formal archives training or skills. Training is difficult to obtain in such a remote location but, being older, most volunteers are not interested in it anyway. The curator is conscious, however, that she lacks the knowledge to properly manage archives. This has resulted in the archives largely being ignored and remaining inaccessible, which threatens their long-term preservation and means they are unable to fulfil their role in collective memory.

\section{Skilled staff: succession}

The curator is over 70 years of age and ready to step down. There is considerable concern, on the part of both the curator and the community stakeholder, about who would follow her (and her husband) in leading the work 
of the Society. This constitutes a considerable risk, both to the organisation and to the archives.

\section{Collaboration}

The historical society has worked hard to collaborate with other organisations to achieve its goals. This work has been very much about ensuring its survival, rather than aimed at developing new services or programmes. It has consumed a huge amount of the time and energy of the volunteers, possibly at the expense of collection-related activities, but there is no doubt that it has contributed to the organisation's survival.

\section{Dynamism}

A small number of members have shown considerable creativity and dynamism in seeking out collaborative opportunities and new ways to operate the Society as a whole. The same level of dynamism has generally not applied to the collection, however, which (largely because of lack of confidence and time) remains inaccessible and not added to. A desire to consider digitisation was expressed, but clearly without much conception or investigation into what is involved in such an exercise. While dynamism has contributed to the sustainability of the organisation, therefore, it has not yet contributed to sustainability of the archival collections.

\section{Preservation}

The Archives lack many basic preservation measures and practices, putting records at considerable risk. There is an awareness of how inadequate the situation is, but lack of resources means the issues are unlikely to be properly addressed in the near future.

\section{Archival practices}

A brief collection policy exists and simple but effective procedures are in place for such things as accessions, donations and reference, but no appraisal or arrangement and description of archives according to archival principles is carried out. This impacts on the long-term evidentiality of the records and their value to collective memory. Some practices, such as splitting records from the same provenance, are not archivally sound. There are also no finding aids (computerised or hard copy) or online access to researchers, meaning considerable reliance on the knowledge of some individuals. 


\section{Community engagement}

For a small community, the number of volunteers and the time each commits indicates a relatively high level of engagement. For many, however, involvement appears to be considered more as a social activity, albeit one with a useful purpose. Outside these few, there is not a great appreciation of the value of the archives and this lack of a broad support group potentially puts the organisation and collections at risk.

Three other factors have been identified which potentially have an impact on sustainabilility.

\section{Character of the archivist}

The curator has a great dedication to her voluntary role and leads the work of the Society in a sensitive and enthusiastic manner. She has brought knowledge and understanding from a related role (librarianship) and is aware of what she does not know, while at the same time bringing significant skills to the Society. This seems to be a significant factor in keeping the Society going at this point but, as with other Community Archives, carries an inherent risk should her involvement cease.

\section{Collections}

The Society's activities are focused on gathering, compiling and sharing information about the area, and members work mostly with secondary sources. As a consequence, the archives are not the primary interest and are neglected. This affects their physical preservation and renders them inaccessible (negating the reason for collecting them) although it does, at least, mean little has been done to threaten their integrity as records and therefore their future value as archival evidence. Overall, however, this neglect has a negative impact on the preservation of the archives and their ability to fulfil their function as collective memory.

\section{External support}

Again, training opportunities are offered through Te Papa National Services but it is not often possible to take advantage of them because of cost and distance. There is an awareness, too, that short courses are not sufficient preparation for working with archives. Only one collection item has been entered into Archives 
New Zealand's free online product to manage collections. As with several of the other Community Archives studied, the cast-off archives storage boxes could, in some very small way, have contributed to the preservation of the archives but, given other factors, this is not seen as significant.

\subsection{Conclusions}

This Society has a majority of factors detracting from sustainability or trending that way, with the key ones being lack of preservation, archival practices, skilled staff and funding. Given that the primary function of a Community Archives is to preserve and make accessible the archives, it would appear to be not sustainable as a Community Archives in the way it currently operates. 


\section{Chapter 8}

\section{Cross-case analysis and findings}

\subsection{Introduction}

The individual case studies in the previous chapters have shown that a number of factors relating to maintenance and sustainability within an organisation impact on others, and that characteristics within factors may relate to more than one factor.

This chapter compares the same factors across the cases, analyses the similarities and differences between organisations and suggests possible explanations for some of the findings.

\subsection{Similarities and differences}

\subsubsection{Governance}

The four Community Archives studied are characterised by fundamental differences in organisation structure, legal constitution and governance. The defining characteristics are:

\begin{tabular}{|l|l|l|}
\hline & Governance/structure & Staffing \\
\hline Hilltown & $\begin{array}{l}\text { Council function } \\
\text { Total local-authority control }\end{array}$ & 2.5 FTE paid \\
\hline Plainstown & $\begin{array}{l}\text { Section within museum trust } \\
\text { Council Organisation; arms-length control }\end{array}$ & 0.27 FTE paid \\
\hline Seatown & $\begin{array}{l}\text { Incorporated Society } \\
\text { Committee }\end{array}$ & $100 \%$ voluntary \\
\hline Clifftown & $\begin{array}{l}\text { Incorporated Society } \\
\text { Executive and management committees }\end{array}$ & $100 \%$ voluntary \\
\hline
\end{tabular}


Two of the Archives, therefore, are council-controlled with paid staff and two are voluntary with no paid staff.

The voluntary organisations are similar in that they both have committees in place for governance purposes but the activities of the organisation are driven very much by the curators or, at most, by two individuals. This characteristic could be significant when considering how to enhance the sustainability of community archives.

The fact that the local-authority controlled Archives both have paid staff, though at different levels, is also significant. There is likely to be a correlation between local-authority control and higher, relatively-assured funding because of the inherently more-enduring organisational structure, legislative requirements to maintain their own archives, public accountability responsibilities and publicity given to their activities and decisions. Of the two organisations with paid staff, it would appear that the one with more funding and more staff (Hilltown) allows the archivist to act effectively as manager of the Archives and to be more 'selfmanaging'. This may be because of increased skills and/or greater ability to achieve as a result of more resources. In both these organisations it is also clear, however, that, while the archivist may have responsibility for day-to-day decisions, big decisions (whether about the future or project expenditure) are made outside the Archives and do not necessarily involve the archivist. This could relate to perceived lack of skills or knowledge on the part of the archivist, or lack of status.

One of the four case studies has a unique governance characteristic which, while it may not be the sole contributor to its enhanced likelihood of being sustainable, may have a strong influence. This is Hilltown, which has an influential external 'friends' group drawn from the community, without whose agreement the policy of the archives cannot be changed. This body plays a key support role in current activities and could wield significant power in the event of a threat to the Archives. 


\subsubsection{Funding}

Budgets vary greatly but, again, the biggest difference is between the voluntary organisations and those which are part of a larger organisation. The latter have a degree of certainty about funding and are able to pay employees. Although the difference between the two is considerable, with staff hours ranging from 0.27 to 2.5 FTE, the existence of paid staff within a formal organisation contributes to a level of accountability for work and some continuity for the function.

Both the voluntary organisations currently receive indirect assistance from the local authority, through provision of premises at a peppercorn rental, but are otherwise dependent on subscriptions and varied - as well as variable - sources of income. The resulting uncertainty means that staff cannot be hired. The low level of the funding results in poor facilities and other preservation measures, lack of training and lack of archival tools. The importance of free premises to the sustainability of these organisations is evident.

For all, however, large projects or capital expenditure are funded from external sources, whether grants from funding agencies or donations. Items mentioned by interviewees as being paid for from such sources included everything from purchase of a photocopier or shelving to publications and digitisation projects. There are possibly two reasons for this: these things are considered outside the core business, or 'nice-to-haves', by management, and/or they are clearly identifiable items which meet the criteria of funding agencies.

The level of funding in all cases also appears to have a relationship to the archives' profile within the community, whether this is for Hilltown within the council structure, or for the voluntary organisations dependent on subscriptions, fundraising, donations, activity fees and in-kind support.

Funding clearly impacts on the numbers and skills of staff, archival tools and practices, preservation, and even on the level of dynamism and community engagement. It is therefore a key factor in the sustainability of Community 
Archives and understanding the factors which influence funding levels is essential.

\subsubsection{Skilled staff}

The biggest difference is, again, between the voluntary organisations and those supported by larger organisations. The latter have paid staff.

Common to all the Archives is the fact that none of the individuals responsible for the archives has formal qualifications and there are no continuing education programmes in place for them. The archivist within the larger organisation with a number of staff, however, has had good training through courses and mentoring.

By contrast, workers in the voluntary organisations have little or no training. This is sometimes because it is not available or affordable, but it is also noticeable that most are not interested in undertaking it. In the two cases studied, this may be attributed to the age of the volunteers but also, in one case, because they believe, erroneously, that they know all they need to know to do their job well.

Although the archivists do not necessarily have archival training, there is a great deal of collection knowledge held by them. This is valuable knowledge but, in many cases, is not captured into an easily accessible 'corporate memory', such as a database. Consequently, in most cases there is considerable dependence on the knowledge of one or two people in all the organisations. Furthermore, planning for their replacement (or capture of their knowledge) is not a priority.

The age of archivists is noteworthy. Only the archivist paid by a large organisation (which presumably sees the Archives as a key function and is able to meet salary expectations of younger employees) is under the age of 60 years. The part-time archivist within the museum is over the age of 60 and the 'archivists' in the two voluntary organisations are over the age of 70 (as are many of the volunteers). In addition to the concern about succession and knowledge transfer, this age characteristic may have an impact on the desire to 
learn about archives and to proactively keep up with professional developments or plan for collection development.

The impact of this lack of skilled and knowledgeable staff on the way the archives are managed - and particularly on the core archival functions of appraisal and arrangement and description - is profound. This is discussed further under Archival Practices. It is possible that lack of skilled and knowledgeable staff also impacts on funding, as suggested under Governance above.

\subsubsection{Collaboration}

Only two of the Archives have seen collaboration as a strategy to achieve their goals: the most well-funded archives within a council structure (Hilltown) and one of the voluntary organisations (Clifftown). In the first case, this collaboration originates from the grass-roots origins of the archives and community interest in heritage and has continued because of community engagement and mutual benefit. For the voluntary society, the collaboration is more directly about survival and, specifically, obtaining premises from which to operate. In both cases, however, there is considerable energy and time put in to organise or foster the collaboration. Both collaborations may be in large part related to the passion, commitment and dynamism of the archivists.

A third Archives (Plainstown) is part of a museum trust exploring the possibility of a very significant collaboration, which could radically change its operations and future direction. The collaboration is not between the Archives and other organisations, however, so the outcome for the Archives will depend on how they are seen by the larger partners in the collaboration. It could greatly enhance its ability to collect, care for and make accessible community archives or it could fundamentally threaten them.

It is noticeable that none of the Community Archives studied has collaborated with other repositories, as recommended by writers such as Dearstyne and New York State Archives, and that any collaboration has been with an unrelated, nonarchival organisation and a 'friends' group. This may be partly explained by the 
geographical location of some, but the research also indicates that a desire for independence is a significant influence.

\subsubsection{Dynamism}

All the Community Archives studied are now passive collectors; there is no surveying of the community, strategy for collecting, macroappraisal or proactive contact with local organisations. In addition, only the two which are part of larger organisations have been pro-active collectors in the past. Consequently, most of the archives hold records only from those who choose to donate to them and there is unlikely to be any advice to community organisations on what should be retained as archives. In addition, none of the Archives is preparing for a future which involves collecting digital archives. All these factors are likely to cause significant gaps in their collections' representation of the community's memory and to impact on their relevance to that community.

Only Clifftown is formally planning for the future, showing creativity and willingness to make significant changes to the way it operates to ensure its survival. Planning is focused on securing premises, however, to the neglect of archival activities. Formal planning for the future does not appear to be expected of the Archives by their parent organisations.

In spite of this, Hilltown and Clifftown do display a considerable degree of dynamism. Hilltown actively explores new methods of outreach and experiments with new technologies to do so. There is evidence, however, that such dynamism may be partly attributable to the particular character of the archivists concerned.

\subsubsection{Community Engagement}

All the Archives studied have in common committed volunteers involved with their operations, including those which are part of a staffed, local-authority structure. Although the $100 \%$-voluntary organisations do not always feel that there is sufficient awareness of their work outside their organisation, or are 
concerned that there are not enough new, young members becoming involved, the fact that they run totally on volunteer help is significant. Community engagement for these organisations is generally focused, and evident, through membership of their own society rather than significant outreach programmes to engage the wider community. To a certain extent, they appear to operate more as clubs, satisfying the social and personal interests of many of their members rather than being focused on collection, preservation and use of archives, and promotion of this work to the wider community.

Apart from that, engagement with the community varies, with only one Archives (Hilltown) having a deliberate strategy to actively engage, be relevant and focus on use of the archives by the community. This is also, of course, the only case where archives management is a dedicated council function, with staffing and funding, and where there is an active collaborative partnership with a 'friends' group.

For all, family history is an important part of their research and information services but, while there are connections with local genealogists, this service is often only partly based on the archives.

All case study participants had a strong belief that the community's archives should remain close to it and that the community would not allow them to be taken away. While this could be seen as simply a reflection of the commitment to their work by the individuals interviewed, in some cases their networks would probably ensure wider community support, should it be tested.

\subsubsection{Preservation}

Only one of the Community Archives studied has archives stored under conditions which meet the Archives New Zealand Storage Standard. This is Hilltown, which is under full local-authority control (and therefore has a legislative requirement to meet the standard) and is also well-funded. This organisation also considers it has an adequate budget for preservation. All the others have some or all collections stored in areas without climate control, at considerable risk of damage or deterioration. Digital, audio and video media are 
noticeably ignored and particularly at risk. While one of the archives with collections at high risk of deterioration has plans for significant improvement, funding is uncertain so this may or may not eventuate. These organisations all have no, or very minimal budget, for preservation activities. There appears to be a direct correlation between the quality of preservation and funding levels, further influenced by the nature of the collections and related legislative requirements for collection storage.

Three out of the four Community Archives have taken advantage of 'cast-off' materials for storage - principally boxes - from larger organisations. These may not be the best packaging for archives, as they have been rejected by those organisations, but they are nevertheless superior to what could be afforded by the Community Archives.

\subsubsection{Archival practices}

In the two voluntary organisations, no appraisal or arrangement and description according to archival principles takes place. For the other two archives, with a small number of paid staff, appraisal takes place but is informal. Documentation on appraisal is not retained, however, so the basis for decisionmaking is not known.

Three of the Archives have simple collection policies but none appear to review them regularly. One of the voluntary Archives (Seatown) has no collection policy and only the barest of statements about what it will collect included its Rules of Incorporation. Only Hilltown, in council control, also has reference and acquisition policies, although others have procedures covering these activities. Procedures vary from none to reasonable and the two case studies which have good procedures suggest that they are only developed where there is a need to communicate consistent practices - for instance, where there are large numbers of volunteers and where archival responsibilities were relatively recently handed on to a new individual with little knowledge of the function.

The two voluntary Archives have practices (past or current) which directly put the evidential value of archives at risk. These include lending out archives for 
years at a time to researchers to use; arranging records or documents by subject; adding information to files; and breaking up archives from a single provenance.

The two Archives with paid staff have good collection documentation and reasonable access to collections, however, although finding aids are manual for one. Only the fully council-controlled Archives has collections documented in a database and online access for users. The two voluntary Archives have very few finding aids and access to collections (or even knowing what is held) is only possible through the one or two knowledgeable people.

The fact that the two voluntary organisations are so lacking in sound archival practices in comparison with the council-controlled organizations, suggests that the existence of sound archival practices is strongly influenced by funding and the skills and knowledge of paid staff.

\subsubsection{Archivist}

One thing all the Archives studied have in common is that the archivist has an enormous personal commitment to the role and a passion for the work. It would not be going too far to say that, in the case of the $100 \%$ voluntary organisations, this is what keeps them going, and they are not unaware of the risks associated with the situation. Even in the two Community Archives where there are paid employees, however, the archivists still commit a significant amount of their own time to making collections more available to users or to promoting their archives to the community.

This implies that, even where there are paid staff, the performance or success of the Archives and the quality of service provided relies a great deal on personal commitment and unpaid work. It suggests that the parent organisations may not truly value the work of the archivist, even to the extent of taking advantage of a vocational commitment to the role. The archivists could also be partly at fault for allowing their organisations to believe that all that is being delivered could be done within paid hours. The fact that, while appreciated, none of the archivists has professional qualifications, possibly leads to both sides placing a lower valuation on time and skills. 


\subsubsection{Collections}

Three of the Community Archives hold a high number of secondary sources, which also consume a significant amount of the archivists' attention, either through compiling and indexing them or using them as sources for research enquiries. Only the council-controlled Archives with a full-time archivist would appear to have a clear focus on managing archives, with secondary sources held primarily as a value-added service to users.

Three out of the four hold local-authority archival records, even though two are not officially local-authority Archives. This is significant, as local authorities have a legislative requirement to maintain their archives to certain standards, which two of these Archives clearly cannot meet. The local authorities would appear to be abdicating their responsibilities, although historical (and possibly even personality) issues could present challenges to finding a solution. One Archives also holds government records, which are covered by the Public Records Act 2005, and the Archives is not an 'approved' repository under the Act.

All the Community Archives studied are opposed to losing control over any archives relating to their community, even if they should be in the care of Archives New Zealand or the relevant local authority. There is an unspoken tension in this situation and the need for a solution is urgent in a scenario such as that of Seatown, where local authority archives are at risk of loss or damage.

\subsubsection{External Support}

Three of the Community Archives studied are aligned more with museum national-support structures than with archival ones, although this is as much determined by the organisations' self-identification as the significance of their collections. For instance, the two historical societies both receive the majority of their training offerings from national museum organisations, even though for Clifftown the archives are probably more significant culturally than its object collections. Because they have received the majority of their support from the national-museum infrastructure, none have received specific archives training, although they have received training in such things as preservation/conservation 
and exhibitions. For all three, however, accessing any support is difficult for cost and location reasons.

The archivist at Hilltown has notably accessed external support in the form of mentoring and guidance from other professional archivists. It is possible that this is as much a consequence of working full-time and being better supported by the organisation (and therefore more engaged with the archival community), as it is of the individual's particular commitment.

All the archivists are aware of Archives New Zealand's free, online database as a potential tool for cataloguing and making their collection known and accessible. Three, however, have not used it since long before the database was taken over and redeveloped by Archives New Zealand. The one who does use it, regards it as an additional promotional tool only (because it is difficult to use and the Archives has its own database). The three who do not use it appear to regard it as an added difficulty rather than a potentially useful tool. The implication is either that this type of support is not required or desired, or that it is not delivered in a way which makes it accessible to most community archives.

Wherever they are in the country, three out of four of the Archives have benefited from cast-off archival packaging materials from larger institutions. Overall, however, the impression gained from the four case studies is that the efforts by national agencies to provide support to community archives is 'token' and not addressing the real needs - either those felt by the participants or those which would be seen by professional archivists as needed to ensure the adequate maintenance of community archives.

\subsection{Overview}

When the rankings assigned to the different factors for each Community Archives, based on their characteristics (see Tables 4-8), are displayed graphically the impact of the combined factors on sustainability is clearly shown. Furthermore, it becomes evident that likely sustainability declines as funding and staffing fall, with the difference between the council organisation 
with 2.5 FTE and a budget of nearly $\$ 250,000$ and the two $100 \%$ voluntary organisations with very small budgets, highlighted. Plainstown, with lower but regular funding and a 'corporate' structure, falls in between (see Figure 17). 


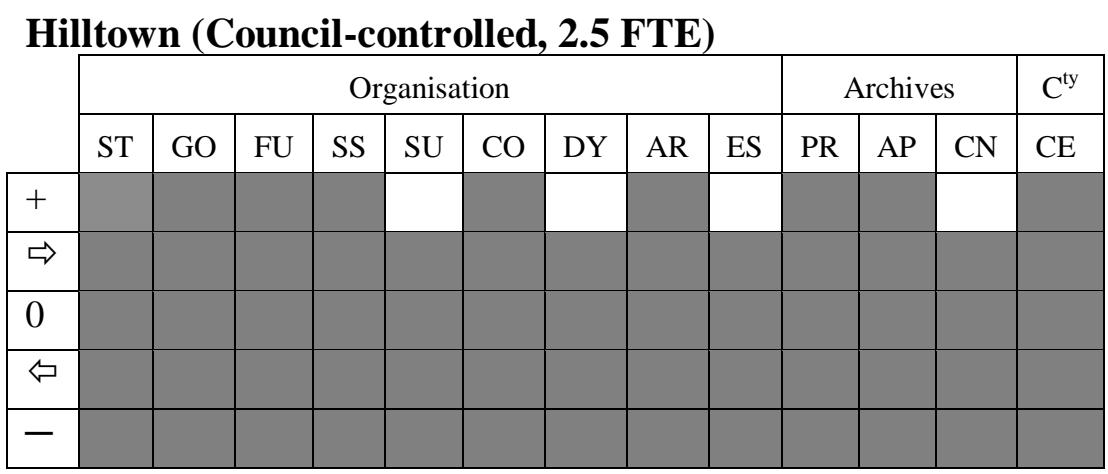

Plainstown (Council Organisation, 0.27 FTE)

\begin{tabular}{|l|l|l|l|l|l|l|l|l|l|l|l|l|l|}
\cline { 2 - 11 } \multicolumn{1}{c|}{} & \multicolumn{7}{c|}{ Organisation } & \multicolumn{3}{c|}{ Archives } & \multicolumn{2}{c|}{ C $^{\text {ty }}$} \\
\hline & ST & GO & FU & SS & SU & CO & DY & AR & ES & PR & AP & CN & CE \\
\hline+ & & & & & & & & & & & & & \\
\hline$\Rightarrow$ & & & & & & & & & & & & & \\
\hline 0 & & & & & & & & & & & & & \\
\hline$\diamond$ & & & & & & & & & & & & & \\
\hline- & & & & & & & & & & & & & \\
\hline
\end{tabular}

Seatown (100\% voluntary)

\begin{tabular}{|c|c|c|c|c|c|c|c|c|c|c|c|c|c|}
\hline & & & & & & & & & & & & & \multirow{3}{*}{$\begin{array}{c}\mathrm{C}^{\mathrm{ty}} \\
\mathrm{CE}\end{array}$} \\
\hline & \multicolumn{9}{|c|}{ Organisation } & \multicolumn{3}{|c|}{ Archives } & \\
\hline & ST & GO & $\mathrm{FU}$ & SS & SU & $\mathrm{CO}$ & DY & AR & ES & PR & $\mathrm{AP}$ & $\mathrm{CN}$ & \\
\hline+ & & & & & & & & & & & & & \\
\hline$\Rightarrow$ & & & & & & & & & & & & & \\
\hline 0 & & & & & & & & & & & & & \\
\hline طم & & & & & & & & & & & & & \\
\hline- & & & & & & & & & & & & & \\
\hline
\end{tabular}

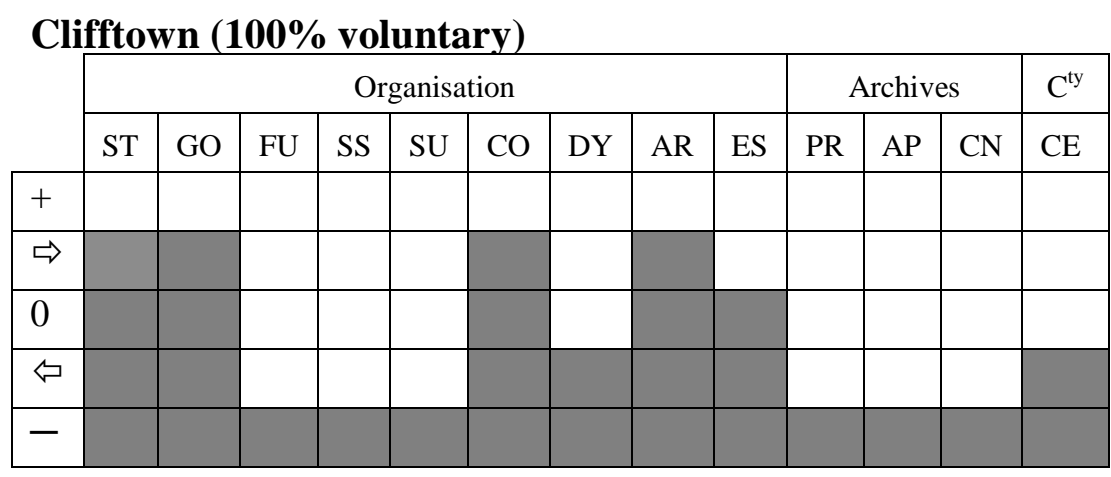

Figure 17: Comparison of Community Archives' sustainability ranking for factors Where ST=Governance:structure, GO=Governance:management, FU=Funding, SS=Skilled staff:knowledge, $\mathrm{SU}=$ Skilled staff:succession, $\mathrm{CO}=$ Collaboration, $\mathrm{DY}=$ Dynamism, $\mathrm{AR}=$ Archivist, $\mathrm{ES}=$ External support, $\mathrm{PR}=$ Preservation, $\mathrm{AP}=$ Archival practices, $\mathrm{CN}=$ Collection, $\mathrm{CE}=$ Community engagement. 
The 11 high-level factors used to analyse Community Archives were also plotted against the records continuum model, first locating the factors on the axis in the fourth dimension to which they primarily relate, then linking them, using directional arrows, to other factors on which they have a strong influence (see Figure 18). (Other influences than those shown are also possible - for instance, the character of the archivist could also influence the level of skills but these were considered secondary and not displayed for the purposes of this research.) The picture of the system required to maintain and sustain Community Archives is shown, in this model, to be highly complex.

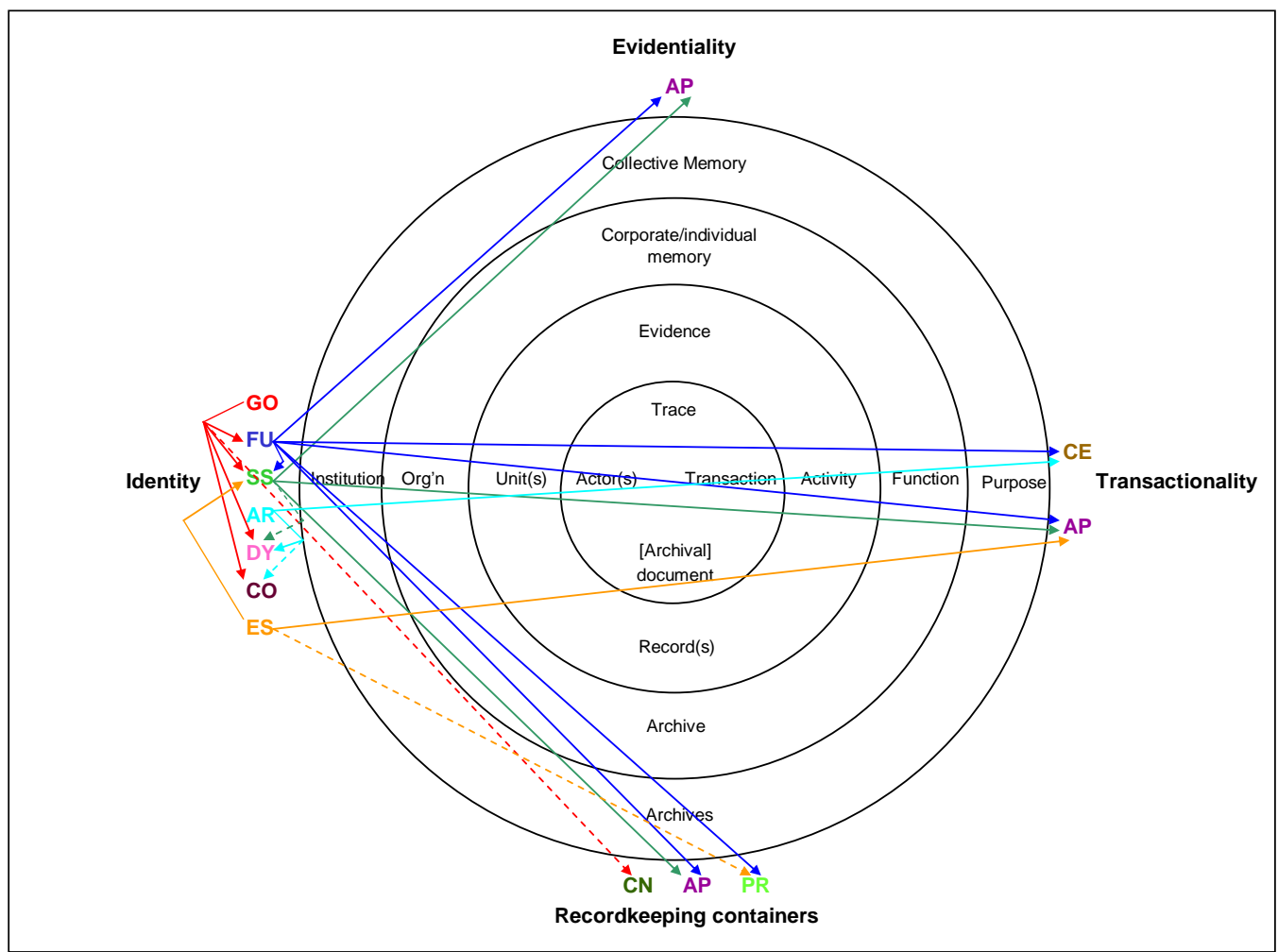

Figure 18: Factors mapped to the records continuum model

Where $\mathrm{ST}=$ Governance:structure, $\mathrm{GO}=$ Governance:management, FU=Funding, $\mathrm{SS}=$ =Skilled staff:knowledge, $\mathrm{SU}=$ Skilled staff:succession, $\mathrm{CO}=$ Collaboration, $\mathrm{DY}=$ Dynamism, $\mathrm{AR}=$ Archivist, $\mathrm{ES}=$ External support, $\mathrm{PR}=$ Preservation, $\mathrm{AP}=$ Archival practices, $\mathrm{CN}=$ Collection, $\mathrm{CE}=$ Community engagement.

A solid line represents a strong influence and a dotted line an indirect or potential influence.

The model also adds considerably to our understanding of sustainability. It shows that governance, funding, skilled staff, archivist character, dynamism, collaboration and external support factors all align with Institution on the 
Identity axis. When the effect that these factors have, or potentially have, on other factors is mapped, their impact on the archival documents themselves (Recordkeeping containers), on the evidential value of the archives (Evidentiality), and on the way the Archives fulfills its purpose in the community (Transactionality), are highlighted. The impact on archival practices, which as a factor is located on three of the axes of the continuum, is particularly pertinent. Archival practices are key to sustaining three out of the four structural elements of the archival continuum. Institutional factors can, however, also impact on the preservation of the items and on the level of community engagement and can even determine the nature of the collections.

\subsection{Conclusions}

Cross-case analysis shows that all the factors investigated are required to ensure sustainability of the community archives system - that is, the records, the evidential value they contain, the custodial organisation and the community connection. The model above (Figure 18) illustrates the particularly strong impact of governance (including structure) and funding on other factors which have a more direct influence on the archival records themselves and their evidential value or contribution to the collective memory of society for the future. Because of their consequential impact on many other factors, these have a major influence on sustainability of Community Archives. It therefore highlights the importance of addressing these issues if we wish to preserve the collective memory represented in the archives. The final chapter discusses possible approaches for this and opportunities for further research. 


\section{Chapter 9}

\section{Looking to the future}

\subsection{Introduction}

This research set out to explore how sustainable Community Archives in New Zealand are, by establishing the characteristics required for maintenance over time and studying four Community Archives to determine how well they meet these maintenance requirements. The differences in the Community Archives, revealed through analysis of the data gathered, allow some conclusions to be drawn about requirements for sustainability and also about likelihood of sustainability for Community Archives in New Zealand over time. This chapter discusses these conclusions and suggests strategies which might enhance sustainability in future. It also reviews the contribution to archival theory made by this research.

\subsection{Contribution to theory}

The fundamental purpose of a Community Archives is to preserve evidence of the past for current and future users. The importance of the evidential value of archival records is a core tenet of archival theory and it is this which gives community archives their key role in collective memory. The essential part played by the evidentiality of the archives is highlighted in the records continuum theory.

The records continuum model, which illustrates the concept of recordkeeping in society and depicts the complex relationships and links between organisation, records, community and the evidence contained in the archives, also contributes to an understanding of many of the situations and issues revealed through this research. Community Archives are part of a system in which a number of 
different factors need to be present to ensure adequate maintenance of the archival records. The case studies carried out in the research show how, in many Community Archives, evidential value may be destroyed or degraded as a direct or indirect result of organisational factors such as governance, funding and staffing. Overlaying these factors and their links to factors which more directly affect the archival records, their evidential value or their ability to be used by the community, confirms that many of the factors required to maintain community archives are interrelated. The continuum theory therefore supports these findings by modelling the various temporal and structural requirements in the archives-keeping universe, and their interrelatedness.

By applying the continuum theory to community archives, which are collected archives, the research addresses issues raised by Terry Cook and described as threatening to divide the collecting archives and corporate recordkeeping worlds. Cook expressed concern that discussion of "societal or collective memory is almost absent in the literature" and wrote of the "potential" for the continuum theory to incorporate private-sector archives manuscripts (Cook, 2000, p. 12). This research shows that, not only does the continuum theory encompass collected manuscripts and archives, but that it also facilitates understanding of their management and importance. Furthermore, by overlaying the factors required for maintenance of community archives on the continuum model, the research forms a bridge between theory and practice which contributes to a deeper understanding of the value of the continuum theory. It may also open up further avenues for development of the theory at the same time as facilitating understanding of its application.

\subsection{Factors required for sustainable Community Archives}

The first of the subsidiary questions designed to explore the issue of how sustainable Community Archives in New Zealand are, was: what factors need to be present in order to maintain community archives over the long term? Based on characteristics established by Dearstyne (2000) as basic elements and prerequisites for successful programmes and a checklist developed for local history 
programmes by New York State Archives (1988), supported and amplified by other literature, requirements were distilled down to eight factors:

Governance

Funding

Skilled staff

Collaboration

Dynamism

Preservation

Archival practices

Community engagement

Four Community Archives were then studied, using this set of factors as a framework to explore how sustainable they are.

Three additional factors affecting sustainability emerged consistently across all four case studies, namely:

Collections (the nature of the collections)

Archivist (the character of the archivist)

External support

Factors were organised into three groups: those relating to the organisation, those relating to the archival records and those relating to community. Although there are overlaps and interrelationships, these groupings provide useful indicators as to where to focus in addressing issues of sustainability.

\subsection{Factors exhibited in case studies - recommended changes}

This section addresses the two remaining subsidiary questions posed by the research: how well do four Community Archives in New Zealand exhibit the factors required for sustainability; and, what changes might be needed to enhance the sustainability of Community Archives? Each of the factors is addressed in turn, first setting out conclusions about the way in which the case studies exhibited that factor, then suggesting possible measures relating to that factor which would enhance sustainability. 


\subsubsection{Governance}

Internal governance arrangements alone do not appear to be a determining factor in sustainability of Community Archives. The reliable, higher levels of funding and ability to employ staff which result from being associated with a 'corporate' structure of some form do, however, appear to be significant. The findings indicate that $100 \%$-voluntary archives may be essentially unsustainable while those within local government, whether directly or indirectly controlled, have a much greater likelihood of being maintained over the long term. Furthermore, an Archives in direct control of a local authority (Hilltown) appears to have the highest likelihood of being sustainable.

If Community Archives are to be associated with an accountable organisational structure, local authorities appear to be the obvious entity because of their legislative requirement to consider the cultural well-being of their communities and because of their current involvement in archives (see sections 2.2.3 and 2.3.3). That involvement suggests that there are two established models for this - direct, through a council function, or indirect through a museum or library. A third possibility could be arms-length involvement through greater support of voluntary organisations. Whichever model is applied, it must be accepted that specialist skills and knowledge, different from those generally found in library, museum, volunteer or clerical staff, are required to ensure preservation of the evidentiality of the records.

\subsubsection{Funding}

Funding is shown to be key to maintenance of many of the factors which contribute to sustainability of the Community Archives system. It purchases skilled staff, preservation and other essential requirements for archives maintenance. The only situation which provided an adequate level of funding was that of the Archives as council function. It is hard to see how purely voluntary Community Archives can achieve more reliable or significant funding than they currently do, given the typical sources of their funds. 
The implication is that the only options for stable and adequate funding are more formal associations with, or incorporation into, the organisational structures of enduring entities such as local authorities. Greater collaboration with external parties may provide this if long-term partnerships can be assured. There is likely to be a trade-off for the Community Archives in such formal associations, in terms of independence or accountability, which would require sensitive handling, as Community Archives can be very protective of their independence (Flinn, et al., 2009). If this ensures the sustainability of the organisation, the archives and the community connection, however, it should be considered a worthwhile trade-off.

\subsubsection{Skilled staff}

Individuals with knowledge of archival theory and practices are needed to preserve the physical archives and the integrity of the records so that they retain their evidential value but findings show these are lacking in the majority of the Community Archives studied. The issue needs to be addressed, taking into account an environment where half the 'archivists' are voluntary. Although all those in the study showed extraordinary commitment to the role, managing community archives is not just about providing an interesting hobby for volunteers. The Archives exist to hold records in trust for current and future generations so they can access the collective memory, therefore a basic level of archival skill and knowledge should be an accepted requirement.

Ways must be found to support these Archives with skills and, possibly, specialist services without losing the passion and connection to the community brought by enthusiasts. Solutions might include local government support which allows for significant volunteer involvement; greater collaboration by archival institutions within a geographical area to allow development and/or sharing of expertise; provision of a pool of expertise by an external agency such as local or central government; or more co-location by Community Archives within reasonable geographic proximity so that pooling of resources can allow employment of a skilled archivist. 


\subsubsection{Collaboration}

The research shows that collaboration can be very effective when it works; it has enabled services to be enhanced and contributed to the actual survival of one organisation. In general, however, collaboration has not been explored as much as it could be, even by the two Archives which have used it, and it is not formally considered as a strategy for achieving the objectives of the Archives. What is particularly noticeable from the findings, is that none of the Community Archives studied has effectively collaborated with other Archives or heritage organisations, as recommended in guidance for Community Archives (Dearstyne, 2000; New York State Archives, 1988). Data gathered from interviews suggests that one of the reasons for this may be the strong parochialism felt by Community Archives, a finding backed by research (Flinn, et al., 2009). The fact that collaboration has, however, successfully occurred with non-archival and even non-heritage institutions suggests that it could be seen in much wider terms than most writers to date have seen it.

Attempts to collaborate should be encouraged long before an Archives reaches the point where it becomes a life or death matter. Appropriate collaborations with similar collecting institutions, or with different organisations with an interest in community archives, could bring much-needed resources if the mutual benefits can be identified. The scope could range from sharing premises, to arrangements for digital archive storage, sharing archival expertise and collecting strategies, or support from commercial or non-profit organisations. Collaboration would have the added advantage of reducing the isolation of some Community Archives and, thus, indirectly enhancing archival practices. Initiating a collaborative arrangement does, however, require time, energy and creativity, therefore facilitation by external support agencies may be of value.

\subsubsection{Dynamic approach}

None of the organisations studied show dynamism in all areas considered essential by Dearstyne, namely commitment to growing collections and users and to changing, including incorporating new archival practices and technologies. They also do not undertake the formal planning required to enable 
them to do more than simply react to day-to-day issues (Dearstyne, 2000). Where dynamism is evident it is often focused on a narrow area and comes at the cost of a balanced programme, also a basic requirement for sustainable Community Archives (Dearstyne, 2000). A culture which supports systematic and comprehensive planning as a business practice is unlikely to exist in a voluntary or part-time staffing situation and it can also be difficult to find in the situation where an archivist is at a low level in an organisational hierarchy. As with collaboration, it may be hard to be dynamic when the small number of resources must, of necessity, be focused on basic collection work such as description and reference. Keeping up with changing technology and archival practices, let alone proactive collecting, is also hampered by lack of skills and knowledge of trends in the archival field.

Dynamism could be enhanced through collaboration, external support, or organisational changes such as increased funding and a consequential increase in skilled staff. This further emphasises the importance of the funding, skilled staff, collaboration and external support factors.

\subsubsection{Preservation}

Three out of the four Community Archives studied did not have adequate premises, materials or practices to ensure the preservation of the archives in their custody. As noted in the previous chapter, this is particularly related to lack of funding, because in most cases (though not all), the archivists were aware of the importance of environmental control, clean and appropriate facilities, specialist storage equipment and materials. Constituted and funded as they are, however, there is little chance most of the Community Archives studied will attain the standards required for preservation of the archives.

The obvious solution to this problem is additional funding. Sources could include one-off grants (although the substantial amounts required might render success in applying for these unlikely) or dependable and substantial local authority support, particularly where the Community Archives holds local authority records. If funding cannot be obtained to provide the appropriate preservation conditions, collaborative arrangements which would allow sharing 
the costs of expensive facilities and services should be strongly encouraged and facilitated. These could include joining with other Community Archives or cultural institutions in their area, negotiating to occupy space which already meets requirements within established facilities such as local authorities or museums, or transferring their collections to another appropriate repository. The last two options could include retaining a degree of control or involvement with the collections, ranging from the high levels suggested by Shilton \& Srinivasan (2007) and Hopkins (2008), to simply having special access for research purposes.

\subsubsection{Archival practices}

The two voluntary organisations included in the study lack most of the essential archival practices and tools required to maintain community archives, the parttime and full-time-staffed Archives lack some. Archival practices, along with staff skills and preservation, is the factor most likely to directly impact on the physical integrity and evidentiality of the records and, therefore, their ability to fulfil their role in collective memory (see Figure 18). By selecting records, providing context for them and interpreting them for users, archivists play an active role in contructing memory (Jimerson, 2009), but the evidential value of the records is only maintained through applying archival principles and accepted standards to appraisal processes, arrangement and description, and finding aids development, to name just the core archival activities. This research has shown how sound archival practices are linked to the availability of skilled staff and, in turn, to funding and governance.

Ways of developing this knowledge and providing tools such as databases within Community Archives, or of providing access to them in some other way, need to be explored. Strategies could include organisations increasing the number of paid, skilled-staff hours; provision of services (such as appraisal or arrangement and description) by an external support agency; collaboration between repositories; or increased training. 


\subsubsection{Community engagement}

Community engagement is essential to the sustainability of Community Archives, both for understanding and nurturing the source of the archives collected and for enabling them to fulfill their purpose of maintaining and providing access to the collective memory. Volunteer involvement is both an important mechanism and an indicator of community engagement. In the voluntary organisations, however, engagement does not necessarily extend far beyond the members of the society.

Voluntary Community Archives may benefit from external guidance on how to engage with the wider community in order to build collections and to give back to it. Strengthening this relationship with the community would also enhance understanding of the value of the archives and, consequently, their sustainability. The research shows that, for one non-voluntary organisation, a 'friends' group is a powerful means of connecting with the community and building support, and a similar strategy may be worth considering by other Archives.

\subsubsection{Collections}

Two key characteristics relating to collections have been identified as potentially impacting on sustainability. The first is the inclusion of local government records in holdings which, being subject to the Public Records Act, should be maintained to certain standards. This improved level of care has, in fact, occurred only where the Archives is a direct council function. The second issue relating to collections is the time and resources devoted to maintaining secondary sources and providing research services based on them. While it is valuable for such collections to be co-located with community archives from a user perspective, limited resources should be prioritised towards preservation of, and access to, unique archival records.

The findings suggest two options for the proper maintenance over time of local authority archives held within a Community Archives: the local authority could contribute regular and adequate funding towards their management (which 
might come with accountability requirements for such things as expertise, training and archival practices), or it could directly support the Community Archives as well as its own Archives (as it does in Hilltown). The alternative is that the local authorities assume control of the records for which they have responsibility and provide the preservation and access required under the Public Records Act. The latter solution may, however, represent a missed opportunity for providing the community with access to a more comprehensive collective memory; a formal alliance with a Community Archives could be beneficial to both parties. To deal with the problem of Archives devoting a disproportionate amount of time to secondary sources, external parties could provide support and guidance on facilitating access to digitised secondary sources for users or sharing such responsibilities with related entities in the area, such as libraries.

\subsubsection{Passion and commitment}

The majority of the Community Archives studied were founded by grass-roots movements and two continue to exist only because of the passion and commitment of one or two individuals. Research shows that it is not uncommon for Community Archives to reflect the founding motivations of a few key individuals and for continuing operations to be driven by the dedication and enthusiasm of a very small number (Flinn, et al., 2009). This passion and commitment is, however, not sufficient to sustain them in the long-term (National Council on Archives, 2007b). It is important not to squander this dedication, not only because of its role in community engagement but because one of the great advantages of voluntary organisations is that a few committed volunteers can achieve an enormous amount (Dollery \& Wallis, 2003).

Support therefore needs to be provided to these volunteers, not only to carry out archival work appropriately, but also to prevent 'burn-out' and ensure continuity of the archive-holding organisation. Dollery and Wallis (2003) consider local government the most appropriate entity to provide this support but it could also be provided by other external agencies. Paid, but relatively isolated, archivists also require support, particularly in terms of formal acknowledgement of the responsibilities associated with custody of archives, provision of training and development opportunities, and realistic expectations by the organisation of 
what can be achieved with limited resource. Some of this support should come from their own organisations, but external agencies could also play a role in information-provision, advocacy and training programmes.

\subsubsection{External support}

The findings of this study suggest that the external support provided now is not contributing significantly to the sustainability of Community Archives. The inference is that the type of assistance offered is not required or desired, that it is not sufficient, or that it is not delivered in a way which makes it accessible to most Community Archives. While Archives New Zealand, with its mandate under legislation to assume a role in this area and its community-archives function (Archives New Zealand, 2009c), appears to be the most appropriate organisation to provide the specialist expertise, it has not to date employed professional archivists in this area. Te Papa National Services also indicates awareness of a role by including a brief section on archives in its system for museum self-assessment (Museum of New Zealand Te Papa Tongarewa, 2010). The National Library has, in the past, provided ad hoc support through the National Preservation Office but, like the other agencies, has not employed professional archivists to lead or provide it. Given the importance of community archives to heritage, identity and cultural well-being (discussed in Chapter 2), and the challenges facing some Community Archives, external support may be one of the most critical factors to address in the short term to ensure preservation of good community memory records.

Local government may be the most appropriate structure through which to deliver support to Community Archives. In addition to its legislated role in promoting the cultural well-being of communities, it is already directly responsible for at least $22 \%$ of existing Community Archives (see section 2.2.3). Furthermore, because local authorities are part of the communities to which the Archives belong they may also be in the best position to do so without diminishing the passion and commitment of the keepers of the archives. This is born out by the research conducted by Dollery and Wallis (2003). The way support to Community Archives is planned, co-ordinated and delivered would be critical; whichever agency took the lead, liaison and co-operation between 
agencies would be required to achieve the best outcome because, as has been shown, a number of national institutions are active in this space. This research suggests that the most effective forms of support would include regular, dependable funding; services such as provision of archival expertise (which could be shared among a number of Community Archives) or digital archives maintenance; and a facilitative or advisory role to encourage collaboration and planning for the future. Support agencies could also play a role in monitoring the health of the sector and individual archives within it.

\subsection{How sustainable are Community Archives in NZ?}

This research has shown that, when four Community Archives are studied, voluntary Community Archives appear to have a low likelihood of being able to ensure the long-term preservation and accessibility of the archives in their care. A Community Archives under direct, local-authority control appears to have the highest likelihood of being sustainable, as a result of key organisational factors being in place. The Community Archives which has a strong, but arms-length, relationship with a local authority falls in between these two categories, in terms of sustainability, with some of the weaknesses shared by the voluntary organisations and some of the strengths which derive from direct local-authority involvement.

Whether the Community Archives identified by this study as lacking in the factors required for sustainability do, in fact, endure as organisations and with adequate preservation and accessibility of their archives will only be known if they are revisited in a number of years' time. All indications are, however, that, unless changes are made to a number of factors, even if the organisation continues to exist the archival records will, at best, have deteriorated. There is certainly unlikely to be a systematic programme to collect, preserve and make accessible new archives to build the community's collective memory. 


\subsection{Further research}

The contribution of this study to the field of community archives, and archives in general, has been to provide an in-depth picture of a variety of Community Archives institutions in New Zealand and to assess how well they exhibit the requirements for maintenance over time, using benchmarks developed from archival literature and informed by writing on community, culture and heritage. In doing so, it has also looked at possible explanations for the findings and, from that, suggested solutions to some of the challenges faced by Community Archives.

It is a starting point only, however. Further work needs to be undertaken into the best form of support for Community Archives, including the most appropriate agencies to deliver this. Research could also be undertaken into specific factors, such as how to ensure Community Archives possess, or have access to, skilled staff, or into mechanisms and opportunities for collaboration.

The methodological framework used in this research could be further developed to help assess the sustainability of Community Archives, whether through a facilitated or a self-assessment process. Such a tool could also form part of an educative process for those involved in Community Archives and provide the foundation for a framework for assessing the overall health and sustainability of New Zealand's Community Archives by policy bodies.

Research could also be undertaken into adaptation of macroappraisal and documentation strategies for communities, to determine whether workable guidelines can be developed for Community Archives in New Zealand to help them build more representative collections.

Finally, digital technology has been shown to be a significant issue for Community Archives. Concerns about growing expectations to digitise collections and the impact of this on core archival work and funding, a lack of preparedness to collect digital archives, and the lack of digital finding aids, all indicate that this would be another fruitful area of research. Investigation into 
the role and implementation of digitisation in Community Archives, how they can be supported in collecting digital archives, and how they might increase use of digital finding aids, could contribute greatly to the sustainability of Community Archives.

\subsection{Conclusion}

Community Archives in New Zealand, as elsewhere, are a testimony to grassroots interest in preserving history (Dearstyne, 2000). It is common, however, to find a lack of understanding of the role of archives and an under-estimation of what is required to maintain them over time amongst those involved in their care and management. The result is that an important part of our heritage is not adequately cared for.

If New Zealand and its citizens believe that it is worth collecting these archives - and the inference to be drawn from central and local government policy and the communities themselves is that it does - more attention needs to be given to assessing and meeting requirements for doing so sustainably.

Worldwide, there is a growing understanding of the importance of retaining the voice of the masses, alongside that of elites (Jimerson, 2009). Those acting as collectors and custodians of these records, whether they appreciate it or not, "are deciding what is remembered and what is forgotten, who in society is visible and who remains invisible, who has a voice and who does not" (Cook, as cited in Jimerson, 2009, p. 233). In the interests of future New Zealanders, therefore, we must find ways to ensure the sustainability of the Community Archives, which often hold records of the lives of ordinary citizens. It is hoped that the findings of this research project will assist in finding ways to better do this. 


\section{Appendix A}

\section{Interview guide: Community stakeholder representative}

1 Introduction/ice-breaker

About yourself and or/your group and your relationship with the Archives

\section{Governance}

What are your views on the way the Archives are set up i.e. who has responsibility, accountability, legal structure etc?

What do you feel the role or mission of the Archives should be?

How well do you think it is fulfilling it?

\section{$3 \quad$ Funding}

What are your views on the level of funding the Archives has?

Do you have any involvement in funding activities?

\section{$4 \quad$ Staff skills}

Do you actively participate in the work of the archives? If so, how?

Have you had any training in how to work with archives?

$5 \quad$ Archival tools and practices

Do you know about the Archives' collection policy?

How easy do you find it to access items in the collection?

6 Preservation

Do you have any views on the way the collections are looked after?

7 Community engagement

Detail of involvement with the Archives e.g. how did it come about, activities

What sort of connection do you feel with the Archives?

Do you feel anything could be done differently?

8 Collaboration

Do you know of any areas in which the Archives works with, or has worked with, other organisations to achieve goals?

What are your views on the Archives working with other similar organisations in the area?

\section{Dynamism}

Do you know what the future plans of the Archives are?

Are you, have you been, involved in plans?

What are your views on the plans?

\section{Other}




\section{Appendix B}

\section{Interview guide: Archives operational manager}

1 Introduction/ice-breaker

About your collections

About the history and origins of the archives

2 Governance

About your governance structure

What works well/what doesn't work so well?

At what level of organisational decision-making about the Archives are you involved?

3 Funding

Where does your funding come from?

How adequate do you feel it is currently?

How secure is it?

Has it changed much over time?

\section{$4 \quad$ Staff skills}

About yourself: background, how you came to this position, what you like about it, etc About the people who work at your archives: backgrounds, hours, attitudes to archives, etc What sort of training/education have you/they had in working with archives?

Do you/they plan to undertake any specialist training/education in working with archives?

\section{Preservation}

About your current facilities and how adequate you feel they are for the purpose

Do you have any plans or projects related to premises?

Are you aware of specialist materials available for archives, and do you use any?

Do you hold any archives whose preservation or conservation you are concerned about?

How much money is spent on specialist materials in a year, and what is it spent on?

$6 \quad$ Archival practices and tools

How do your collections come to you? OR

How do you decide what you are going to collect?

How do you decide what you are going to keep?

What do you do about collections or items you decide not to keep?

What sort of work do you do to organise the collection?

Can you describe any standards you use in your work?

How do people find out what you hold in your archives and access them?

7 Community engagement

How is the community involved with the Archives?

Do you know what the wider community thinks of the archives?

8 Collaboration

Do you work with other organisations on matters relating to the archives?

9 Dynamism

What are your plans or projects for the future?

How do you feel about collecting digital archives?

10 Issues and Challenges

What issues and challenges do you face?

What do you think makes your archives a success? Is there anything that might change that?

11 Anything else? 


\section{Appendix C}

\section{Interview guide: Governance funding/policy decision-maker}

\section{Introduction/ice-breaker}

About yourself: role in relation to management of the archives, background, how you came to this position, etc

About the organisation's history in establishing/managing the archives

Any significant events in its history

2 Governance

What is the governance structure and where does decision-making takes place e.g. management, elected representatives, archivist.

How well does the current situation work? Do you think there should be any changes?

What long-term commitment has the organisation made to the Archives?

\section{$3 \quad$ Funding}

What is the history of funding for the Archives?

Has it changed much over time; why; what was the impact?

How adequate do you feel it is currently?

How secure is it? What long-term commitment has been made to funding?

$4 \quad$ Staff skills

How important do you consider it is to have qualified archivists running and working in the archives?

What long-term commitment has the organisation made to appropriate staffing?

\section{Preservation}

What plans or commitments have been made to appropriate premises or other aspects of preservation?

6 Archival practices and tools

What is your view about the importance of following professional archival principles and practices in running the Archives?

7 Community engagement

How do you see the role of the Archives in relation to the community?

8 Collaboration

What are your views on collaboration with other organisations to achieve the outcomes of the Archives?

In what areas do you think this might take place?

9 Dynamism

What do you see as the future of the Archives?

What plans are currently in place?

10 Issues and challenges

What do you believe are the issues and challenges facing the Archives?

How do you think they should be dealt with?

11 Anything else? 


\section{References}

Abraham, T. (1991). Collection policy or documentation strategy: Theory and practice. American Archivist, 54(Winter), 44-52.

Abraham, T. (1995). Documentation strategies: A decade (or more) later. Paper presented at the Society of American Archivists. Retrieved August 10, 2009, from http://www.uiweb.uidaho.edu/special-collections/papers/docstr10.htm

Acland, G. (1992). Managing the record rather than the relic. Archives and Manuscripts, 20(1), 57-63.

Adams, E. (2010). Towards sustainability indicators for museums in Australia:

Collections Council of Australia.

Ander, E. (2007). Black and minority ethnic community archives in London. London: Museums Libraries Archives London.

Archives New Zealand (2007). Storage Standard. Wellington: Author.

Archives New Zealand (2008). Community archives survey report 2007. Wellington: Author.

Archives New Zealand (2009a). The Community Archive. Retrieved August 5, 2009: http://thecommunityarchive.org.nz/

Archives New Zealand (2009b). Directory of archives in New Zealand (2.0 ed.). Wellington: Author.

Archives New Zealand (2009c). Statement of Intent 2009-2012. Wellington: Author.

Bastian, J. A. (2003). Owning memory: How a Caribbean community lost its archives and found its history. Westport, CT: Greenwood.

Bettington, J., Eberhard, K., Loo, R., \& Smith, C. (Eds.). (2008). Keeping archives (3rd ed.). Canberra: Australian Society of Archivists.

Butterworth, S. (2001). Local archives; 'Say not the struggle naught availeth'. New Zealand Archivist, XII(4), 4-7.

Collier, R. (2004). Ratana archives centre opens. New Zealand Archivist, XV, 1-2.

Cook, T. (2000). Beyond the screen: The records continuum and archival cultural heritage. Paper presented at the Australian Society of Archivists Conference. Retrieved August 5, 2009, from www.archivists.org.au/files/Conference_Papers/2000/terrycook.pdf

Cook, T. (2005). Macroappraisal in theory and practice: Origins, characteristics, and implementation in Canada, 1950-2000. Archival Science, 5, 101-161.

Cox, R. J. (1994). The documentation strategy and archival appraisal principles: A different perspective. Archivaria, 38(11-36).

Cox, R. J. (1996a). Documenting localities: A practical model for American archivists and manuscript curators. Lanham, Md., \& London: Scarecrow Press.

Cox, R. J. (1996b). The record in the manuscript collection. Archives and Manuscripts, 24(1), 46-61.

Cox, R. J., \& Samuels, H. W. (1988). The archivist's first responsibility: A research agenda to improve the identification and retention of records of enduring value. American Archivist, 51(Winter and Spring), 28-42.

Cresswell, J. W. (2003). Research design: Qualitative, quantitative, and mixed methods approaches (2nd ed.). Thousand Oaks: Sage Publications.

Crooke, E. (2008). An exploration of the connections among museums, community and heritage. In B. Graham \& P. Howard (Eds.), The Ashgate research companion to heritage and identity (pp. 415-424). Aldershot: Ashgate Publishing.

Cunningham, A. (1998). From here to eternity: Collecting archives and the need for a national documentation strategy. LASIE, 29(1), 32-45. 
Davis, C. (1987). Conference papers 1986: Regional Archives. Archifacts(1987/2).

Dearstyne, B. W. (2000). Managing historical records programs: A guide for historical agencies. Walnut Creek, CA: Altamira Press.

Delaney, J. (2009). Archival description in New Zealand: Should we be taking a stand on standards? Archifacts(October 2008-April 2009), 22-53.

Dollery, B. E., \& Wallis, J. L. (2003). The political economy of the voluntary sector: A reappraisal of the comparative institutional advantage of voluntary organizations. Cheltenham: Edward Elgar.

Eberhard, K. (2008). Getting organised. In J. Bettington, K. Eberhard, R. Loo \& C. Smith (Eds.), Keeping Archives (3rd ed.). Canberra: Australian Society of Archivists.

Flinn, A. (2007). Community histories, community archives: Some opportunities and challenges. Journal of the Society of Archivists, 28(2), 151-176.

Flinn, A. (2008). Other ways of thinking, other ways of being. Documenting the margins and the transitory: What to preserve, how to collect. In L. Craven (Ed.), What are archives? Cultural and theoretical perspectives: A reader (pp. 109128). Aldershot: Ashgate Publishing.

Flinn, A., Stevens, M., \& Shepherd, E. (2009). Whose memories, whose archives? Independent community archives, autonomy and the mainstream. Archival Science, 9, 71-86.

Freeman, C. (2006). Introduction: Developing inclusive communities. In M. ThompsonFawcett \& C. Freeman (Eds.), Living together: Towards inclusive communities (pp. 15-23). Dunedin: Otago University Press.

Gilliland, A., \& McKemmish, S. (2004). Building an infrastructure for archival research. Archival Science, 4(3-4), 149-197.

Graham, B., \& Howard, P. (2008). Introduction: Heritage and identity. In B. Graham \& P. Howard (Eds.), The Ashgate companion to heritage and identity (pp. 1-15). Aldershot: Ashgate Publishing.

Guelke, J. K., \& Timothy, D. J. (2008). Locating personal pasts: An introduction. In D. J. Timothy \& J. K. Guelke (Eds.), Geography and genealogy: Locating personal pasts. Aldershot: Ashgate Publishing.

Hadlow, E. (2008). Preservation. In J. Bettington, K. Eberhard, R. Loo \& C. Smith (Eds.), Keeping archives. Canberra: Australian Society of Archivists.

Hofman, H. (2005). The archive. In S. McKemmish, M. Piggott, B. Reed \& F. Upward (Eds.), Archives: Recordkeeping in society (pp. 131-158). Wagga Wagga: Centre for Information Studies, Charles Sturt University.

Hopkins, I. (2008). Places from which to speak. Journal of the Society of Archivists, 29(1), 83-109.

International Standards Organisation (2001). ISO 15489-1 Information and documentation - Records management - Part 1: General. Geneva: Author.

Jimerson, R. C. (2009). Archives power: Memory, accountability, and social justice. Chicago: Society of American Archivists.

Jordan, T. (2005). The establishment of the Whakatane Museum \& Gallery: Gaining recognition for small archives. Paper presented at the Joint Australian Society of Archivists and Archives \& Records Association of New Zealand Conference.

Lavoie, B., Eakin, L., Friedlander, A., Berman, F., Courant, P., Lynch, C., et al. (2008). Sustaining the digital investment: Issues and challenges of economically sustainable digital preservation: Blue Ribbon Task Force on Sustainable Digital Preservation and Access. 
Local Government Act 2002. Retrieved April 16, 2010, from http://www.legislation.govt.nz/act/public/2002/0084/latest/DLM170873.html?se arch=ts_act_local+government_resel $\& \mathrm{p}=1$

Lozano, R. (2008). Envisioning sustainability three-dimensionally. Journal of Cleaner Production, 16(17), 1838-1846. doi:10.1016/j.jclepro.2008.02.008

Matthews, M. (2005). Cultural well-being, local government and mainstreets. Paper presented at the 2nd Trans-Tasman Mainstreet and Town Centres Conference. Retrieved July 21, 2009, from www.culturalwellbeing.govt.nz/.../martin matthews 2 November presentation confere $\underline{\text { nce.pdf }}$

McCulloch, B. (1998). The evolution of a community archive: The story of the North Otago Museum archive. Archifacts(October), 43-56.

McDowell, S. (2008). Heritage, memory and identity. In B. Graham \& P. Howard (Eds.), The Ashgate research companion to heritage and identity (pp. 37-53). Aldershot: Ashgate Publishing.

McKemmish, S. (1996). Evidence of me... Archives and Manuscripts, 24, 28-45.

McKemmish, S. (1997). Yesterday, today and tomorrow: A continuum of responsibility. Paper presented at the Records Management Association of Australasia 14th National Convention. Retrieved March 1, 2009, from http://www.sims.monash.edu.au/research/rcrg/publications/recordscontinuum/

McKemmish, S. (2001). Placing records continuum theory and practice. Archives \& Museum Informatics, 1(4), 333-359.

McKemmish, S., Acland, G., Ward, N., \& Reed, B. (1999). Describing records in context in the Continuum: The Australian recordkeeping metadata schema. Archivaria, 48(Fall), 3-37.

McKinlay, P. (2005). Future of local government summit: A New Zealand perspective. Paper presented at the Future of Local Government Summit. Retrieved June 8, 2009, from http://www.mav.asn.au/CA256C2B000B597A/All/A77ED9AE2165C6D3CA25 755400049173?OpenDocument\&1=10-None \&2=0-PP+-+FOLG++Future+of+Local+Government+Project+-+Resources-2005 \&3=

McNamara, B. L. (1980). The Marlborough Historical Society archives. Archifacts(September), 345-353.

Meethan, K. (2008). Remaking time and space: the internet, digital archives and genealogy. In D. J. Timothy \& J. K. Guelke (Eds.), Geography and genealogy: Locating personal pasts (pp. 99-116). Aldershot: Ashgate Publishing.

Miles, M. B., \& Huberman, M. A. (1994). Qualitative data analysis (2nd ed.). Thousand Oaks, Ca: Sage Publications.

Millar, L. (1998). Discharging our debt: The evolution of the total archives concept in English Canada. Archivaria, 46, 103-146.

Millar, L. (1999). The spirit of Total Archives: Seeking a sustainable archival system. Archivaria, 1(47).

Milton, L. (2008). Arrangement \& description. In J. Bettington, K. Eberhard, R. Loo \& C. Smith (Eds.), Keeping Archives (3rd ed.). Canberra: Australian Society of Archivists.

Ministry for Culture \& Heritage (2008). Cultural well-being and local government report 1: Definitions and contexts of cultural well-being: Author.

Ministry for Culture \& Heritage (c.2005). Cultural well-being: What is it? Retrieved July 21, 2009, from www.culturalwellbeing.govt.nz/node/1 
Museum of New Zealand Te Papa Tongarewa (2010). Module 2: Care of collections and taonga. New Zealand museums standards scheme Retrieved April 16, 2010, from

http://www.tepapa.govt.nz/NationalServices/Resources/StandardsScheme/Pages/ Overview.aspx

Museums Association (2008). Sustainability and museums: your chance to make a difference. London: Author.

National Council on Archives (2000). British archives: the way forward. United Kingdom: Author.

National Council on Archives (2007a). Community Archives Development Group helpsheet: Engaging with wider agendas. United Kingdom: Author.

National Council on Archives (2007b). The impact of community archives: Summary of independent research commissioned by the Community Archives Development Group. United Kingdom: Author.

National Library of New Zealand (2005). Managing and preserving community archives. Wellington: Author.

New York State Archives (1988). Ensuring a usable past for your community: The New York citizen's guide to evaluating and improving historical records programs Albany, N.Y.: Author.

New Zealand Society of Genealogists (2007). Forty years on: The development of the New Zealand Society of Genealogists 1967-2007: New Zealand Society of Genealogists.

New Zealand Tourism Research Institute Auckland University of Technology (2009). New Zealand museums barometer, special focus: Collections (No. 3).

Oxford University Press (2009). OED online Retrieved June 18, 2010, from Www.oed.com

Patton, M. Q. (2002). Qualitative evaluation and research methods (3rd ed.). Thousand Oaks, Ca: Sage Publications.

Pearce-Moses, R. (2005). Glossary of archival and records terminology. Chicago: Society of American Archivists. Retrieved July 30, 2009, from http://www.archivists.org/glossary/term_details.asp?DefinitionKey=225

Public Records Act 2005. Retrieved April 16, 2010, from http://www.legislation.govt.nz/act/public/2005/0040/latest/DLM345529.html?se arch $=$ ts_act_public+records_resel $\& \mathrm{p}=1$

Punch, K. F. (2005). Introduction to social research: Quantitative and qualitative approaches (2nd ed.). London: Sage Publications.

Sanderson, K. (2007). Private archives. In R. Young \& A. Fields (Eds.), Informing New Zealand: Libraries, archives and records (pp. 175-186). Wellington: Open Polytechnic of New Zealand.

Schellenberg, T. R. (1956). Modern archives: Principles and techniques. Chicago: The University of Chicago Press.

Shilton, K., \& Srinivasan, R. (2007). Participatory appraisal and arrangement for multicultural archival collections. Archivaria, 63(Spring), 87-101.

Smith, W. I. (1978). Archives in New Zealand: a report. Wellington: Archives and Records Association of New Zealand.

Society of American Archivists (1994). Guidelines for the evaluation of archival institutions Retrieved June 15, 2009, from http://www.archivists.org/governance/guidelines/evalgui.asp

Stake, R. E. (1995). The art of case study research. Thousand Oaks, Ca.: Sage Publications. 
Strachan, S. R. (1983). Local archives in New Zealand. Archifacts(2), 4-21.

Taylor, H. A. (1982). The collective memory: Archives and libraries as heritage. Archivaria, 15, 118-130.

Thompson-Fawcett, M., \& Freeman, C. (Eds.). (2006). Living together: towards inclusive communities. Dunedin: Otago University Press.

Upward, F. (1996). Structuring the records continuum - part one: Postcustodial principles and properties. Archives and Manuscripts, 24(2).

Upward, F. (1997). Structuring the records continuum, part two: Structuration theory and recordkeeping. Archives and Manuscripts, 25(1).

Upward, F. (2005). The records continuum. In S. McKemmish, M. Piggott, B. Reed \& F. Upward (Eds.), Archives: Recordkeeping in society. Wagga Wagga: Centre for Information Studies, Charles Sturt University.

Walsham, G. (1995). Interpretive case studies in IS research: nature and method. European Journal of Information Systems 4, 74-81.

Wareham, E. (2001). "Our own identity, our own taonga, our own self coming back": Indigenous voices in New Zealand record-keeping. Archivaria, 52, 26-46.

Winter, G. (2000). Creating a positive community archive. New Zealand Archivist, $X I(3)$.

Yeates, R., \& Guy, D. (2006). Collaborative working for large digitisation projects. Emerald, 40(2), 137-156. doi:10.1108/00330330610669262

Yin, R. K. (2003). Case study research: Design and methods (3rd ed.). Thousand Oaks, Ca: Sage Publications. 